\title{
Continuity of Care in Children's Mental Health: Development of a Measure
}

Juliana I. Tobon, The University of Western Ontario

Supervisor: Graham J. Reid, Ph.D., The University of Western Ontario

A thesis submitted in partial fulfillment of the requirements for the Doctor of Philosophy degree in Psychology

(c) Juliana I. Tobon 2013

Follow this and additional works at: https://ir.lib.uwo.ca/etd

Part of the Child Psychology Commons, Clinical Psychology Commons, Community Psychology Commons, and the Health Policy Commons

\section{Recommended Citation}

Tobon, Juliana I., "Continuity of Care in Children's Mental Health: Development of a Measure" (2013). Electronic Thesis and Dissertation Repository. 1348.

https://ir.lib.uwo.ca/etd/1348

This Dissertation/Thesis is brought to you for free and open access by Scholarship@Western. It has been accepted for inclusion in Electronic Thesis and Dissertation Repository by an authorized administrator of Scholarship@Western. For more information, please contact wlswadmin@uwo.ca. 


\title{
CONTINUITY OF CARE IN CHILDREN'S MENTAL HEALTH:
}

DEVELOPMENT OF A MEASURE

(Thesis format: Integrated Article)

by

\author{
Juliana I. Tobon
}

Graduate Program in Psychology

A thesis submitted in partial fulfillment of the requirements for the degree of

Doctor of Philosophy

The School of Graduate and Postdoctoral Studies

The University of Western Ontario

London, Ontario, Canada

(C) Juliana I. Tobon 2013 


\begin{abstract}
Continuity of care, which is how a patient experiences care over time as coherent and linked, has been identified as an indicator of health system performance and is considered an ethical principle of care. Yet, no instrument exists to measure continuity of care as experienced by families receiving services through the children's mental health $(\mathrm{CMH})$ system. A new measure, Continuity of Care in Children's Mental Health $(\mathrm{C} 3 \mathrm{MH})$, is presented. The project involved four phases: item generation, pre-testing, pilot testing, and validation. In the validation study, the 42 -item C3MH was administered to 364 parents of children and youth ( $M=12$ years; $S D=3.50 ; 57 \%$ boys $)$, recruited from $13 \mathrm{CMH}$ agencies in Ontario. Using EQS, a CFA was conducted to determine the fit of data to the hypothesized model. A fivefactor model had an excellent fit $\left(\mathrm{Y}-\mathrm{B} \chi^{2}=514.93, p<.001\right.$; NNFI $=.93 ; \mathrm{CFI}=.94$; IFI $=$ $.94 ;$ RMSEA $=.046 ; 90 \%$ C.I. $=.039, .053)$. Cronbach's alphas for the subscales ranged from .80 to .93 and test-retest reliabilities ranged from .75 to .92 . The $\mathrm{C} 3 \mathrm{MH}$ was related to: higher satisfaction with services; higher child internalizing problems; less impact of problems on the family; having a case manager, and not dropping out of treatment. The transitions scale was negatively related to parental depression, externalizing problems, total problems, child impairment, and impact of problems on the family. A youth-report version was also piloted with 57 youth and these results are presented. The $\mathrm{C} 3 \mathrm{MH}$ is the first parentreport measure of continuity in $\mathrm{CMH}$ and will be useful for assessing and tracking improvements in system integration and service coordination.
\end{abstract}

\title{
Keywords
}

Children's mental health, Continuity of care, Measurement development, Qualitative, Mixedmethods, Confirmatory factor analysis 


\section{Co-Authorship Statement}

This dissertation is composed of two manuscripts, which were prepared by Juliana Tobon as part of her dissertation. Ms. Tobon conducted all statistical analyses, and wrote all manuscripts. Feedback from Ms. Tobon's supervisory committee was provided during the preparation of these manuscripts. The manuscripts are mainly the work of Ms. Tobon, thereby ensuring that the integrity of the academic dissertation and Ms. Tobon as an independent researcher are maintained.

The manuscripts submitted for publication are not the same as the versions presented in this dissertation and may involve editing and revisions based on journal reviewers' feedback. The first manuscript submitted for publication is co-authored by Dr. Graham Reid, Ms. Tobon's thesis supervisor, and Dr. Judith Brown, who was a co-investigator on both studies and provided input on the qualitative design and analyses. The second manuscript is co-authored by Dr. Graham Reid and Dr. Richard Goffin, a member of the advisory committee, who provided input on statistical analyses. Co-authorship was determined based on the guidelines for authorship developed by the International Committee for Medical Journal Editors. 


\section{Acknowledgments}

I would like to thank all of the families and youth who participated in this research project. This project would not have been possible without their involvement. I would also like to recognize the support of all of the children's mental health agencies that have been involved throughout various stages, from the initial qualitative study to the validation study. It has been a pleasure to collaborate with the various executive directors, researchers, managers, and clinicians who have all demonstrated a genuine commitment to this research, which will provide feedback on how the system is functioning from the perspective of the families they serve. I would like to acknowledge the critical role played by the research staff and volunteers: Christina Sommerdyk (Research Assistant), who helped to set up the study in the critical early stages; Joyce Li (Research Assistant), who helped tremendously in recruiting and tracking participants, and in helping the study to run smoothly through the final phases. Thanks also to Justine Dol, Kaitlyn Bruyns, Kayleigh Abbott, and Annie Zhao for all of their help with recruitment and data collection. I would like to thank the co-investigators on the grant that supported the larger research project: Shannon Stewart, Barrie Evans, Judith B. Brown, and Richard Goffin, for their expertise in children's mental health services, statistical analysis, and interpretation of the data. I would like to acknowledge the support of the Canadian Graduate Scholarship from the Canadian Institutes of Health Research, as well as the Mitacs-Accelerate Internship, with joint partnerships with SickKids and Multi-Health Systems (MHS). Particular thanks go to Bruce Ferguson (Director, Community Health Systems Resource Group) at SickKids for his support and mentoring during the final phase of the project, as well as to Thomas Gale and Jenni Pitkanen at MHS for their support through the Mitacs-Accelerate Internship. Thanks to all of my examiners for their constructive feedback. I would like to thank Graham Reid for his encouragement, mentorship, and support through all of these years, which has extended beyond supporting my dissertation work to contributing to my professional growth and development. Finally, I would like to thank my mother, for all of her moral support, from pre-school through all of my degrees and pursuits. 


\section{Table of Contents}

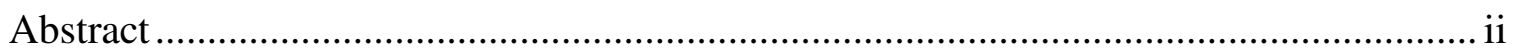

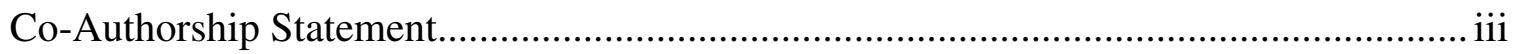

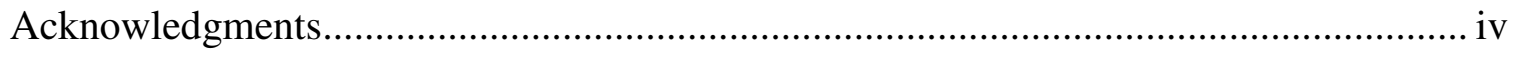

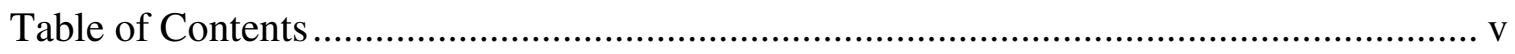

List of Tables ................................................................................................... viii

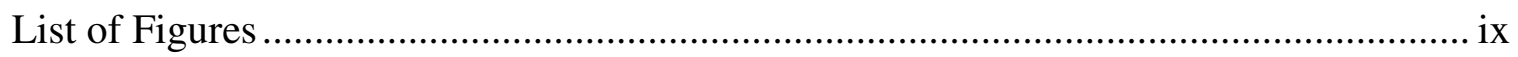

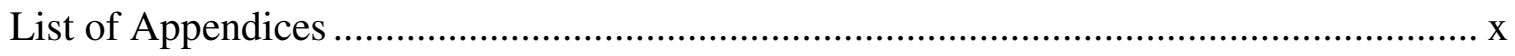

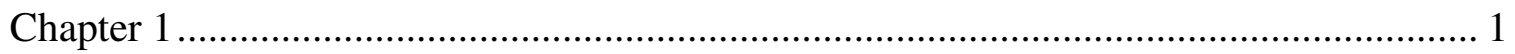

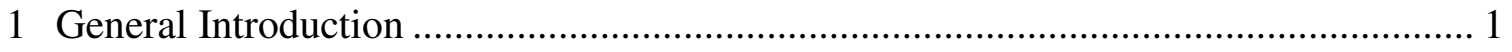

1.1 (Dis)continuity in Children's Mental Health Care.............................................. 1

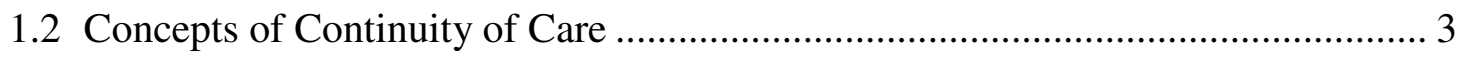

1.3 Measures of Continuity of Care .................................................................... 6

1.3.1 Organization-level Measures ....................................................... 6

1.3.2 Patient-level Measures ...................................................................... 9

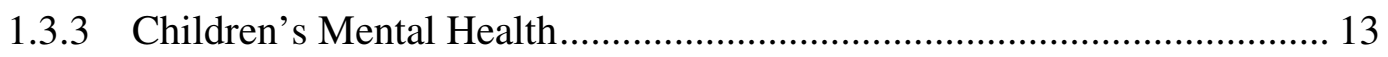

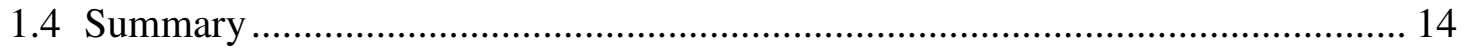

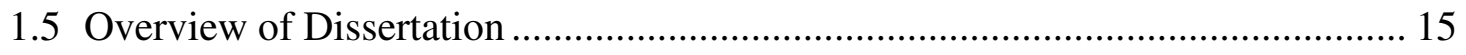

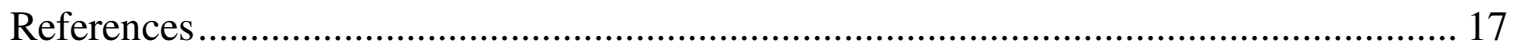

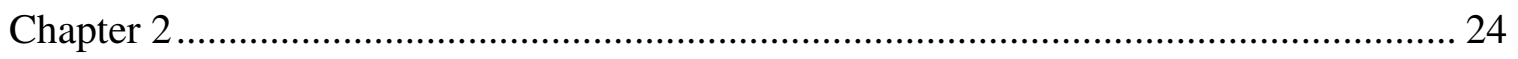

2 Continuity of Care in Children's Mental Health: Parent, Youth and Professional

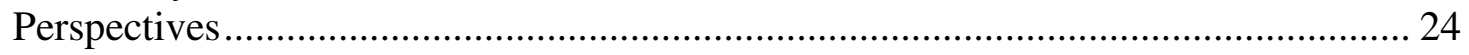

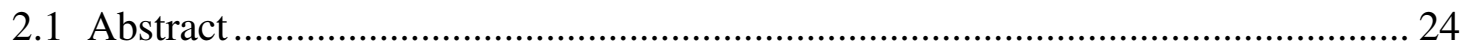

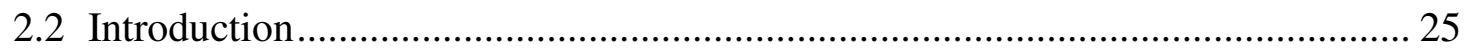

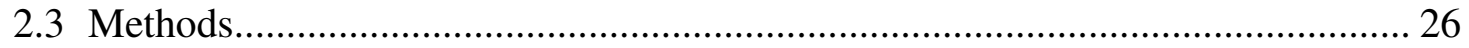




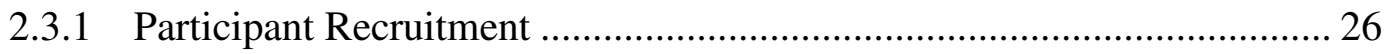

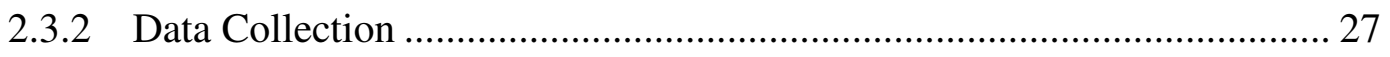

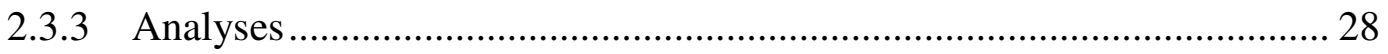

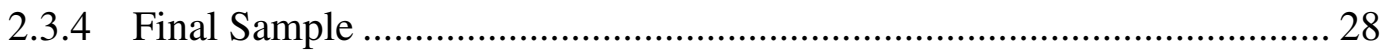

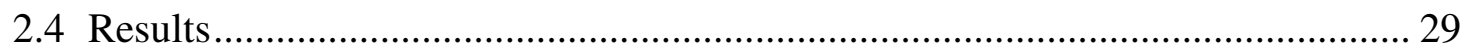

2.4.1 Relational Continuity ......................................................................... 30

2.4.2 Informational Continuity ...................................................................... 33

2.4.3 Management Continuity.............................................................................. 36

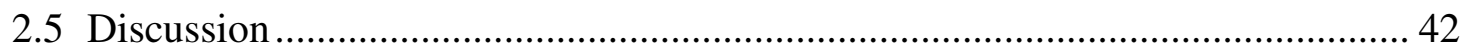

2.5.1 Relational continuity ………………………...................................... 43

2.5.2 Informational Continuity ...................................................................... 44

2.5.3 Management Continuity........................................................................... 44

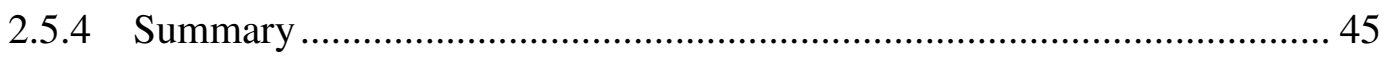

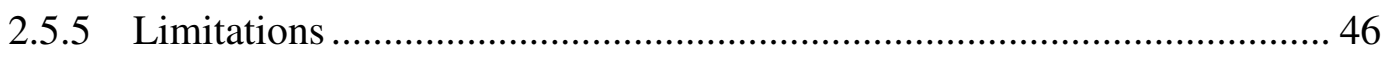

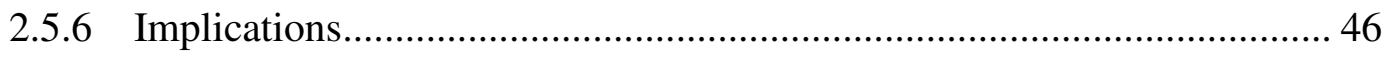

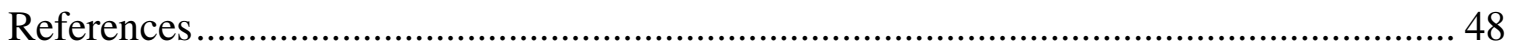

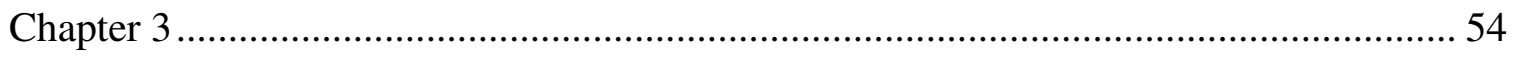

3 Continuity of Care in Children's Mental Health: Development of a Measure ............ 54

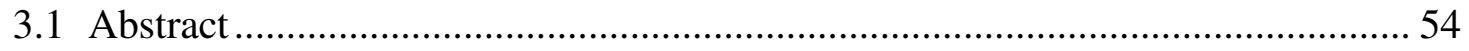

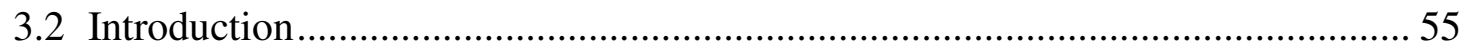

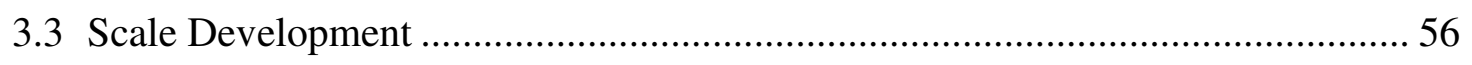

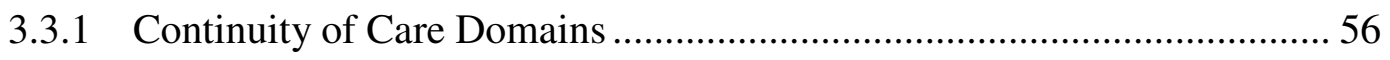

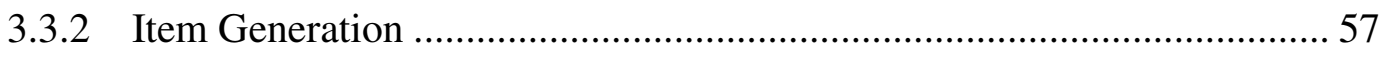

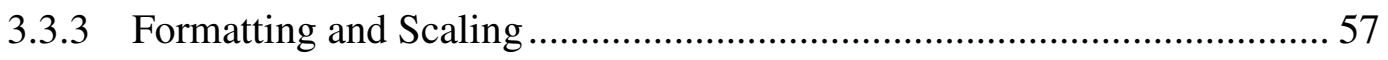

3.3.4 Pretesting for Content Validity ………………................................... 58

3.3.5 Sub-dimension Classification ............................................................ 58 


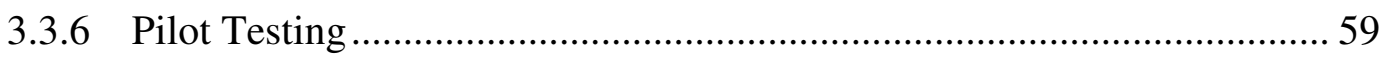

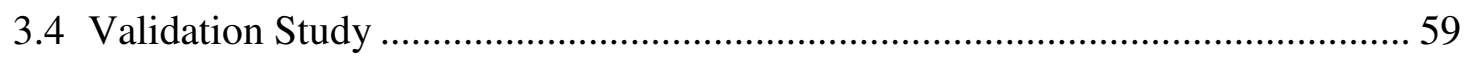

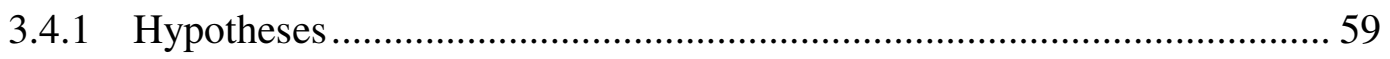

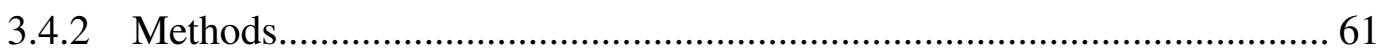

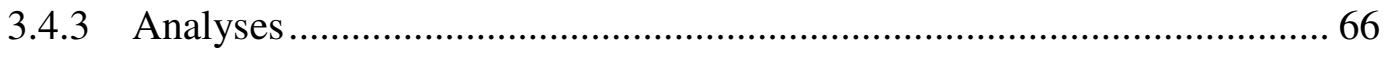

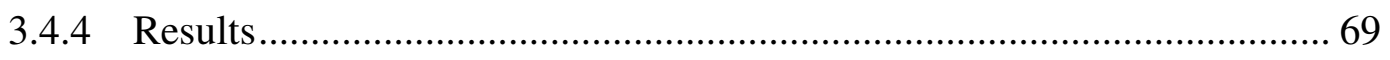

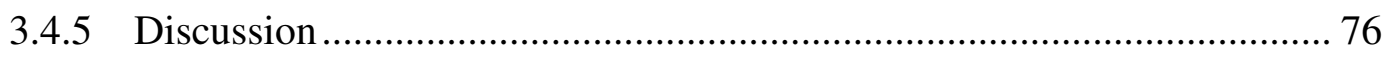

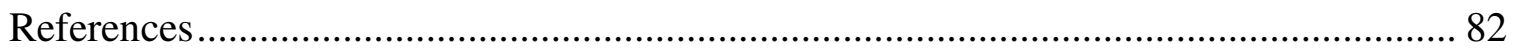

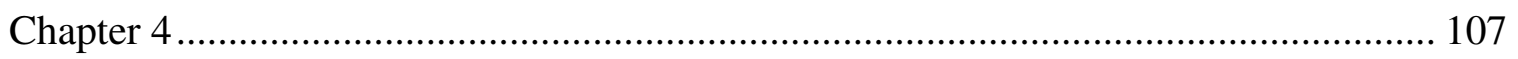

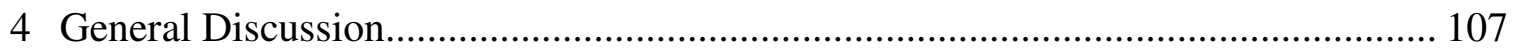

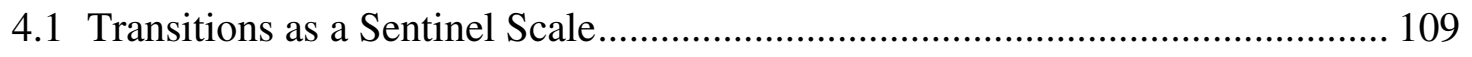

4.2 Family Participation and Collaboration ................................................. 110

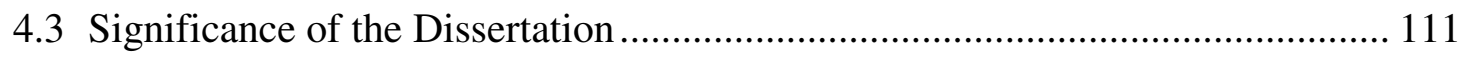

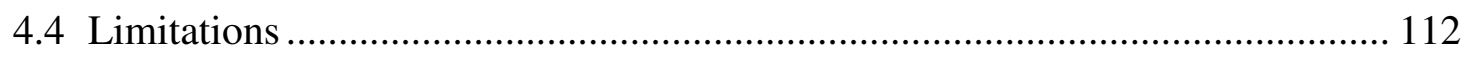

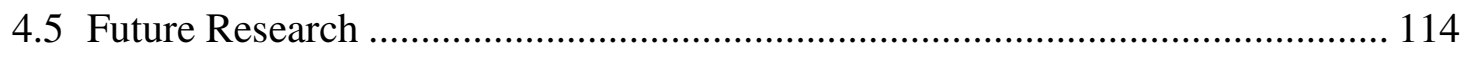

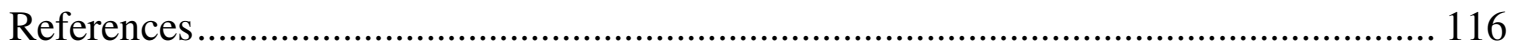

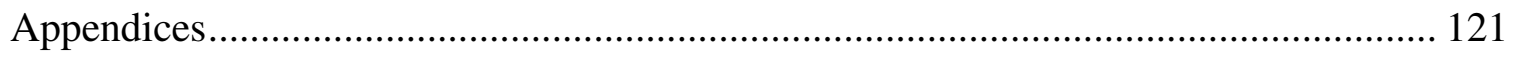

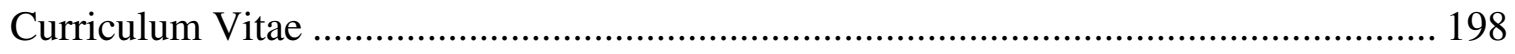




\section{List of Tables}

Table 2.1: Comparison between study samples and population of all parents and youth seen at children's mental health agencies in Ontario ................................................................ 52

Table 2.2: Correspondence between continuity themes ................................................... 53

Table 3.1: Definitions of Continuity Scales................................................................ 93

Table 3.2: Demographic Characteristics of C3MH Parent Validation Sample .................... 95

Table 3.3: Correlations Between C3MH Parent Scales ................................................. 99

Table 3.4: Test-retest Reliability of C3MH Means, Standard Deviations, and Intraclass

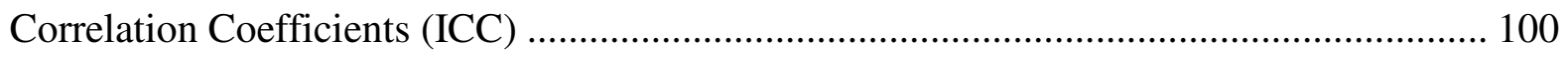

Table 3.5: Convergent and Discriminant Validity Correlations for the C3MH-P.............. 101

Table 3.6: C3MH Parent Scale Comparisons between Agencies with $n$ > 15................... 104 


\section{List of Figures}

Figure 3.1: Mean Scale Scores by Group: Case Manager vs. No Case Manager................ 105

Figure 3.2: Mean Scale Scores by Group: Drop Out vs. No Drop Out ............................. 106 


\section{List of Appendices}

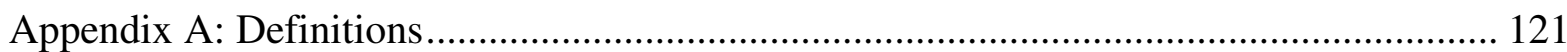

Appendix B: Summary of Relevant Measures of Continuity of Care ................................. 134

Appendix C: Study 1 Interview Protocol: Parents / Youth.................................................... 141

Appendix D: Study 1 Interview Protocol: Service Providers ................................................. 143

Appendix E: Study 1 Recruitment Handout ...................................................................... 145

Appendix F: Informed Consent Telephone Script for Parents.............................................. 146

Appendix G: Study 1 Consent to Participate - Parents/Youth ............................................ 148

Appendix H: Study 1 Consent to Participate - Professionals ............................................... 149

Appendix I: Study 1 Letter of Information: Parents ....................................................... 150

Appendix J: Study 1 Letter of Information: Youth.............................................................. 152

Appendix K: Study 1 Letter of Information: Professionals .................................................. 154

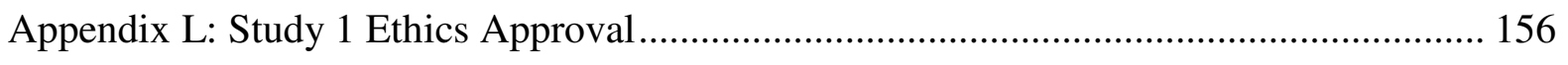

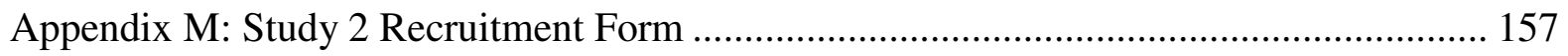

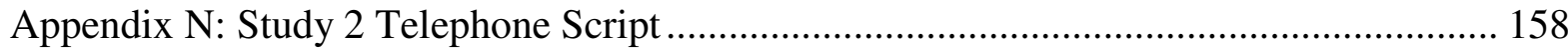

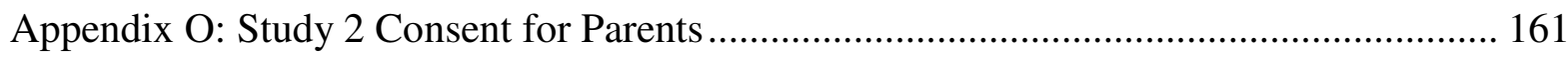

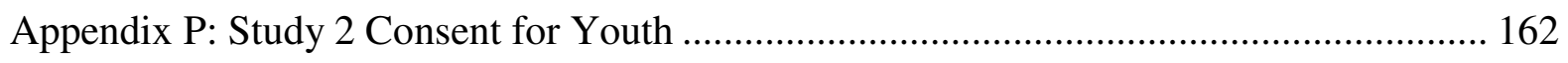

Appendix Q: Study 2 Letter of Information for Parents ..................................................... 163

Appendix R: Study 2 Letter of Information for Youth ...................................................... 165

Appendix S: Study 2 Thank-You Letter Parents/Youth ..................................................... 167 
Appendix T: Study 2 Thank-You Letter Clinician 168

Appendix U: Study 2 Ethics Approval ......................................................................... 169

Appendix V: Demographic Characteristics of C3MH Test-Retest Sample........................... 170

Appendix W: Demographic Characteristics of C3MH-Y Validation Sample...................... 172

Appendix X: C3MH-P Item Descriptives ........................................................................... 174

Appendix Y: C3MH-P Social Desirability Correlations, Item Efficiency Index and CFA

Factor Loadings 178

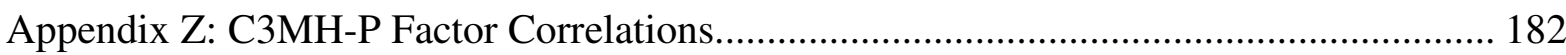

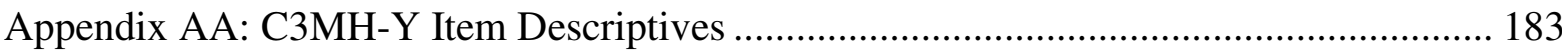

Appendix BB: C3MH-Y Social Desirability Correlations, Item Efficiency Index and Factor Loadings 186

Appendix CC: C3MH-P Confirmatory Factor Analysis Models......................................... 188

Appendix DD: C3MH-P Nested Model Comparisons........................................................... 190

Appendix EE: C3MH-Y Confirmatory Factor Analysis Models ......................................... 191

Appendix FF: Correlations Between C3MH-Y Scales ...................................................... 192

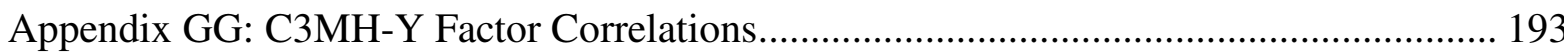

Appendix HH: C3MH-Y Convergent and Discriminant Validity Correlations .................... 194

Appendix II: C3MH-P Demographic Correlations................................................................ 195

Appendix JJ: C3MH-Y Demographic Correlations............................................................ 196

Appendix KK: Maximum Number of Allowable Item Omissions ........................................ 197 


\section{Chapter 1}

\section{General Introduction}

For over two decades, the systems-of-care philosophy in children's mental health has recognized the need to respond to a fragmented service system through greater integration and coordination. Continuity of care, which is how a patient experiences care over time as coherent and linked (Reid, Haggerty, \& McKendry, 2002), has been identified as an indicator of health system performance and of quality of care (The Provincial Centre of Excellence for Child and Youth Mental Health at CHEO, 2006) and is considered an ethical principle of care (Thornicroft \& Tansella, 1999). Indeed, studies of families with disabled children have indicated that parents ranked continuity and consistency of providers over time as one of the most important aspects of care (Baine, Rosenbaum, \& King, 1995; Rosenbaum, King, \& Cadman, 1992). Fragmentation of services is not unique to children's mental health, and the effort to enhance continuity of services in the adult medical and mental health system has increased in Canada and worldwide (Reid et al., 2002). International policy reports and charters have recommended a collaborative effort to enhance continuity of care (Fulop \& Allen, 2000; Institute of Medicine, 1996; Rubenstein et al., 1995; World Health Organization, 1996). In 2001, with input from over 500 stakeholders, the Canadian Health Services Research Foundation (CHSRF) identified continuity of care as a research priority in Canada (Canadian Health Services Research Foundation, 2001). Although a comprehensive definition of continuity of care (Reid et al., 2002) and a new instrument to measure continuity of care (Adair et al., 2004) resulted from this mandate, the focus was primarily on adult medical and mental health services.

\section{1 (Dis)continuity in Children's Mental Health Care}

Children with psychosocial problems frequently require a complex array of services that span across various service sectors (i.e., mental health, medical, education, 
child welfare, and juvenile justice), but connecting these services becomes difficult due to administrative and fiscal barriers. As the number of providers involved increases, the number of potential interfaces among providers increases exponentially, which makes it difficult to coordinate services (Koren et al., 1997). The complexity of the children's mental health system has been captured by research examining help-seeking, and patterns of service utilization. For example, in our recent study of the experiences of 300 families seeking children's mental health services across one of 15 agencies in Ontario (Reid et al., 2006), we found that $15 \%$ of families were involved with four or five of the five sectors that provide services for children (i.e., children's mental health, medical, education, juvenile justice, and child welfare). In my Master's thesis, using secondary data analyses from the same study, I found that approximately half of the families interviewed had contacted two or more agencies in the previous year and these families were more likely than families who only contacted only one agency to contact multiple other service sectors (Tobon, 2008). In a qualitative study on continuity of care in rural Ontario, the authors concluded that the children's mental health system in rural Ontario is "more like a labyrinth or a tangled web than a pathway" (Boydell et al., 2006, p.187). Thus, unlike the medical sector, in which the model of care involves having a "medical home" and continuity of care is defined most simply as seeing the same provider, the measurement of continuity of care in children's mental health care is more difficult given the complexity of the system, but just as important, given the fragmentation of services.

The need to respond to a fragmented system has been recognized in the systems of care philosophy (Stroul, 1996), which was developed over two decades ago. The goal of a system of care is to provide individualized, community-based, culturally competent services in the least restrictive, clinically appropriate environment (Huang et al., 2005). Since this time, the few empirical studies related to continuity of care in the field of children's mental health have primarily approached the topic from the perspective of organizational systems (Koren et al., 1997). These studies have examined existing linkages within networks of agencies (Heflinger, 1996b; Morrissey, 1992), primarily by relying on the perspective of agency staff, thus providing no information on the 
perspective of service users (Koren et al., 1997). One large study, the Fort Bragg Evaluation Project, was designed to test whether a "continuum of care" was more costeffective than services delivered in a more fragmented system (Bickman, 1996). Other studies that have focused on the family perspective in children's mental health have either been strictly qualitative in nature (e.g., Boydell et al., 2006; Minore, Boone, Arthur, \& O'Sullivan, 2005), or have emphasized one facet of continuity of care, such as service coordination (Koren et al., 1997). Overall, continuity of care is a component of care that has been recognized as important to children's mental health but, currently, no instrument exists to measure continuity of care from the family's perspective. This deficiency severely limits efforts to understand, and ultimately improve, continuity of mental health care for children.

The aim of this dissertation was to develop a valid and reliable instrument of continuity of care for children's mental health. Before outlining the development of a new measure of continuity of care in children's mental health, it is necessary to briefly examine the history of the concept and measurement of continuity of care from the literature on primary care, chronic mental illness in adults, and on chronic medical illness in children.

\subsection{Concepts of Continuity of Care}

The concept of continuity has been used across medical disciplines and specialties since the 1940s (Bachrach, 1981). In primary medical care, the emphasis has been on longitudinal, relational, or personal continuity (Haggerty et al., 2003). Continuity of care is an integral part of family medicine and centers on the idea that one physician cannot replace another like parts of a machine (Mathews \& Barnsley, 2003). A stable patientprovider relationship leads to the provider knowing more about the patient and also creates more trust, mutual understanding and sustained responsibility toward the patient (Reid et al., 2002). Likewise in adult mental health care, since deinstitutionalization from psychiatric hospitals, continuity of care has been recognized as an essential component of 
quality mental health services for patients with serious, chronic mental illness (White, 1992) as these patients in the community continue to require lengthy treatment across a variety of service settings (Bachrach, 1981). Thus, in mental health care, continuity has referred to the coordination of services and to the stability of patient-provider relationships over time (Haggerty et al., 2003). Typically, this relationship is with a team and not a single provider. In 1980, Barbara Starfield argued that a lack of a consensus definition of continuity was interfering with recognizing its importance (Starfield, 1980). Certainly, the interchangeable use of the terms continuum of care, coordination of care, discharge planning, case management, integration of services, and seamless care has created "continuous confusion" (Starfield, 1980; Haggerty et al., 2003).

In reference to mental health care in particular, Bachrach (1981) defined continuity of care as, "a process involving the orderly, uninterrupted movement of patients among the diverse elements of the service delivery system" (p.1449). She characterized continuity across the following seven dimensions: 1) temporal (longitudinal continuity), 2) individual (patient-centredness), 3) cross-sectional (comprehensiveness), 4) flexibility, 5) relationship, 6) accessibility and 7) communication. According the Bachrach (1981), continuity begins when the need arises and ends when the need is fulfilled. Similarly, Harris and Bergman (1984) suggest that the continuity of care strategy should simulate the weaning process and change according to the patient's need for contact over time, with some patients requiring continued intense contact while for others, occasional contact is sufficient. A more recent definition of continuity specifies the following dimensions: continuity of services provision (i.e., whether the patient remains in touch with services), the extent of breaks in service delivery, continuity of contact with particular professionals, implementation of plans for services, co-ordination with primary care services, and co-ordination with informal and formal carers outside of the specialist mental health services (Johnson, Prosser, Bindman, \& Szmukler, 1997). To date, there continues to be a wide number of definitions that range from simple to complex and from abstract to concrete (Ware, Dickey, Tugenberg, \& McHorney, 2003). 
In their review of the literature on the concept of continuity of care, Robert Reid and colleagues argue that continuity could be viewed from either a person-focused or a disease-focused perspective. In their report, Reid et al. (2002) state that continuity has two core elements and that there are three different types of continuity. First, the unit of measurement in continuity is the individual (person-focused), not the system, which is consistent with Bachrach's (1981) dimension of patient-centredness. It is how the individual patient experiences integration of services and coordination. Second, continuity of care is received over time: a chronological dimension distinguishes continuity from quality of interpersonal communication during a single clinical encounter; this overlaps with Bachrach's (1981) longitudinal dimension. Reid et al. (2002) argue that three types of continuity: informational, relational and management, should all be measured from the patient's perspective. Informational continuity links care from one provider to another or from one event to another; this is consistent with Bachrach's (1981) dimension of communication. Relational continuity refers to the consistency in staff, which provides the patient with a sense of predictability and coherence; this overlaps with Bachrach's (1981) dimension of relationship. This dimension has also been referred to as 'longitudinal' (Brekke, Ansel, Long, Slade, \& Weinstein, 1999; Johnson et al., 1997; Ware et al., 2003) or 'interpersonal' continuity (O'Malley, 2004). In primary care, where the patient is loyal to the physician and the physician is responsible to the patient, this dimension is highly valued. Management, or 'cross-sectional' continuity refers to the provision of complementary and timely services across providers that are responsive to the changing needs of the patient (Haggerty et al., 2003; Reid et al., 2002). This dimension overlaps with Bachrach's (1981) dimensions: cross-sectional, flexibility, and accessibility. The ideal situation is when the patient's experience of care over time is coherent and linked as a result of good information flow (informational continuity), interpersonal skills (relational continuity) and coordination of care (management continuity) (Reid et al., 2002). As Haggerty et al. state, "For patients and their families, the experience of continuity is the perception that the providers know what has happened before, that different providers agree on a management plan, and that a provider who knows them will care for them in the future" (Haggerty et al., 2003). See 
Appendix A for a selection of definitions of continuity of care relevant to children's mental health care. For a more comprehensive table of definitions across all fields, see Reid et al. (2002).

\subsection{Measures of Continuity of Care}

In the same way that the literature is replete with various concepts of continuity of care, it is also replete with various ways of measuring them. In their review of measures of continuity, including primary care, mental health, nursing, and condition-specific articles across both adults and children, Reid et al. (2002) found a paucity of measures that examine continuity across settings and professional groups and they found that most measures examined a single aspect of continuity in a single context. Measures of continuity can be divided into two categories: organization-level measures, which measure the concept of continuity at the agency- or system-level without the patient's input, and patient-level measures, which incorporate the patient's perspective, and are person-focused as opposed to disease-focused. Both types of measures will be reviewed here [see Appendix B for a summary of relevant measures].

\subsubsection{Organization-level Measures}

In the 1970s, a number of organization level measures and algorithms to quantify continuity were developed, including number of referrals, the duration and intensity of patient/provider affiliation [e.g., Usual Provider Continuity (UPC; Breslau \& Reeb, 1975)], or the concentration of care among different providers [e.g., Continuity of Care index; (COC; Bice \& Boxerman, 1977; Reid et al., 2002)]. These measures usually only require administrative data to calculate an index of continuity. For example, the COC index in adult medical care is an equation that results in a number between 0 and 1 and represents both the dispersion and concentration of care among all providers seen. The COC is calculated using two variables: the number of visits to provider $i$ and $N$, the total number of visits in a defined period. The problem with these proxy measures of continuity measured at the organization level is that they often tap discontinuity (e.g., 
"gaps," "lags," "interruptions," or "breaks" in care) and may leave a gap between the concept and measure of continuity (e.g., when continuity is measured as the presence of case management; Ware et al., 2003). In general, these organization-level measures oversimplify the concept of continuity and examine a single aspect of continuity in a single context (Reid et al., 2002).

In children's mental health, organization-level proxy measures of continuity include adequate duration of treatment, planned discharge, and transition between levels of care (The Provincial Centre of Excellence for Child and Youth Mental Health at CHEO, 2006). Only one study to date has examined a "continuum of care" through organization-level measures. The seminal Fort Bragg Evaluation Project was designed to test whether a "continuum of care" was more cost-effective than services delivered in a more fragmented system (Bickman, 1996). The $\$ 80$ million project offered free mental health and substance use services to more than 42,000 children and adolescents in the Fort Bragg catchment area. The results of this study indicated that, although an "integrated continuum" was successfully implemented with "greater continuity of care," the cost was higher and the clinical outcomes were no different than those of the Comparison site (Bickman, 1996, p.689). The researchers' definition of a "continuum of care" included access to a range of services including residential, intermediate, and nonresidential services, as well as individualized ongoing case management, a centralized point of intake, and comprehensive and individualized assessment and treatment (Bickman, 1996; Heflinger, 1996a). It was expected that these changes implemented at the Demonstration site would result in service system coordination (Heflinger, 1996a) and the researchers did conclude that the Demonstration successfully executed a "coordinated, individualized, community-based and family-focused continuum of care" (Bickman, 1996, p.692). They measured "coordination" by surveying community service providers using the self-administered "Fort Bragg Children and Youth Services Network Study" questionnaire, which measures the linkages between the respondent's agency and other agencies and providers in the mental health network. The Demonstration site had significantly better ratings of services system performance (i.e., the extent to which 
services were coordinated and responsive to needs) than the Comparison site, based on the service provider ratings (Heflinger, 1996b).

The previously mentioned confusion over definitions of "continuity of care" is evident in the Fort Bragg study. A continuum of care, in their study, refers to service system integration (i.e., an organizational and population-based approach) more than service integration (i.e., a service intervention at the level of the individual patient) (Goldman, Thelander, \& Westrin, 2000), and was measured from the organization-level as opposed to the patient-level. Moreover, proxy indicators of "continuity" were used, such as receiving follow-up services within 30 days after a hospital discharge (Bickman, 1996). The controversial results of the mental health outcome study suggested that the continuum of care theory was not supported (Bickman, 1996). Greater coordination of services at the systems level was not related to better clinical outcomes (e.g., lower symptomatology post-treatment).

\subsubsection{Summary and implications related to organization-level measures}

Three inferences can be drawn from the above review as they relate to the current study. First, continuity of care may be a necessary, but not sufficient, ingredient affecting clinical outcomes. Other ingredients, such as implementing evidence-based interventions at the individual level may also be necessary (Weisz, Han, \& Valeri, 1997). As Bickman contends, the Fort Bragg project may have been an "impressive structure" built on a “weak foundation” (Bickman, 1996, p.695).

Second, the clinical outcomes of the children may not be the only outcome of interest. Studies examining the processes of care for children with chronic medical illnesses indicate that parental stress and satisfaction with services are primary outcomes of importance (King, King, \& Rosenbaum, 2004). In the Fort Bragg Study, there was significantly more parental satisfaction with care at the Demonstration compared to the Comparison site (Bickman, 1996). Although not examined in the Fort Bragg study, it is 
likely that for parents of children with chronic mental health problems, increasing the experience of continuity of care may alleviate parental stress more than it might affect clinical outcomes. Another outcome of interest related to continuity of care is dropout rates. In the Fort Bragg study, dropout was defined as receiving only one visit. The researchers found that $7 \%$ of the clients in the Demonstration site dropped out compared to more than $18 \%$ at the Comparison site (Bickman, 1996). Thus, variables other than mental health outcomes for the child, such as satisfaction, parental stress, and drop out rates may be important to examine in relation to continuity.

Finally, perhaps a "continuum of care," as measured by provider-ratings of coordination and integration of service systems, is a related, but different construct than "continuity of care" as the patient experiences it over time (Reid et al., 2002). Until recently, little attention was paid to the patient's perspective on continuity (Reid et al., 2002). It may be that patient-level measures of continuity are more relevant to clinical outcomes. Several patient-level measures will be reviewed in the areas of primary care, adult mental health, pediatrics, and finally, in children's mental health.

\subsubsection{Patient-level Measures}

\subsubsection{Primary care}

One of the first researchers to examine continuity from the patient's perspective developed a patient's (adult self-report) perception of continuity scale (PC) for family medicine (Chao, 1988). This measure provided distinct information from the provider continuity formulas mentioned previously. For example, the PC scale had greater correlation with patient satisfaction than two other commonly used system-level measures (e.g., UPC, COC). The PC scale was not significantly correlated to either of the formula measures. Several measures of relational continuity have included the patient's perspective, especially in primary care. For example, the Primary Care scale measures patient's preference for being seen by a primary physician, trust in the physician and whether patient feels known (Reid et al., 2002). There is also the Primary Care 
Assessment tool and the Primary Care Assessment Survey, both of which measure aspects of relational continuity (Reid et al., 2002). These instruments frequently refer to a patient's "medical home" and in particular, to the relationship with the primary care physician. These instruments would not be applicable in children's mental health for a number of reasons. Although children receiving specialized mental health care typically have a family physician, s/he may not be the central clinician responsible for providing or coordinating mental health care for these children.

\subsubsection{Adult mental health}

In adult mental health care, two scales have been developed to measure continuity from the patient's perspective. The CONNECT scale by Ware and colleagues is a formal, multi-item, multi-scale assessment tool that assesses continuity from the perspective of patients (Ware et al., 2003). The CONNECT scale consists of 13 scales and one singleitem indicator. Although the original tool was developed for use with adults diagnosed with serious mental illness, the developers suggest that future efforts should test it on other populations, such as those without serious mental illness or children (Ware et al., 2003); to our knowledge, the CONNECT has not been tested with children to date.

Another instrument is the 47-item Alberta Continuity of Services Scale-Mental Health (ACSS-MH; Adair et al., 2004). This scale was developed as a standard measure of continuity of mental health services from both the patient and the provider's perspective (Adair et al., 2005). Unlike CONNECT, the sample used in developing the scale ranged from more acutely ill patients who had recently entered the mental health system to patients with chronic illness and long-term involvement (Joyce et al., 2004). The ACSS-MH has since been cross-validated in a new sample of patients using community and outpatient mental health programs in three regions of Ontario (Durbin, Goering, Streiner, \& Pink, 2004). In the cross-validation, however, Durbin suggests that the ACSS-MH needed more validity testing on the interpersonal domain of the scale and that it may benefit from incorporating some of the Ware tool domain and items (Durbin, 
2005). None of these measures have been used in children's mental health, or with any child population.

\subsection{Implications for a children's mental health measure}

The field is ripe for the development of a continuity of care scale for children's mental health based on both the CONNECT and the ACSS-MH scales. Items for a new measure of continuity of care in children's mental health can be informed, in part, by these two existing instruments in adult mental health. These items may or may not be applicable, however, to children's mental health care. Thus, a qualitative study was conducted to get a better understanding of how parents and youth experienced continuity of care in order to better capture this experience in a multi-item, multi-dimensional measure developed specifically for this population.

\subsubsection{Pediatrics}

In pediatrics, coordination of care has been emphasized for children with special health care needs (i.e., children who have or are at increased risk for physical, developmental, behavioural, or emotional conditions and who require greater health related services than other children; Stille \& Antonelli, 2004). In a study that adapted an adult continuity index for parents presenting at a primary care clinic, Christakis, Wright, Zimmerman, Bassett and Connell (2003) found that continuity of care was associated with well-coordinated care as reported by parents on the Components of Primary Care Index (CPCI) care coordination domain. As reviewed by O'Malley (2004), the current evidence on the impact of continuity of care in pediatrics suggests that greater clinician continuity has been associated with higher patient-, physician-, and parent-satisfaction, greater treatment adherence, greater use of preventative visits, lower emergency department and hospital use, and fewer missed appointments. O'Malley (2004) notes the paucity of studies on the effectiveness of clinician continuity (i.e., relational continuity) on clinical outcomes of at-risk groups, among which she includes children and adolescents with mental illness. 
For families of a child with a chronic illnesses or disability, continuity of care has been a particularly important factor in determining satisfaction with care and parental well-being. In contrast, families with a non-disabled child are less concerned about continuity (Breslau \& Mortimer, 1981; Breslau, 1982). Indeed, parents of disabled children have ranked continuity and consistency of providers over time as one of the most important aspects of care and more important than components such as family-centered care, a team approach, emotional support, and advocacy (Baine et al., 1995; Rosenbaum et al., 1992). Based on these findings, King, Rosenbaum and King (1995), in Hamilton, Ontario, developed the Measures of Processes of Care (MPOC) scale to determine the relationship between processes of care for children with disabilities (i.e., relationship between health care professionals and families) and parental psychosocial well-being. The final measure includes a subscale related to continuity (i.e., coordinated and comprehensive care for the child and family scale). One study of parents of children with disabilities (i.e., cerebral palsy, spina bifida, or hydrocephalus) found that the caregiving process, as measured by the MPOC, was a significant predictor of parent's well-being (i.e., less distress and depression; King, King, Rosenbaum, \& Goffin, 1999).

\subsection{Implications for children's mental health}

Although related to mental health care, these studies have all focused on children with chronic medical illnesses and disabilities. As mentioned previously, existing measures developed for one population, children with chronic medical illnesses, cannot simply be administered to another population, children with psychosocial problems. Children's mental health care can involve up to five service sectors (i.e., mental health, medical, education, child welfare, and justice), whereas chronic illness care typically does not. Moreover, children's mental health care tends to follow a short-term, crisisbased approach to mental health problems, as opposed to a chronic care model, in which children would be followed-up for long-term management. These differences necessitate a better understanding of how continuity of care is unique in children's mental health, 
and how certain items from existing measures developed with other populations may or may not be applicable to this population.

\subsubsection{Children's Mental Health}

Two proxy measures of continuity of care exist in the field of children's mental health. These measures do not explicitly refer to "continuity of care," but instead focus specifically on one aspect of continuity of care, service coordination. Koren and colleagues (1997) refined the 18-item Service Coordination Scale (DeChillo \& Lebow, 1992), and retained 9 of the original items. They reported that the single Service Coordination score had an alpha coefficient of .88, indicating a high level of internal consistency (Koren et al., 1997). The researchers found that high problem severity was moderately associated with less service coordination, and that service coordination was significantly associated with greater overall satisfaction, and greater comprehensiveness (i.e., the extent to which parents reported that their child's needs were met in eight categories: leisure, education, social, health, mental health, primary, facilitation, and support). This instrument only measures one dimension of continuity: management continuity, or the coordination of care. Moreover, it simplifies the multiple linkages between various service providers (e.g., the family physician and the school, or the agency and child welfare) into one category of "service providers" in each of the 9-items (e.g., "The service providers have worked together for my child"). It is possible that this item does not capture the complex experience of families receiving services from multiple providers. This problem was addressed in this thesis by first examining families' experiences in receiving care across multiple providers through qualitative interviews before developing questionnaire items, and then including "modules" in the new instrument to examine continuity between providers across sectors.

The other proxy measure of continuity comes from the University of South Florida's System of Care Practice Review -Revised (SOCPR; University of South Florida, 2007). A subsection of this semi-structured interview focuses on integration and coordination. The interviewer asks the family open-ended questions about the "group of 
people" that helps the family, such as how the different providers integrate and coordinate with each other and how the child and family are involved in the communication between providers. Preliminary evidence shows good psychometric properties for the SOCPR, but no studies to date have used subsections of the SOCPR. This instrument, however, is qualitative in nature and does not specifically focus on continuity of care. It is a good basis on which to begin to develop a new measure, by first interviewing parents, youth, and professionals on their perspectives on continuity of care in children's mental health care.

A more recent study examining continuity of care for children with special needs in rural northern Ontario used chart reviews to determine to what extent care was continuous based on the six dimensions outlined by Johnson et al. (1997): whether services maintain contact with patients, whether patients consistently see the same staff, success of transfer between services, degree to which plans of services are followed through, integration between service providers, and comprehensiveness in meeting needs (Minore et al., 2005). The researchers found that about half of families had "breaks" (i.e., "substantial time gaps in services") in care for several reasons, including staff turnover, client non-attendance, or the child's clinical status. They also found that most children have the same care providers over extended periods of time, but that changes may occur as clients explore other therapeutic options, or because of staff turnover (Minore et al., 2005).

\subsection{Summary}

In summary, the concept of continuity of care has existed for over 70 years, and has been recognized as important to children's mental health in particular for over 20 years. Within the past 10 years, the CHSRF identified continuity of care as a research priority in Canada (Canadian Health Services Research Foundation, 2001), and a new measure of continuity of care in adult mental health as well as a comprehensive review of the literature, and two qualitative studies in children's mental health resulted from this 
mandate. Yet, no instrument currently exists that explicitly measures the multidimensional concept of continuity of care from the family's perspective. Existing measures in primary care, adult mental health care, and pediatrics, and some onedimensional, proxy measures of continuity in children's mental health were reviewed to provide ideas for the development a new instrument specific to children's mental health care.

\subsection{Overview of Dissertation}

Continuity of care is a component of care that has long been recognized as important to children's mental health, but, to date, no multi-dimensional instrument exists to measure continuity of care from the family's perspective. This deficiency severely limits efforts to understand, and ultimately improve, continuity of mental health care for children. In order to better understand continuity of care within children's mental health, the current dissertation built on the conceptual foundation laid out by Reid et al.'s (2002) comprehensive definition of continuity of care, as well as on existing measures to develop a new measure of continuity of care. The objectives for this dissertation were:

1. To better understand and define continuity of care in children's mental health

2. To develop a valid and reliable measure of continuity of care for children's mental health

3. To pilot a youth-report version of the newly developed continuity of care measure.

These objectives were addressed through two studies. The first study, presented in Chapter Two, refined the construct of continuity of care as it applies to the children's mental health system. Given the aforementioned differences between the children's mental health system and primary care, adult mental health, and pediatrics, it was first necessary to clarify and refine the continuity of care construct. To this end, qualitative interviews with parents, youth, and service providers who were currently involved in obtaining or providing services were conducted in order to better capture the experience 
of continuity of care from their perspective, and to better understand how to best capture the complexity of the multitude of relationships within the agency and across sectors in a questionnaire. In addition to helping refine the conceptual dimensions of continuity of care as it applies to children's mental health, the study interviews also served as a source for generating questionnaire items, with the goal of developing a new measure of continuity of care.

The second study, presented in Chapter Three, involved the development of the new measure of Continuity of Care for Children's Mental Health $(\mathrm{C} 3 \mathrm{MH})$ and administration of the measure to parents to test its psychometric properties. In addition, a pilot youth measure was developed and administered to youth. The study involved four phases: item generation, pre-testing, pilot testing, and validation. In the validation study, the $\mathrm{C} 3 \mathrm{MH}$ - Parent version was administered to parents of children and youth and the pilot youth measure was administered to youth. Confirmatory factor analysis was conducted, and convergent and discriminant validity were calculated. Chapter Four discusses the results from these two studies, implications for children's mental health services research, and potential areas for future research.

A parallel line of ongoing research (not included in this dissertation) examines the "modules," which include separate sections that parents and youth complete if they experienced particular events, or received particular services. These modules are: having multiple providers, having a change in providers, being discharged from intensive services, or receiving mental health services from the following: family doctor, pediatrician, psychiatrist, school, child welfare, another agency, or a private provider. These modules help to capture the complexity of children's mental health services. 


\section{References}

Adair, C. E., McDougall, G. M., Mitton, C. R., Joyce, A. S., Wild, T. C., Gordon, A., ... Beckie, A. (2005). Continuity of care and health outcomes among persons with severe mental illness. Psychiatric Services, 56, 1061-1069.

doi:10.1176/appi.ps.56.9.1061

Adair, C. E., Wild, C. T., Joyce, A., McDougall, G., Gordon, A., Costigan, N., ... Lu, M. (2004). Continuity of mental health services study of Alberta: A research program on continuity of mental health care. Ottawa, ON: Canadian Health Services Research Foundation.

Bachrach, L. L. (1981). Continuity of care for chronic mental patients: A conceptual analysis. American Journal of Psychiatry, 138, 1449-1456. Retrieved from PM:7294213

Baine, S., Rosenbaum, P., \& King, S. (1995). Chronic childhood illnesses: what aspects of caregiving do parents value? Child Care, Health and Development, 21, 291-304. doi:10.1111/j.1365-2214.1995.tb00759.x

Bice, T. W., \& Boxerman, S. B. (1977). A quantitative measure of continuity of care. Medical Care, 15, 347-349. Retrieved from PM:859364

Bickman, L. (1996). A continuum of care: More is not always better. American Psychologist, 51, 689-701. doi:10.1037/0003-066X.51.7.689

Boydell, K. M., Pong, R., Volpe, T., Tilleczek, K., Wilson, E., \& Lemieux, S. (2006). Family perspectives on pathways to mental health care for children and youth in rural communities. Journal of Rural Health, 22, 182-188. doi:10.1111/j.17480361.2006.00029.x 
Brekke, J. S., Ansel, M., Long, J., Slade, E., \& Weinstein, M. (1999). Intensity and continuity of services and functional outcomes in the rehabilitation of persons with schizophrenia. Psychiatric Services, 50, 248-256. Retrieved from PM:10030485

Breslau, N. (1982). Continuity reexamined: Differential impact on satisfaction with medical care for disabled and normal children. Medical Care, 20, 347-360. doi:10.1097/00005650-198204000-00001

Breslau, N., \& Mortimer, E. A., Jr. (1981). Seeing the same doctor: Determinants of satisfaction with specialty care for disabled children. Medical Care, 19, 741-758. doi:10.1097/00005650-198107000-00005

Breslau, N., \& Reeb, K. G. (1975). Continuity of care in a university-based practice. Journal of Medical Education, 50, 965-969. Retrieved from PM:1159765

Canadian Health Services Research Foundation. (2001). Open grants competition: 2001 project summaries. Canadian Health Services Research Foundation. Retrieved from http://www.chsrf.ca/funding_opportunities/ogc/2001_project_summaries_e.php

Chao, J. (1988). Continuity of care: Incorporating patient perceptions. Family Medicine, 20, 333-337. Retrieved from PM:3266158

Christakis, D. A., Wright, J. A., Zimmerman, F. J., Bassett, A. L., \& Connell, F. A. (2003). Continuity of care is associated with well-coordinated care. Ambulatory Pediatrics, 3, 82-86. doi:10.1367/1539-4409(2003)003<0082:COCIAW>2.0.CO;2

DeChillo, N., \& Lebow, W. (1992). Help when it's needed: Community mental health crisis services for children and youth. Portland, OR: Portland State University, Regional Research Institute for Human Services. 
Durbin, J. (2005). Continuity of care for individuals with severe mental illness: Measurement and mechanisms. Dissertation Abstracts International B, The Sciences and Engineering, 65, 5068.

Durbin, J., Goering, P., Streiner, D. L., \& Pink, G. (2004). Continuity of care: Validation of a new self-report measure for individuals using mental health services. Journal of Behavioral Health Services and Research, 31, 279-296. doi:10.1007/BF02287291

Fulop, N. \& Allen, P. (2000). National listening exercise: Report of the findings. London England: NHS Service Delivery and Organization National R\&D Programme.

Goldman, H. H., Thelander, S., \& Westrin, C. G. (2000). Organizing mental health services: An evidence-based approach. The Journal of Mental Health Policy and Economics, 3, 69-75.

Haggerty, J. L., Reid, R. J., Freeman, G. K., Starfield, B. H., Adair, C. E., \& McKendry, R. (2003). Continuity of care: A multidisciplinary review. British Medical Journal, 327, 1219-1221. doi:10.1136/bmj.327.7425.1219

Harris, M., \& Bergman, H. C. (1984). Reassessing the revolving door: A developmental perspective on the young adult chronic patient. American Journal of Orthopsychiatry, 54, 281-289. doi:10.1111/j.1939-0025.1984.tb01495.x

Heflinger, C. A. (1996a). Implementing a system of care: Findings from the Fort Bragg evaluation project. Journal of Mental Health Administration, 23, 16-29. doi:10.1007/BF02518640

Heflinger, C. A. (1996b). Measuring service system coordination in managed mental health care for children and youth. Evaluation and Program Planning, 19, 155-163. doi:10.1016/0149-7189(96)00006-7 
Huang, L., Stroul, B., Friedman, R., Mrazek, P., Friesen, B., Pires, S., \& Mayberg, S. (2005). Transforming mental health care for children and their families. American Psychologist, 60, 615. doi:10.1037/0003-066X.60.6.615

Institute of Medicine. (1996). Primary Care: America's Health in a New Era. Washington, DC: National Academy Press.

Johnson, S., Prosser, D., Bindman, J., \& Szmukler, G. (1997). Continuity of care for the severely mentally ill: Concepts and measures. Social Psychiatry and Psychiatric Epidemiology, 32, 137-142. Retrieved from ISI:A1997WT90200003

Joyce, A. S., Wild, T. C., Adair, C. E., McDougall, G. M., Gordon, A., Costigan, N., ... Barnes, F. (2004). Continuity of care in mental health services: Toward clarifying the construct. Canadian Journal of Psychiatry, 49, 539-550. Retrieved from PM:15453103

King, G., King, S., Rosenbaum, P., \& Goffin, R. (1999). Family-centered caregiving and well-being of parents of children with disabilities: Linking process with outcome. Journal of Pediatric Psychology, 24, 41-53. doi:10.1093/jpepsy/24.1.41

King, S., King, G., \& Rosenbaum, P. (2004). Evaluating health service delivery to children with chronic conditions and their families: Development of a refined Measure of Processes of Care (MPOC-20). Children's Health Care, 33, 35-57. doi:10.1207/s15326888chc3301_3

King, S., Rosenbaum, P., \& King, G. (1995). The Measure of Processes of Care: A means to assess family-centred behaviors of health providers. Hamilton, ON: CanChild Centre for Childhood Disability Research.

Koren, P. E., Paulson, R. I., Kinney, R. F., Yatchmenoff, D. K., Gordon, L. J., \& DeChillo, N. (1997). Service coordination in children's mental health: An empirical study from the caregiver's perspective. Journal of Emotional and Behavioral Disorders, 5, 162-172. doi:10.1177/106342669700500304 
Mathews, M., \& Barnsley, J. (2003). Patients seeking care during acute illness. Why do they not see their regular physicians? Canadian Family Physician, 49, 1498-1503. Retrieved from PM:14649989

Minore, B., Boone, M., Arthur, A., \& O'Sullivan, J. (2005). Managing continuity of care for children with special needs in rural and remote parts of northern Ontario. Ottawa, ON: Canadian Health Services Research Foundation. Retrieved from www.coespecialneeds.ca/PDF/continuityofcare.pdf

Morrissey, J. P. (1992). An interorganizational network approach to evaluating children's mental health service systems. In L. Bickman \& D. Rog (Eds.), Children's mental health services: Methodological issues (pp. 85-98). San Francisco, CA: Jossey Bass.

O'Malley, A. S. (2004). Current evidence on the impact of continuity of care. Current Opinion in Pediatrics, 16, 693-699. doi:10.1097/01.mop.0000142488.67171.02

Reid, G. J., Brown, J. B., Evans, B., Cunningham, C. E., Lent, B., Stewart, M. A., .. Ure, G. (2006). Help - I need somebody: The experiences of families seeking treatment for children with psychosocial problems and the impact of delayed or deferred treatment. Ottawa, ON: Canadian Health Services Research Foundation. Retrieved from http://30334.vws.magma.ca/final_research/ogc/reid_e.php

Reid, R., Haggerty, J., \& McKendry, R. (2002). Defusing the confusion: Concepts and measures of continuity of healthcare. Ottawa, ON: Canadian Health Services Research Foundation. Retrieved from http://www.chsrf.ca/Migrated/PDF/ResearchReports/CommissionedResearch/cr_co ntcare_e.pdf

Rosenbaum, P. L., King, S. M., \& Cadman, D. T. (1992). Measuring processes of caregiving to physically disabled children and their families. I: Identifying relevant 
components of care. Developmental Medicine and Child Neurology, 34, 103-114. doi:10.1111/j.1469-8749.1992.tb14976.x

Rubenstein, L. V., Fink, A., Yano, E. M., Simon, B., Chernof, B., \& Robbins, A. S. (1995). Increasing the impact of quality improvement on health: An expert panel method for setting institutional priorities. Joint Commission Journal on Quality Improvement, 21, 420-432.

Starfield, B. (1980). Continuous confusion? American Journal of Public Health, 70, 117 119. Retrieved from PM:7352602

Stille, C. J., \& Antonelli, R. C. (2004). Coordination of care for children with special health care needs. Current Opinion in Pediatrics, 16, 700-705. doi:10.1097/01.mop.0000144442.68016.92

Stroul, B. A. (1996). Children's mental health: Creating systems of care in a changing society. Baltimore, MD: Paul H. Brookes Publishing Co.

The Provincial Centre of Excellence for Child and Youth Mental Health at CHEO. (2006). Indicators of Quality for Child and Youth Mental Healthcare in Ontario.

Thornicroft, G., \& Tansella, M. (1999). Translating ethical principles into outcome measures for mental health service research. Psychological Medicine, 29, 761-767. doi:10.1017/S0033291798008034

Tobon, J. I. (2008). Factors associated with help-seeking and agency involvement patterns in children's mental health over one year (Unpublished Master's Thesis). The University of Western Ontario, London, ON.

University of South Florida. (2007). System of care practice review -revised: Finding your way in a local system of care. Retrieved from logicmodel.fmhi.usf.edu/resources/PDF/SOCPR-Protocol.pdf 
Ware, N. C., Dickey, B., Tugenberg, T., \& McHorney, C. A. (2003). CONNECT: A measure of continuity of care in mental health services. Mental Health Services Research, 5, 209-221. Retrieved from PM:14672500

Weisz, J. R., Han, S. S., \& Valeri, S. M. (1997). More of what? Issues raised by the Fort Bragg study. American Psychologist, 52, 541-545. doi:10.1037/0003066X.52.5.541

White, D. (1992). De-Constructing continuity of care: The deinstitutionalization of support services for people with mental health problems. Canadian Journal of Community Mental Health (Revue canadienne de santé mentale communautaire), 11, 85-99. Retrieved from http://cjcmh.metapress.com/index/N474M560221RHWG6.pdf

World Health Organization. (1996). The Ljubljana Charter on Reforming Health Care. Retrieved from http://www.euro.who.int/AboutWHO/Policy/20010927_5 


\section{Chapter 2}

\section{Continuity of Care in Children's Mental Health: Parent, Youth and Professional Perspectives}

\section{$2.1 \quad$ Abstract}

Continuity of care, how individuals experience care over time as coherent and linked, is considered an ethical principle of care. Our lack of understanding of continuity of care in children's mental health limits the ability to improve the care that families of a child with mental health problems receive. The aim of the current study was: 1) to refine the construct of continuity of care using semi-structured interviews with parents, youth, and service providers in children's mental health agencies in Ontario, Canada, and 2) to generate items for a new questionnaire. We found that relational, informational, and management continuity were interrelated and that where discontinuity existed in the system, individual providers often attempted to bridge gaps, which families appreciated. The understanding gained from this study can be used to inform changes in the way we care for some of the most vulnerable individuals within our society, children with mental health problems and their parents. 


\subsection{Introduction}

Continuity of care, the way in which individuals experience care over time as coherent and linked (Reid, Haggerty, \& McKendry, 2002), is considered an ethical principle of care (Thornicroft \& Tansella, 1999). The experience of continuity of care is especially important for families seeking children's mental health services, a "system" recognized as fragmented (Boydell, Bullock, \& Goering, 2009), and as the “orphan's orphan" of Canada's health care system (Kirby \& Keon, 2006, p.155). Despite its importance, few studies have examined continuity of care for children and youth receiving mental health care.

The Fort Bragg study examined the effects of providing a better continuum of services by designing a coordinated system of care within one military base in the United States (Bickman, Lambert, Andrade, \& Penaloza, 2001). However, few studies have examined the experience of continuity from the perspective of parents receiving services. A recent meta-synthesis of qualitative studies on continuity of care did not find any studies in the area of children's mental health (Waibel, Henao, Aller, Vargas, \& Vasquez, 2012). In Boydell et al.’s (2006) qualitative study exploring access to mental health in rural Ontario, the authors concluded that the children's mental health system is "more like a labyrinth or a tangled web than a pathway" (p.187). Indeed, in the province of Ontario, Canada, publicly-funded, specialized children's mental health $(\mathrm{CMH})$ services are provided by multiple agencies and professionals whose funding comes from three main provincial government ministries: the Ministry of Children and Youth Services, the Ministry of Health and Long-Term Care, and the Ministry of Education. Additional services are provided in primary and secondary schools and within the juvenile justice system. This division of services in separate "silos" makes it difficult for families to navigate the "system" and to access services they need (Government of Ontario, 2011). We view the chaotic process that parents described in trying to seek help for their children in a recent study on help-seeking (Reid et al., 2011) as reflecting, in part, a lack of continuity within the children's mental health system. Examining how parents experience continuity of care, particularly in relating to service providers across sectors, 
will contribute to a better understanding of the impact of continuity of care on youth and parental well-being. In addition, the perspectives from this study contributed to item generation for the development of a new questionnaire (see Chapter Three).

\subsection{Methods}

The current study used a qualitative descriptive approach (Sandelowski, 2000) to explore parent, youth, and service professionals' experiences in receiving and providing services within the children's mental health system in Ontario. Semi-structured interviews were conducted with (a) parents of a child/youth (ages 4 to 18 years) who were receiving services from children's mental health $(\mathrm{CMH})$ agencies; (b) youth (ages 15 to 18 years) receiving services, and (c) service providers working in these agencies.

\subsubsection{Participant Recruitment}

Two procedures were used to recruit participants. Parents and youth were recruited either through the receptionist when they arrived for a visit at a participating $\mathrm{CMH}$ agency, or by a research assistant in the waiting room. Families were required to have had at least two face-to-face visits in the previous year at the agency from which they were recruited; this was deemed the minimal time needed for families to comment on the experience of continuity of care. Service providers were recruited through a primary contact person at each agency who forwarded the information of clinicians who were willing to participate in the study. All participants provided informed consent prior to the interview. Participants were compensated with a $\$ 20$ gift certificate of their choice. The study was approved by the Research Ethics Board at The University of Western Ontario and, when required, by the ethics committees at participating $\mathrm{CMH}$ agencies.

To obtain a maximum variation sample of families, we recruited families that varied in terms of child sex, age, type of problem, and chronicity of service utilization. The agencies from which families were recruited served both urban and rural populations. Maximum variation sampling is a method of purposeful sampling that aims to capture common themes, core experiences, or shared impact across diverse 
characteristics (Patton, 2001). Recruitment and data collection ceased once the criterion of theme saturation, or interviewing people within each of the three groups (i.e., parents, youth, providers) until no new themes emerged, was achieved (Streiner \& Norman, 2003).

\subsubsection{Data Collection}

Parents and youth participated individually in a semi-structured in-depth-interview conducted at the agency by one interviewer. They were asked about the "group of professionals" (e.g., child and youth worker, physician, psychologist) that helped their family, including how the different providers coordinated with each other, their relationship with their provider(s), and the process of receiving care. Participants were asked about their history of care (both type and duration) and questions about their experiences regarding continuity of care (e.g., their perception of service coordination both within the agency and across sectors) along with any experiences of continuity or discontinuity of care. Specific probes related to experiences within and between different sectors (e.g., health, education) were used (e.g., Have you every received services from more than one service provider at the same time?; How did they connect and share information?; Has your [family physician/psychiatrist/pediatrician/school] been involved in this process?; Tell me about their involvement; How did they connect with the agency/ school/ others?). Participants were asked to focus on the previous six-months to minimize recall bias. Interviews took approximately 60 minutes to complete. The following demographic information was collected for parents and youth: sex, date of birth, dates of first contact with the CMH "system" (i.e. contact with any of the following sectors: mental health, medical, educational, child welfare or justice) and the $\mathrm{CMH}$ agency from which they were recruited.

Professionals were asked about how their agency integrates and coordinates services within the agency and across different sectors (e.g., "When clients receive a range of services, from your center as well as other organizations, to what extent are these services coordinated [e.g. between psychiatrists, psychologists and family 
physicians when pharmacological intervention is required]? Do you have concerns about this issue? What works? What would you change?"). For professionals, demographic information including sex, professional role, and number of years at the agency and in the "system" was collected. Interviews were audiotaped and transcribed verbatim.

\subsubsection{Analyses}

The analysis of the data was iterative and interpretive. The data were analyzed in the following phases: immersion, generation of categories and themes, coding the data, synthesis and interpretation, searching for alternative understanding and writing the results (Marshall \& Rossman, 2010). Although the researchers were aware of the conceptual framework of continuity of care by Haggerty et al. (2003), this framework was set aside during the initial analysis and only re-visited after themes had been generated from immersion in the data. First, the three researchers reviewed the transcripts to identify key concepts and exemplary quotes from the data. In the immersion phase, researchers become engrossed in the data, which allows for sensitivity to the tone, range, mood and context of the data during the analyses. The three researchers then met to discuss key themes and selected exemplar quotes to illustrate these themes. A coding scheme was developed to reflect themes, and researchers met to discuss and refine the coding scheme. Discrepancies were discussed and resolved as needed. Disconfirming examples of a theme were discussed and coded via consensus. All of the transcripts were entered into NVivo (QSR International, 2007), a computer program that helps to organize individual quotes under key concepts and themes. Finally, the themes were compared with the extant literature. During this phase, which involved writing the results, the themes were categorized into relational, informational, and management continuity. Credibility and trustworthiness of the data were enhanced through the use of verbatim transcripts, and independent and team analysis.

\subsubsection{Final Sample}

Parents of a child/youth $(N=15)$ and youth $(N=11$; ages $15-18$ years $)$, receiving mental health services in one of five $\mathrm{CMH}$ agencies located in the province of Ontario, 
Canada were interviewed; between two and four parents and youth per agency were interviewed. All parents interviewed were female and five were single parents. The average age of their child in treatment was 13.2 years (6 to 18). Parents were asked the date of the first contact for their child's problems at the agency from which they were recruited, as well as the earliest date of contact with any sector related to $\mathrm{CMH}$ (i.e., medical, mental health, education, child welfare, justice). The average length of involvement with the $\mathrm{CMH}$ agency from which they were recruited was 2.9 years $(<1$ to 14) and the average length of involvement with the CMH system was 4.7 years $(<1$ to 18). Of the 11 youth interviewed, 7 were female and 4 were male. The average age was 16.5 years (15 to 18 ). The average length of agency involvement was 3.0 years (0 to 8); the average length of involvement with the $\mathrm{CMH}$ system was 6.3 years ( $<1$ to 12 years). There were no significant differences on measures of child/youth problem severity between the study sample and the sample of youth from Children's Mental Health Ontario (CMHO) (See Table 2.1).

Mental health providers $(N=10)$ providing direct services to children and families, or who had provided direct services in the past at one of four $\mathrm{CMH}$ agencies were interviewed; two or three providers per agency were interviewed. Service providers interviewed had been employed in their current positions for an average of 14.9 years (2 to 37) and had been working in their profession for an average of 25.1 years (2 to 43). Most providers (70\%) had completed a Master's degree either in social work or psychology, one had completed some graduate work in psychology, one had a M.D. (a psychiatrist), and one had completed a Ph.D. in psychology. Seven of the providers interviewed were female.

\subsection{Results}

Three broad themes emerged from the interviews with the parents, youth, and providers: relational, informational, and management continuity. These themes reflected the experiences of all three groups. Subthemes within each of these broad themes will be 
discussed in turn, and will span the experiences of parents, youth, and providers, respectively.

\subsubsection{Relational Continuity}

Parents, youth and providers all discussed the importance of the ongoing therapeutic relationship. The quality of this relationship appeared to be derived from a number of specific aspects of the relationship: attachment and connection, consistency, trust, and flexibility and commitment. In addition, a specific risk to relational continuity, transitions, was conceptualized under the category of relational continuity.

\subsubsection{Attachment and connection}

Parents discussed the importance of their child connecting with their clinician. As one parent expressed "If you can't connect with the clinician, you're not going to go anywhere." Many individuals discussed the relationship as being not with just a clinician, but with the $\mathrm{CMH}$ agency as a whole. A parent described: "I have a better rapport with [Agency] because [Agency's] workers sit back and let me do my thing. They know my strengths." A youth expressed his/her experience of immediate connection at intake: "Everybody's really nice and you feel comfortable, like, pretty much right off the bat." All service providers recognized the importance of the therapeutic relationship, particularly in terms of treatment outcomes.

\subsubsection{Consistency}

Parents expressed both an expectation of consistency of contact (i.e., seeing the same provider over time) and satisfaction when this expectation was met. "I can't speak on behalf of other families, [but] my experience has been amazing. I've finished with the same workers that I've started with." An advantage of this consistency was increased knowledge of the child/youth. On the other hand, having more than one person involved was, at times, also recognized as positive: “...we can brainstorm more." Youth also discussed their preference for seeing the same provider over time, sometimes for several 
years. Several providers emphasized consistency of contact as one of the most important aspects of continuity of care. "The number one thing ... [is] having the same clinician or worker as much as possible, and if it has to change, trying to make that as seamless as possible for the family."

\subsubsection{Trust}

Trust emerged as a key component of the therapeutic relationship, and hence relational continuity. A parent expressed: "[Trust is] the be all and end all of any type of success with my family. If I lose trust in you . . I just won't open up." Youth similarly felt that "trust is the most important thing." As one youth expressed, "You can't expect someone just to open up straight away. You need to earn [my] trust." Service providers discussed the impact of mandatory reporting to child welfare on trust. "You have to make that call, and I find that can be so damaging to the therapeutic relationship ...you're saying trust me, share your secrets, let's work on these things; but oh, I need to call the authorities, and report you now."

\subsubsection{Flexibility and commitment}

Many parents commented on the flexibility and commitment of agency staff and clinicians in meeting their families' needs: "The workers that I've had have all gone over and above the call of duty to do the little things for me that I couldn't do, to free me up to be able to do what I could do with my children." Several youth gave examples of how agency staff made exceptions to rules in order to better serve them. As a youth described, "I've seen [counselor] for a year, and you're only supposed to be there for three months." Flexibility was also important in service provision from the perspective of service providers: "What I found with [Agency] in the time that I've been here is, is that nothing is written in stone . . Things go based on what makes sense for the client." 


\subsubsection{Relational continuity through transitions}

When a family begins treatment, they face various transitions, during which they may terminate with one provider and begin services with another. Three important points of transition were highlighted: at intake, when a family changed clinicians, or when a family returned for services.

All service providers discussed transitions between intake and the initial assessment and/or treatment. A provider explained: "We really try to get the person who's doing the initial consultation to also do the brief intervention, [which creates] wonderful continuity of service for the client." However, practical limitations related to the family seeing the same provider were often described. The effect of these hand-offs emerged in one parent's description of her experience at intake:

At the very beginning it was kind of confusing because I had one interview with a lady ... but then I think she got transferred somewhere else and then I got another interview with another lady. I think I did three [interviews] until I got the right one finally.

Parents often described coming back to an agency for services months or years after they had completed one episode of care. Service providers discussed their agency's approach to connecting families with the same provider. As one provider described, "[Families] like the same workers but if they need a different worker, we can accommodate that." The "need" for a different worker included times when a clinician recognized that "a fresh pair of eyes" would be helpful. Staff turnover could affect whether families would be able to reconnect with the same worker over time.

Parents described the difficulties their children experienced in transitioning to new providers. "He's had three different counselors in less than a year, at [Agency], which is very hard for [him]." A youth explained: "I had formed a really good relationship with her but then she left. So it was hard for me to open up to a brand new person." One youth who had been in care for a long time said s/he was no longer affected 
by transitions, which suggested an attitude of resignation and even some hopelessness. As a provider described, youth who have been in the system a long time have experienced many transitions: "For them the transition sometimes doesn't matter so much, because, well yeah, it's just another worker I'm meeting. Okay. I'll work with you for a year, no big deal."

Service providers described the benefits of creating smooth transitions by creating bridges from one provider or program to the next.

If they develop that rapport, that trust, and then it's almost like you need to have a stamp of approval that this [new] person is [someone] you can trust as well, and then hand over the baton... I like to do that in person so that they specifically see... you're saying this person is okay.

Parents also described smooth transitions that were planned: "they already had somebody waiting for her, which was great." Transitions were most difficult when little or no notice of the change was provided: "There was no warning that she was leaving and the sessions were done. I remember thinking, 'Well what am I going to do now?'”

Overall, relational continuity was a common value for families and was a goal for providers. Although continuity may have been lacking at times (e.g., through critical periods such as transitions), continuity provided by individual providers appeared to be important and was generally positive.

\subsubsection{Informational Continuity}

Sharing information with families, within an agency, and between sectors emerged as key themes that were conceptualized under the broad category of informational continuity. When informational continuity was lacking, families had to repeat their stories, and often took it upon themselves to liaise between providers.

\subsubsection{Sharing information with families}

Parents expressed a need to be informed about their child's care. Open communication was related to positive relationships with providers. As one parent expressed: "I think our relationship was based on mutual respect and communication; 
and openness in that communication regardless of how difficult things got." A provider explained how at his/her agency, families "have copies of every case conference. Psychological reports are given to them." This sharing information with families was consistently identified an important aspect of continuity of care. Several providers expressed concern that some families may not understand the information that is shared with them.

\subsubsection{Sharing information within an agency}

As a parent described, when she needed services again she turned to the same agency because "they had a record of what was going on with her [child]" from a previous episode of care. In general, parents, youth and service providers indicated that communication was "ongoing" between treatment team members, either in "weekly rounds or some other form." As a youth noted, "No one was left out of the loop." Sharing information within an agency was described as easier than between agencies. As a provider noted, verbally sharing information helped with transitions between providers:

"....if I know that family has to transfer to a different program I would work with the clinician... and give some background information and try to do some overlap sessions, just to make it as seamless as possible to the family." In contrast, sharing information between agencies "just takes a lot longer."

\subsubsection{Sharing information between sectors}

Information sharing between sectors was also important, but often problematic. Typically this information was shared in reports. Providers described a common problem as the lack of follow through on recommendations, usually made in those reports, "you had kids discharged with certain recommendations, [and these] recommendations aren't followed." Providers noted that working with the Children's Aid Societies (CAS; child welfare agencies in Ontario) depended a lot on their relationships with the individual workers. "I know people at Children's Aid [...] who I can call up and say, 'I've got this family, they are really struggling and he is being discharged. What's your wait list like?" Specific difficulties were described in communicating with certain sectors. "I think 
probably the most difficult is communicating with doctors in the community and then also with CAS."

Many parents described how they had to organize meetings in order to share information between different providers. "I started orchestrating meetings between his classroom teacher, the EA [educational assistant], classroom EA, the principal, myself, his dad (who never shows), and his worker at the day care." Similar efforts at connecting providers were common: "I made the effort to make sure everybody knew what everybody else was thinking." This theme did not emerge with youth.

\subsubsection{Repeating story}

When families transitioned from one provider to another and there was a lack of information sharing, they typically had to tell their stories repeatedly. This was a source of frustration for parents, and was especially difficult for sensitive topics. A parent described: "Well if you're going there for sensitive issues that happened to you, you don't want to be telling different people because it's private and it's hard to come out and say what happened to you." One youth, however, was pleased that "I didn't have to repeat myself over and over and over" because of good information sharing. A provider noted, "I hear from families when they have to go through that process again and [about] the stress of having to tell their stories again to different people."

Informational continuity was recognized as important in terms of communication between families and their providers, as well as between providers. Most participants felt informational continuity was fairly good and most often, families did not have to repeat their stories; providers felt that this was especially important as families are already burdened. Also, providers did not have to "reinvent the wheel" in working with the family as they could use information gathered previously to inform how they would move forward. 


\subsubsection{Management Continuity}

Teamwork, family and child/youth involvement in treatment, and case management emerged as key themes that were conceptualized under the broad category of management continuity. Coordination across the various sectors serving families with mental health problems, namely, the mental health, education, medical, child welfare and justice sectors were uniquely important to continuity of care in children's mental health.

\subsubsection{Teamwork}

Parents endorsed teamwork. "If whatever is happening is beyond their scope, then bring in somebody else, by all means. Make it a team effort." Some youth also expressed the need for teamwork. "I think no matter where you work, you've got to be a team." Many programs have multidisciplinary teams, and providers described the process of working together on these teams, with regularly scheduled meetings. "When we do [collaborate], I have to say it's so wonderful, and the feeling is just great . . because the weight of these treatments is big. It's nice to share that [with the team]."

\subsubsection{Involvement in treatment}

\subsection{Family involvement}

Parents expressed a desire to be involved in their child's treatment. "I really think that the way [provider] included me - that was the model that we should all follow with kids in mental health." The level of parental involvement varied based on the type of treatment offered as well as on the developmental level of their child. Parents of youth were not as involved in their child's treatment compared to younger children. As a parent expressed, "I don't know if I'm going to hear any more except for what he chooses to reveal to me ... I'm not bitter or anything. It's good to have another adult perspective that's not your parent's." Youth also varied in their desire to have their family involved. One youth explained that his/her family was "Very involved. Like they go with me every time I go and they like if I can't remember an answer, well, they'll help me remember." In contrast, another youth did not want his/her parents involved. "I couldn't tell [my 
counselor] anything because my family was there. And I'm not very open with my family." Service providers emphasized the importance of including the family in all aspects of care: “... we don't make any decisions without the family.” Although family involvement was a goal of service provision, this goal was not always met for a variety of reasons. Some participants gave the example that family participation is often not possible if team meetings were during the "nine to five" day. In other cases, it may be that the families are "so burned out by the time the child gets here" that they "lose that ability to invest."

\subsection{Child/Youth involvement}

Youth involvement varied as a function of the diagnosis/problem, and with respect to their desire to be involved. For example, a youth explained how with an eating disorders program, “....you didn't have a say because your say would always be to say, 'I have an eating disorder.' So you [would] not get better. But you did have input like if you are uncomfortable they would work around it." Another youth who was involved in the child welfare system for many years expressed how he/she "didn't really have a say" and "didn't care anymore." Another youth, when asked if he/she would like more involvement in his/her treatment planning said, "I'm okay, no way." Several providers described how children and youth were involved in many aspects of treatment, especially in goal setting. "They could be actively involved in all aspects of treatment. Everything from... being part of those assessment reviews, signing off on documents, [they] feel they've got a voice."

\subsubsection{Case management}

The few parents who mentioned receiving case management/coordination services were satisfied with their respective coordinators. One parent described a coordinator who worked as a liaison for all of the programs in the city that her child was involved with. "He coordinates; tries to get the best help for a child; whatever they need - he's really, really good." Another parent described her child's primary service provider as "the pivotal person in directing, guiding [my child] from this person to that person ... she's 
been the coordinator of the flow, which has been very good; it's been very smooth." In contrast, other parents described feeling that their child "fell through the cracks" because they did not fit into existing programs and could not access appropriate services. As a provider asked in these situations, "who owns these kids?" Providers described how case coordinators were formally assigned at some agencies. The role of the case coordinator/case manager was to facilitate continuity of care. One issue that was raised was the need to be clear regarding who was assigned as the case manager: "I think the rule of thumb is, whoever has the most contact with the client is supposed to be the case manager. That doesn't always happen." There was a recognized need for case management and coordination for families with high levels of need. Case management was described not simply as a means to coordinate interventions, but as "an intervention. It's part of your job."

\subsubsection{Coordination}

Some parents experienced the services they received as well coordinated, with " $a$ lot of communication" between providers. As a parent expressed, "all of the services worked together like a zipper. [If] the bottom part doesn't come together; you can't pick up that coat and keep warm." The ideal for parents was that services communicate and coordinate.

Continuity of care would be that if my daughter [goes] from the hospital to the psychiatrist to this program and to wherever else that she may end up, there's somebody liaising between each of those services, and not her having to . . be presenting it for the first time ever.

Service providers recognized the importance of coordination given the fragmentation of services across sectors and government ministries. Most service providers shared the following perspective on coordination: "You carry that philosophy in your head - your working partnerships are your best strengths in the community and you let those go at your peril." Yet there was a tension between an "awareness of a need to communicate and coordinate" and a "lack [of] resources [and] time to do the ideal." 


\subsubsection{Cross-sector coordination}

In children's mental health, children and families may be involved with up to five sectors: children's mental health, education, medical, child welfare and juvenile justice. Participants discussed how services were coordinated (or not) across these sectors.

\subsection{Education sector}

Some parents described the importance of involving the school, especially with respect to accommodating their child in terms of emotional or behavioral issues as well as identifying his/her learning needs. Many parents reported that their child had missed a lot of school as a result of their problems, but, in general, they were satisfied with the accommodations received. However, not all parents included the school as part of their child's treatment. One parent stated that, at her child's request, she did not disclose to the school personnel any information regarding her child's mental health issues. Other parents, in contrast, expressed frustration with how the school dealt with their child's behavior problems.

[My child] knows how to get suspended. So he'll push all the buttons to get it, then he does not have to go to school for a couple of days ... He's missed a lot of school, but they're still passing him.

Youth reported a variety of experiences with respect to their school's involvement in their treatment, from satisfaction with services, to disliking anything related to school. For example, a youth described how "The school was really understanding" while another, who had been in child welfare for the majority of his/her life, described how he/she disliked school: "I've been to, how many schools I've been in my life, I couldn't count them ... I got expelled or suspended a lot ... [and] agency schools just stress me out." 


\subsection{Medical sector}

Parents generally found that their family physicians were not knowledgeable in the specific areas of mental health necessary to treat their children:

Our family doctor was more, 'Give him up, put him into foster care, and be done with him.' ... 'Do you want some drugs? I don't know how you get through every day.' We've got a new family doctor now.

Some parents described how their family physician lacked knowledge of the service system. One parent explained how her family physician knew about a program only because his son had been through it. "I'm not sure what my family doctor's knowledge of the program would have been if he hadn't had a son going through that."

For youth, experiences with psychiatrists and family physicians were generally negative. For the most part, youth described how their family physician lacked knowledge or were not helpful to them. "My family doctor - I don't think she really knows anything, to be honest with you." One exception was a youth who described how his/her family physician, who is "in his seventies," has been "so helpful" and has become better in dealing with mental health issues over time: "when [my family doctor] took school, I don't think mental health was really a big issue when they did it ... so it's, kind of, like, not his fault. ...[But he's become] a lot better [with experience]."

Service providers discussed the scarcity of child psychiatrists available to their respective agencies as a particularly problematic aspect of the system. In general, there was recognition of both the lack of child psychiatrists within the community as well as the lack of psychiatrists on-site at agencies. One child psychiatrist at a tertiary agency stated that his/her role was primarily as a consultant because of the scarcity of child psychiatry in area. With respect to family physicians, providers indicated that it was difficult "getting them on board." Although one provider described an exceptional case of a family physician that made house calls for a young boy with severe anxiety, the provider recognized that "it's pretty rare to find a doctor that would do that." 


\subsection{Child welfare}

Parents had a range of experiences with the child welfare sector, from very positive to very negative. The positive experiences involved access to services and advocacy and coordination with a $\mathrm{CMH}$ agency; the negative experience involved the family being contacted by the CAS for child protection or "policing." One parent was advised to call CAS for help by a worker at the CMH agency.

Where I'm from, you don't call Children's Aid because Children's Aid can come and take your kids away. So now, I have a completely different perception of their services because they're not there to criticize you . . . They're there to point you in a better direction.

Other experiences were more negative. According to a parent with extensive experience with CMH services, "Years ago CAS used to offer support, used to offer programming like [this agency] does, the only thing they offer now is policing." Although youth did not comment on CAS involvement in general, a youth who was in CAS care for most of his/her life described how "they don't really help me whatsoever."

Several providers alluded to the CAS having a different mandate (i.e., child protection), which sometimes interfered with their ability to work collaboratively. "Sometimes there's a feeling like our mandates are at cross purposes, and so people come in feeling like we can't support each other's work. . There's this idea, the safety of the child versus the process of treatment." As a result of these different mandates, a family may be passed back and forth between the CAS and the agency: "sometimes I feel like they're playing hot potato." Collaboration and communication between the CAS and an agency seemed to depend on relationships between individual workers as well as sharing mutual goals.

It all depends on the person that you're working with and if you can build that professional relationship with them, because I think no matter where you are and no matter what the policies are, if you have someone who is truly invested in this 
child, they're going to try to make it work for how it makes sense for a kid, not for the role.

\subsection{Juvenile justice}

The few parents with experiences with the justice sector reported a range of experiences, from satisfaction with the help they received, to frustration for not receiving what they wanted. A parent described her experience in seeking help from the police for what happened to her child: "I just kept being bounced from police station to police station ... the bickering literally went on for about two weeks between both departments [across jurisdictions]." Another parent found that "[the probation officer] offered more at the table than a lot of the other people." In contrast, another parent was dissatisfied when she contacted the police for help: "even [the police] didn't offer the help that they should have." The few youth with experience in the justice system described their experiences as "scary" or "unpleasant." One youth recounted how although he/she was able to access services because of the police, "It was a little scary at first [to have police involvement]; [but] now I understand it." Although service providers indicated that involvement with the justice sector did not "happen that much," they indicated that there was good collaboration with probation officers and the courts.

The management of children's mental health services was neither consistent nor coherent across sectors. Families described a variety of experiences, from very positive to very negative across sectors. The most contentious relationships were with the CAS and the most disappointing relationship was with family physicians. As with relational and informational continuity, examples of flexibility and responsiveness to a family's needs were reflective of individual workers' efforts and goals over and above systemic barriers and limitations.

\subsection{Discussion}

Through a qualitative descriptive approach using in-depth interviews with parents, youth, and professionals in the field of children's mental health care, the current study 
aimed to understand (1) the elements of continuity of care that are specifically relevant in children's mental health and (2) the quality of continuity that participants experienced in the $\mathrm{CMH}$ system. The elements that emerged from the data were organized broadly into relational, informational, and management continuity, which reflect Reid et al.'s (2002) and Waibel et al.'s (2012) broad categorizations. The current study extended these categories, however, to include specific sub-themes unique to children's mental health, such as coordination across multiple sectors, including health, child welfare, education, and juvenile justice. Each of the themes will be discussed and compared with the current literature and participants' experiences.

\subsubsection{Relational continuity}

The current study revealed the following sub-themes of relational continuity: attachment/connection, consistency, trust, and flexibility and commitment. These subthemes overlap conceptually with Reid et al.'s (2002) dimensions of relational continuity: consistency of personnel and ongoing patient-provider relationship. The sub-themes of attachment, trust, and flexibility and commitment overlap with the concept of an ongoing patient-provider relationship (See Table 2.2 for comparison). In general, the data revealed that relational continuity was highly valued by all participants, and that families were generally satisfied when they perceived good relational continuity. As with previous studies, greater consistency was related to greater satisfaction (Cabana \& Jee, 2004; Saultz \& Albedaiwi, 2004; Starfield, Shi, \& Macinko, 2005; Van Walraven, Oake, Jennings, \& Forster, 2010; Woodward, Abelson, Tedford, \& Hutchison, 2004). An exception emerged with a youth who had been involved in the care of child welfare for most of his/her life and expressed indifference towards seeing a consistent provider. This attitude, while adaptive in an unstable context involving frequent transitions, serves as a reminder of the long-term effects on youth who lack stability and consequently develop an inability to form positive attachments. While not the focus of this specific study, it is clear that children and youth in child welfare are particularly vulnerable to discontinuity and that continuity of care is particularly important for this population (Gauthier, Fortin, 
\& Jeliu, 2004). Relational continuity was noted as being especially critical through transitions, when there is a greater risk of discontinuity with respect to relationships.

\subsubsection{Informational Continuity}

Information sharing within and between both agencies and sectors emerged as an important theme. This theme overlaps conceptually with Reid et al.'s (2002) dimension of 'information transfer,' which refers to the patient's perception of information exchange between providers (see Table 2.2). What is unique in this study is the information transfer between the various sectors involved in children's mental health. In terms of the quality of informational continuity, participants described instances of discontinuity and solutions to this problem. For instance, a unique consequence of perceived discontinuity of information sharing was that some parents described becoming liaisons between providers in order to transfer information and create continuity. Another consequence of this discontinuity was parents and youth having to repeat their story, which was common across other studies (Freeman \& Hughes, 2010; Nair, Dolovich, Ciliska, \& Lee, 2005; Von Bültzingslöwen, Eliasson, Sarvimäki, Mattsson, \& Hjortdahl, 2006; Wong, Watson, Young, \& Regan, 2008). Reid et al.'s (2002) dimension of accumulated knowledge did not emerge as a major theme in the current study, but was discussed as a consequence of consistency of contact, which is consistent with the findings of Waibel et al.'s (2012) meta-synthesis. Furthermore, a consequence of accumulated knowledge is that families do not have to repeat their story, which leads to less frustration.

\subsubsection{Management Continuity}

The themes of case management, coordination, involvement in treatment, and teamwork emerged as important aspects of management continuity in children's mental health. While there is some overlap with Reid et al.'s (2002) sub-dimensions (see Table 2.2), their sub-dimensions of consistency of care and flexibility were conceptualized as sub-themes of relational continuity in the current study. While accessibility did not emerge as a specific theme, case management and coordination were sub-themes that overlap conceptually in terms of accessing services across providers. The absence of 
accessibility as a key theme is expected given that the current sample was drawn from families who had already accessed services at a CMH agency; however, they may have encountered issues with access to other services.

In terms of the quality of management continuity described, it is useful to frame the discussion in terms of Haggerty et al.'s (2003) two-part definition of management continuity. First, management continuity is defined as a consistent and coherent approach to the management of a health condition (Haggerty et al., 2003). In the present study, the management of children's mental health services was neither consistent nor coherent across sectors. Families described a variety of experiences, from very positive to very negative across sectors. The most contentious relationships, as described by both families and service providers at children's mental health agencies, were with child welfare and family physicians. The second part of Haggerty et al.'s (2003) definition is that management continuity needs to be responsive to a patient's changing needs. As with relational and informational continuity, examples of flexibility and responsiveness to a family's needs were reflective of individual workers' efforts and goals over and above systemic barriers and limitations (Reid \& Brown, 2008).

\subsubsection{Summary}

The current study affirmed the broad categories of relational, informational and management continuity described by Reid et al. (2002) as relevant to $\mathrm{CMH}$, but also included additional sub-themes that were unique to children's mental health. Waibel et al. (2012), in their meta-synthesis, suggest that the different types of continuity of care are best conceptualized as interdependent. The present study provides support for the notion of interdependence amongst the elements that constitute continuity of care. For example, having consistent personnel (relational) reduces communication barriers and increases accumulated knowledge (informational), which improves treatment plans and supports mutual understanding (management; Waibel et al., 2012). In addition to defining the elements that constitute continuity of care in children's mental health, the present study 
attempted to understand the quality of continuity that exists in the current system and the risks and consequences of perceived discontinuity in children's mental health.

\subsubsection{Limitations}

Interviews were conducted at five $\mathrm{CMH}$ agencies in the province of Ontario, Canada. Parents, youth, and service providers who agreed to participate in the study may have had different experiences of services than families who did not participate. While it is possible that they may have been more satisfied with services and thus more willing to participate, the interviews reflected a range of experiences, from very satisfied to very dissatisfied. Interviewees were selected based on maximum variation sampling and theme saturation was achieved and trustworthiness was supported through the team analysis. Additional comparisons between the study sample and the $\mathrm{CMHO}$ population revealed no differences on measures of problem severity (see Table 2.1). Nevertheless, it is possible that parents, youth, and service providers included in this sample differ in other ways from the families seen at other CMH agencies or in other jurisdictions. This study used a sample drawn from $\mathrm{CMH}$ agencies. Again, it is possible that families seen exclusively through another sector, such as child welfare, or the school, would have different stories and perspectives.

\subsubsection{Implications}

Continuity of care was clearly an element in the process of $\mathrm{CMH}$ care that was valued by parents, youth, and service providers. A continuum of services and supports is emphasized in Ontario's policy framework for Child and Youth Mental Health (Ministry of Children and Youth Services, 2006); however, it is evident that this continuum has not been achieved. Limited and complex funding, the complexity of multiple sectors, and the high demand for services (Reid \& Brown, 2008) are factors which may impede achieving a high degree of continuity. Nevertheless, it is clear that where risks of discontinuity exist, there are often individual efforts at the level of the worker to overcome discontinuity and to bridge these potential service gaps. This finding is consistent with Reid and Brown's (2008) study of managers at children's mental health services in 
Ontario, which found a similar tension between a lack of resources in the children's mental health system and the need for local solutions to achieve greater integration and collaboration across agencies and sectors. Similar to the implications from that study, it is clear that local solutions need to be emphasized to overcome potential barriers for families in accessing continuous services. Moreover, commitment and flexibility at the provider level were highly valued by families. As outlined in recent policy frameworks in Ontario, it is about doing what makes sense for the family and having a shared responsibility (Ministry of Children and Youth Services, 2006). 


\section{References}

Bickman, L., Lambert, W. E., Andrade, A. R., \& Penaloza, R. V. (2001). The Fort Bragg continuum of care for children and adolescents: Mental health outcomes over 5 years. Journal of Consulting and Clinical Psychology, 68, 710-716. doi:10.1037/0022-006X.68.4.710

Boydell, K. M., Bullock, H., \& Goering, P. N. (2009). Getting our acts together: Interagency collaborations in child and youth mental health. Ottawa, ON: The Provincial Centre of Excellence for Child and Youth Mental Health at CHEO.

Boydell, K. M., Pong, R., Volpe, T., Tilleczek, K., Wilson, E., \& Lemieux, S. (2006). Family perspectives on pathways to mental health care for children and youth in rural communities. Journal of Rural Health, 22, 182-188. doi:10.1111/j.17480361.2006.00029.x

Cabana, M. D., \& Jee, S. H. (2004). Does continuity of care improve patient outcomes? Journal of Family Practice, 53, 974-980. Retrieved from http://www.jfponline.com/pages.asp?aid=1830

Crabtree, B. F., \& Miller, W. L. (1999). Doing qualitative research. 2nd ed. Thousand Oaks, CA: Sage Publications, Inc.

Freeman, G. K., \& Hughes, J. (2010). Continuity of care and the patient experience: An inquiry into the quality of general practice in England. London, England: The King's Fund.

Gauthier, Y., Fortin, G., \& Jeliu, G. (2004). Clinical application of attachment theory in permanency planning for children in foster care: The importance of continuity of care. Infant Mental Health Journal, 25, 379-396. doi:10.1002/imhj.20012

Government of Ontario. (2011). Open minds, healthy minds: Ontario's comprehensive mental health and addictions strategy. Retrieved from 
http://www.health.gov.on.ca/en/common/ministry/publications/reports/mental_healt h2011/mentalhealth.aspx

Haggerty, J. L., Reid, R. J., Freeman, G. K., Starfield, B. H., Adair, C. E., \& McKendry, R. (2003). Continuity of care: a multidisciplinary review. British Medical Journal, 327, 1219-1221. doi:10.1136/bmj.327.7425.1219

Kirby, M. J. L., \& Keon, W. J. (2006). Out of the shadows at last: Transforming mental health, mental illness and addiction services in Canada. Ottawa, ON: The Standing Senate Committee on Social Affairs, Science and Technology. Retrieved from http://www.parl.gc.ca/Content/SEN/Committee/391/soci/rep/rep02may06-e.htm

Marshall, C., \& Rossman, G. B. (2010). Designing qualitative research. Thousand Oaks, CA: Sage Publications Inc.

Ministry of Children and Youth Services. (2006). A shared responsibility: Ontario's policy framework for child and youth mental health. Toronto, ON: Queen's Printer for Ontario

Nair, K. M., Dolovich, L. R., Ciliska, D. K., \& Lee, H. N. (2005). The perception of continuity of care from the perspective of patients with diabetes. Family Medicine, 37, 118-124. Retrieved from http://scholar.googleusercontent.com/scholar?q=cache:5dUnnNC9FhUJ:scholar.go ogle.com/+The+perception+of+continuity+of+care+from+the+perspective+of+pati ents+with+diabetes\&hl=en\&oe=ASCII\&as_sdt=0,5

Patton, M. Q. (2001). Qualitative Research \& Evaluation Methods. Thousand Oaks, CA: Sage Publications, Incorporated.

QSR International. (2007). NVivo [Computer software]. Cambridge, MA: QSR International Pty. Ltd. 
Reid, G. J., Cunningham, C. E., Tobon, J. I., Evans, B., Stewart, M., Brown, J. B., ... Zaric, G. S. (2011). Help-seeking for children with mental health problems: Parents' efforts and experiences. Administration and Policy in Mental Health and Mental Health Services Research, 38, 1-14. doi:10.1007/s10488-010-0325-9

Reid, G. J., \& Brown, J. B. (2008). Money, case complexity and wait lists: Perspectives on problems and solutions at children's mental health centres in Ontario. Journal of Behavioral Health Services \& Research, 35, 346. doi:10.1007/s11414-008-9115-5

Reid, R., Haggerty, J., \& McKendry, R. (2002). Defusing the confusion: Concepts and measures of continuity of healthcare. Ottawa, ON: Canadian Health Services Research Foundation. Retrieved from http://www.chsrf.ca/Migrated/PDF/ResearchReports/CommissionedResearch/cr_co ntcare_e.pdf

Richards, L., \& Morse, J. M. (2012). Readme first for a user's guide to qualitative methods. Thousand Oaks, CA: Sage Publications, Inc.

Sandelowski, M. (2000). Whatever happened to qualitative description? Research in Nursing \& Health, 23, 334-340.

Saultz, J. W., \& Albedaiwi, W. (2004). Interpersonal continuity of care and patient satisfaction: A critical review. The Annals of Family Medicine, 2, 445-451. doi:10.1370/afm.91

Starfield, B., Shi, L., \& Macinko, J. (2005). Contribution of primary care to health systems and health. Milbank Quarterly, 83, 457-502. doi:10.1111/j.14680009.2005.00409.x

Streiner, D. L., \& Norman, G. R. (2003). Health measurement scales: A practical guide to their development and use. Oxford, New York: Oxford University Press. 
Thornicroft, G., \& Tansella, M. (1999). Translating ethical principles into outcome measures for mental health service research. Psychological Medicine, 29, 761-767. doi:10.1017/S0033291798008034

Van Walraven, C., Oake, N., Jennings, A., \& Forster, A. J. (2010). The association between continuity of care and outcomes: A systematic and critical review. Journal of Evaluation in Clinical Practice, 16, 947-956. doi:10.1111/j.13652753.2009.01235.x

Von Bültzingslöwen, I., Eliasson, G., Sarvimäki, A., Mattsson, B., \& Hjortdahl, P. (2006). Patients' views on interpersonal continuity in primary care: a sense of security based on four core foundations. Family Practice, 23, 210-219. doi:10.1093/fampra/cmi103

Waibel, S., Henao, D., Aller, M. B., Vargas, I., \& Vasquez, M. L. (2012). What do we know about patients' perceptions of continuity of care? A meta-synthesis of qualitative studies. International Journal for Quality in Health Care, 24, 1-10. Retrieved from http://intqhc.oxfordjournals.org/content/24/1/39.short

Wong, S. T., Watson, D. E., Young, E., \& Regan, S. (2008). What do people think is important about primary healthcare? Healthcare Policy, 3, 89-104. Retrieved from http://www.ncbi.nlm.nih.gov/pmc/articles/PMC2645139/

Woodward, C. A., Abelson, J., Tedford, S., \& Hutchison, B. (2004). What is important to continuity in home care? Perspectives of key stakeholders. Social Science \& Medicine, 58, 177-192. doi:10.1016/S0277-9536(03)00161-8 
Table 2.1: Comparison between study samples and population of all parents and youth seen at children's mental health agencies in Ontario

Demographic characteristics $\quad$ Study sample $\quad \mathrm{CMHO}^{\mathrm{a}} \quad$ Sample vs. CMHO

$$
(M \pm S D)
$$

Parent-reported child

adjustment

Internalizing

Externalizing

Child functional impairment

Total Mental Health

Self-reported youth adjustment

Internalizing

Externalizing

Child functional impairment

Total Mental Health
$66.7(13.2)$

$68.9(14.2)$

$71.6(17.3)$

$67.2(14.6)$

$70.1(13.8)$

$68.0(12.4)$

0.15

0.26

0.03

0.25
$57.2(13.9)$

$58.7(12.3)$

$-0.10$

$61.4(9.0)$

$60.9(11.3)$

0.05

$61.9(12.8)$

$63.7(12.1)$

$-0.13$

$60.2(11.6)$

$60.9(11.4)$

$-0.06$

${ }^{\text {a }} \mathrm{CMHO}$, data from all agencies affiliated with Children's Mental Health Ontario (Brian

O'Hara, CMHO, personal communication, August, 2011). $N=18,820$ for parents and 3,565 for youth.

NOTE. All $t$-test comparisons were non-significant. 
Table 2.1: Correspondence between continuity themes

\begin{tabular}{|c|c|c|}
\hline Type & Reid et al. Dimensions & Study Themes \\
\hline \multirow{5}{*}{$\begin{array}{l}\text { Relational } \\
\text { Continuity }\end{array}$} & Consistency of personnel & Consistency \\
\hline & $\begin{array}{l}\text { Ongoing patient-provider } \\
\text { relationship }\end{array}$ & Attachment/connection \\
\hline & & Trust \\
\hline & & Flexibility and commitment \\
\hline & & $\begin{array}{l}\text { Relational continuity through } \\
\text { transitions }\end{array}$ \\
\hline \multirow{4}{*}{$\begin{array}{l}\text { Informational } \\
\text { Continuity }\end{array}$} & Information transfer & Sharing information with families \\
\hline & & $\begin{array}{l}\text { Information sharing within an } \\
\text { agency }\end{array}$ \\
\hline & & $\begin{array}{l}\text { Information sharing between } \\
\text { sectors }\end{array}$ \\
\hline & Accumulated knowledge & Repeating story \\
\hline \multirow{6}{*}{$\begin{array}{l}\text { Management } \\
\text { Continuity }\end{array}$} & Consistency of care & Consistency* \\
\hline & Accessibility & Case Management \\
\hline & & Coordination \\
\hline & Flexibility & Flexibility and commitment* \\
\hline & & Involvement in treatment \\
\hline & & Teamwork \\
\hline
\end{tabular}

* Conceptualized as sub-theme of Relational Continuity 


\section{Chapter 3}

\section{Continuity of Care in Children's Mental Health: Development of a Measure}

\subsection{Abstract}

A new measure, Continuity of Care in Children's Mental Health (C3MH), is presented. The study involved item generation, pre-testing, pilot testing, and validation. The C3MH was administered to 364 parents recruited from 13 children's mental health agencies in Ontario, Canada. The measure includes five scales supported by confirmatory factor analysis. Scale validity was supported through analyses of relationships with established measures of satisfaction, problem severity, and therapeutic alliance, as well as through known-group differences. The results of a pilot youth-report version $(N=57)$ are presented. The $\mathrm{C} 3 \mathrm{MH}$ will be a useful tool for assessing improvements in system integration. 


\subsection{Introduction}

Children with psychosocial problems frequently require a complex array of services that span across various service sectors. Connecting these services becomes difficult due to administrative and fiscal barriers. As the number of providers involved increases, the number of potential interfaces among providers increases exponentially, which makes it difficult to coordinate services (Koren et al., 1997). For over two decades, the systems-of-care philosophy in children's mental health has recognized the need to respond to a fragmented service system through greater integration and coordination (Stroul \& Friedman, 1986). Continuity of care, which is how a patient experiences care over time as coherent and linked (Reid, Haggerty, \& McKendry, 2002), has been identified as an indicator of health system performance and of quality of care (The Provincial Centre of Excellence for Child and Youth Mental Health at CHEO, 2006) and is considered an ethical principle of care (Thornicroft \& Tansella, 1999). Unlike the medical sector, in which the model of care involves having a "medical home" (e.g., Rosenthal, 2008) and continuity of care is defined as seeing the same provider, measuring continuity of care in children's mental health care is more difficult, given the complexity of the system, but equally important, given the fragmentation of services.

Since the development of the systems of care philosophy over two decades ago (Stroul, 1996), the few empirical studies related to continuity of care in the field of children's mental health have primarily approached the topic from the perspective of organizational systems (Koren et al., 1997). These studies have examined existing linkages within networks of agencies (Heflinger, 1996; Morrissey, 1992) by relying on the perspective of agency staff, thus providing no information on the perspective of service users (Koren et al., 1997). One large study, the Fort Bragg Evaluation Project, was designed to test whether a "continuum of care" was more cost-effective than services delivered in a more fragmented system (Bickman, 1996). The researchers found no differences in clinical outcomes between the Demonstration site (which had higher costs) and the Comparison site; however, they measured "coordination" through a network analysis, which relied on the perspective of agency staff. Other studies that have focused 
on the family perspective in children's mental health have either been strictly qualitative in nature (e.g., Boydell et al., 2006; Minore, Boone, Arthur, \& O’Sullivan, 2005), or have emphasized one facet of continuity of care, such as service coordination (Koren et al., 1997). Although continuity of care is a component of care that has been recognized as important to children's mental health, no instrument exists to measure continuity of care from the family's perspective. This deficiency severely limits efforts to understand, and ultimately improve, continuity of mental health care for children.

The objective of the present study was to develop a measure of continuity of care for children's mental health based on previously developed measures for adult mental health and chronic child health problems and our qualitative study with parents, youth and service providers at children's mental health $(\mathrm{CMH})$ agencies in Ontario (see Chapter Two). The measure was based on the conceptual foundation laid out by Reid et al.'s (2002) comprehensive definition of continuity of care. Measure development proceeded in three phases. The first phase involved item generation through a qualitative study and review of related instruments. The second phase involved pretesting the items for content validity by researchers, clinicians and service users, and pilot testing the measure with families. The draft questionnaire was administered in an individual interview format in order to understand participants' understanding and interpretation of the items and the relevance of the items to their experiences receiving mental health services (Adamson, Gooberman-Hill, Woolhead, \& Donovan, 2004). The final phase of instrument development, the validation study, involved administering the scale to a large sample of parents from $\mathrm{CMH}$ agencies and then reducing the measure to a concise number of items while maintaining optimal psychometric properties.

\subsection{Scale Development}

\subsubsection{Continuity of Care Domains}

The three broad domains of continuity of care as defined by Haggerty and colleagues (Haggerty et al., 2003), which were consistent with our qualitative findings, 
were used to classify items. The sub-domains as defined by Reid (2002) were used to create a priori scales. See Table 3.1 for definitions.

\subsubsection{Item Generation}

A total of 123 items were generated based on (1) related instruments (ACSS-MH; Adair et al., 2004; Chao, 1988; CONNECT; Ware, Dickey, Tugenberg, \& McHorney, 2003; PACIC; Glasgow et al., 2005; MPOC; King, Rosenbaum, \& King, 1995; SOCPR; University of South Florida, 2007; Service Coordination Scale; Koren et al., 1997; Components of Primary Care Index; Flocke, 1997), and (2) semi-structured interviews with the target population from a qualitative study described in Chapter Two (e.g., "I had to repeat my history every time we needed help"). Items were drafted and worded for relevance to parents currently using children's mental health services.

Each item underwent a reading difficulty analysis using the Flesh-Kincaid Grade Level test [0.39 x (words/sentences) + $11.8 \times$ (syllables/words) - 15.59] (Kincaid, Fishburne Jr., Rogers, \& Chissom, 1975), to determine if the item was consistent with Grade 7 or less, which is considered appropriate for the general public (DeVellis, 2011). Thirty-four items were reworded in order to lower their readability level. Our research team then reviewed each item for relevance, wording, and redundancy (Holmbeck \& Devine, 2009). Through consensus, 26 items were eliminated, resulting in 97 items.

\subsubsection{Formatting and Scaling}

During the item generation phase, decisions were made regarding how the $\mathrm{C} 3 \mathrm{MH}$ questionnaire would be formatted and scaled. Two stems were created for different sets of items: "Over the past 12 months, when I received help from [agency], the staff who worked with my child ..." or, "Over the past 12 months..." Parents chose from one of five response options on a Likert scale: Strongly Disagree, Disagree, Neutral, Agree and Strongly Agree. All items were worded in past tense. Parents reported preferences for a five-point scale during pilot testing. 


\subsubsection{Pretesting for Content Validity}

Clinicians $(N=10)$ from two CMH agencies, as well as graduate students $(N=$ 10) from the Clinical Psychology Program at the University of Western Ontario, evaluated the content validity of each item according to the following criteria: a) their conformity to the definition of the scale, and b) their clarity/freedom from ambiguity (Jackson, 1970). Since this measure is intended for use in CMH agencies, it was important to involve service providers from these agencies in the development of the instrument by having them assess the content validity (Holmbeck \& Devine, 2009). Clinical psychology graduate students' input was considered important given their knowledge of measure development and mental health services.

For each item, participants were asked to classify the item under management, informational or relational continuity based on definitions provided, as well as to rate the clarity of the item on a 5-point scale. Only every other point was labeled: 1: Not clear at all, 3: Adequate, but should be improved and 5: Completely clear. Participants also provided comments on each item. A total of 20 items were eliminated based on the comments provided (e.g., "item vague", "will parents understand what the system is?" etc.), the clarity rating (unless the item was deemed important by the research team), dimension ratings between $45-55 \%$ (i.e., the item did not clearly fit into one of the 3 dimensions), or because of redundancy. This resulted in retaining 77 items. The mean clarity of retained items was 4.6/5. Based on the comments, some small changes were made to the wording of 18 of the items.

\subsubsection{Sub-dimension Classification}

After items were classified into the broad dimensions of management, informational, and relational continuity, each member of our research team then classified each item into a scale based on definitions provided (see Table 3.1). The average intra-class correlation coefficient indicated a high level of reliability, ICC $=.94$, $95 \%$ CI [.91, .96]. 


\subsubsection{Pilot Testing}

Pretesting with a small sample of 10 parents and 5 youth across four $\mathrm{CMH}$ agencies was conducted to determine the acceptability of the administration procedures, the clarity of instructions and items, and the acceptability of the response scales (Holmbeck \& Devine, 2009). Parents and youth were then asked to "think-aloud" as they filled out a draft of the measure (Adamson et al., 2004). Based on this information, the format was refined and problems with instructions and item wording were addressed (e.g., negatively worded items were changed to positive wording). A "Not Applicable" (N/A) option was added to five items that were not relevant to all participants (e.g., items on transition could not be answered if the child/youth had not experienced a transition). Youth provided information to explore validity of the youth-report version. Participants were compensated with a $\$ 20$ gift certificate to one of four commercial establishments of their choice.

\subsection{Validation Study}

\subsubsection{Hypotheses}

The first a priori hypothesis related to the construct validity of the measure, described below. Related constructs that were expected to relate to continuity in general were chosen prior to pilot testing to provide support for the construct validity of the measure. The term "greater continuity" was used to indicate the expectation that all aspects of continuity would be related to other factors; when specific aspects of continuity were expected to differentially relate to other factors (after the hypothesized scales were finalized), this was stated explicitly.

\subsubsection{Construct validity}

The Continuity of Care for Children's Mental Health Scale (C3MH) would have at least three factors (relational, informational, and management continuity) and seven scales: Management: Collaboration; Management: Transitions; Management: Flexibility; 
Informational: Information Exchange; Informational: Provider Knowledge; Relational: Interpersonal; and Relational: Transitions.

\subsubsection{Convergent validity}

Convergent validity, the degree of convergence between the target measure and other instruments measuring related constructs (Holmbeck \& Devine, 2009) was evaluated through the following hypotheses: (1) Better continuity of care would be strongly ${ }^{1}$ (Cohen, 1992) related to higher satisfaction with mental health services (Bickman, 1996; Heflinger, Sonnichsen, \& Brannan, 1996); (2) Lower continuity on the collaboration, transitions, relational: interpersonal and relational: consistency scales was expected to have a small negative relation with parental stress, depression, anxiety, and burden of illness (King, King, \& Rosenbaum, 2004; King et al., 1995); (3) Longer time in treatment at the CMHC would be moderately related to provider knowledge and relational: consistency. With longer durations of care, there is better opportunity to develop a relationship with the therapist (Brannan, Sonnichsen, \& Heflinger, 1996); (4) The relational continuity scales would be strongly positively associated with therapeutic alliance with the child's primary mental health clinician (Bickman, 1996; Brannan et al., 1996) as rated by the participant and the clinician; (5) More barriers to service utilization would be weakly related to lower scores on transitions; (6) There would be a moderate negative relationship between continuity and symptomatology, impairment and impact on the family; and (7) Clinician ratings of: a) consistency would be moderately related to provider knowledge and relational: consistency; b) teamwork would be moderately related to collaboration; c) service linkages would be moderately related to transitions; and overall coordination moderately related to higher collaboration, transitions, relational: interpersonal and relational: consistency. It was expected that all correlations would be statistically significant.

\footnotetext{
${ }^{1}$ Cohen's $(1992)$ criteria for strong $( \pm 0.5)$, moderate $( \pm 0.3)$ and weak $( \pm 0.1)$ correlations were used.
} 


\subsubsection{Discriminant validity}

Discriminant validity, the degree to which the target measure is not associated with other measures that assess different constructs, was evaluated with the hypotheses that the $\mathrm{C} 3 \mathrm{MH}$ scales would be weakly correlated (no greater than \pm 0.1 ) with: 1 ) the Ideas subscale of the NEO-Personality Inventory-Revised (NEO-PI-R); and, 2) to the Impression Management (IM) scale of the Balanced Inventory of Desirability Responding (BIDR; Paulhus, 1991; Paulhus \& Reid, 1991). The lack of a strong correlation with the social desirability scale would demonstrate the lack of a self-report bias for the $\mathrm{C} 3 \mathrm{MH}$ scales.

\subsubsection{Criterion validity}

It was hypothesized that families with a case manager would experience greater continuity of care than those without a case manager and that families who had dropped out of treatment would have lower continuity scores than families who did not.

\subsubsection{Relationship to demographic characteristics}

It was expected that the $\mathrm{C} 3 \mathrm{MH}$ scales would not be related to parent sex, race, marital status, relationship to child, family income, education, employment, or child sex and age. For youth, the $\mathrm{C} 3 \mathrm{MH}$ would not be related to living situation, his or her own employment status, income source, sex, or age.

\subsubsection{Methods}

\subsubsection{Sampling methods}

Data collection took place between March 2011 and October 2012. Parents were recruited using administrative data from one of 13 children's mental health $(\mathrm{CMH})$ agencies in Ontario, Canada. Two methods of recruitment were used.

The first method involved extracting parent names and addresses from administrative databases. Inclusion criteria were 1) parents who spoke English and 2) 
child or parent had at least 3 face-to-face visits in the previous year to allow utilization patterns to develop (Christakis, Wright, Zimmerman, Bassett, \& Connell, 2003). Children with Developmental Disorders or Autism were excluded, as previous studies have already examined continuity of care for children with these types of difficulties. Research staff worked with staff at each agency to mail recruitment letters to potential participants (see Appendix M). A self-addressed stamped envelope was provided to return the form. The second method involved recruitment through either a clinician at participating agencies or by the receptionist in the waiting area.

\subsubsection{Procedures}

After receipt of their contact information form $(N=698)$, research assistants attempted to contact each potential participant by telephone. At least 10 attempts, in 4 different timeslots (morning, afternoon, evening and weekends) over a minimum of 4 weeks and a maximum of 8 weeks, were made to contact each participant before efforts ceased and the participant was dropped (Traugott, 1987). It required an average of 2 (SD $=1.58$, range $1-13$ ) telephone calls to recruit parents who agreed to participate. When participants could be contacted by telephone, they were informed about the study and if they were interested and eligible, they were either mailed or emailed a package of questionnaires including the Continuity of Care in Children's Mental Health (C3MH) and other measures used in the validity analyses. Ethics approval for this study was obtained from The University of Western Ontario Research Ethics Board and all participating $\mathrm{CMH}$ agencies approved the study protocol.

A total of 551 parents were interested, and of these, 502 were screened; the remainder $(n=49)$ were unable to be contacted because of a wrong telephone number or no answer after repeated attempts. Of the parents contacted, 434 were eligible and agreed to participate and 364 returned completed questionnaires. The average time between parents returning the contact information form and completing the questionnaire was 41 days $(\mathrm{SD}=32$; median $=32$ ). This time was shorter for parents who completed the 
questionnaire via email/web-based survey $(N=207 ; M=33$ days, $S D=29$; median $=21$ days) versus mail ( $N=157 ; M=52$ days, $S D=33$ days; median $=44$ days $)$.

\subsubsection{Measures}

The following measures were collected in addition to the $\mathrm{C} 3 \mathrm{MH}$.

\subsection{Clinician-rated continuity}

Participants identified one person at the agency from which they were recruited as their "primary clinician.” For participants who consented, clinicians completed a webbased measure of continuity of care in which they rated the following using the relative percentile method (Goffin \& Olson, 2011): (a) how well providers involved the family in their care, (b) the consistency with which the family saw the same provider, (c) how well providers at the agency worked together as a team for the family, (d) the extent of service-to-service linkages within the agency for the family, and (e) how well the family's care was coordinated overall. Clinicians also completed the Working Alliance Inventory (WAI), which has adequate internal consistency (Cronbach's alpha = .87; Horvath \& Greenberg, 1989; Tracey \& Kokotovic, 1989).

\subsection{Satisfaction scales}

Parents and youth completed the Client Satisfaction Questionnaire (CSQ; Larsen, Attkisson, Hargreaves, \& Nguyen, 1979), an 8-item standardized measure of satisfaction with high concurrent validity and internal consistency (Cronbach's alpha $=.93$ ).

\subsection{General stress}

Parents completed the Perceived Stress Scale (PSS; Cohen, Kamarck, \& Mermelstein, 1983), which is a 14-item measure of the degree to which situations in one's life are appraised as stressful. The measure has adequate internal consistency (Cronbach's alpha $>.84)$, test-retest reliability (Cronbach's alpha $=.85)$ and concurrent validity. 


\subsection{Parental depression, anxiety, and stress}

The Depression Anxiety and Stress Scales 21 (DASS-21; Henry \& Crawford, 2005 ) is a 21 -item short-form measure of depression, anxiety and stress. Reliability, measured using Cronbach's alpha, has been shown to be adequate: alpha $=.93$ for the total scale. The DASS-21 has shown good convergent and discriminant validity when compared with other measures of depression and anxiety.

\subsection{Therapeutic alliance}

Parents and youth completed the short-form of the Working Alliance Inventory (WAI; Horvath \& Greenberg, 1989; Tracey \& Kokotovic, 1989), a 12-item measure assessing therapeutic alliance. Youth- and parent-report versions have adequate reliability and validity, alpha = .93-.95 (Hawley \& Garland, 2008; Wintersteen, Mensinger, \& Diamond, 2005).

\subsection{Brief Child and Family Phone Interview}

The Brief Child and Family Phone Interview (BCFPI; Boyle et al., 2009; Cunningham, Boyle, Hong, Pettingill, \& Bohaychuk, 2009) was used to assess the severity of children's presenting problems. Youth completed the self-report version of the BCPFI. The parent-report version includes measures of: (a) child symptomatology and functioning (i.e., internalizing, externalizing, functional impairment, total psychopathology), (b) parents' depression, (c) barriers to service utilization, and (d) impact on the family (i.e., burden of illness). Validity data include factor analytic support for the construct of each scale in both population and clinical samples. Internal consistency reliabilities (Cronbach's alpha) are all $>.75$ and test-retest reliabilities (in population samples) $>.65$.

\subsection{Length of involvement}

Parents were asked the first date of contact with the agency for their child's problems. Length of involvement was the difference (in months) between the 
questionnaire completion date and the date of earliest involvement. Outliers ( $>2$ SDs; $n=$ 13) were removed to eliminate the effect of a few extreme outliers on the correlations.

\subsection{Ideas facet of the NEO-Personality Inventory- Revised}

Parents completed this subscale measuring intellectual curiosity; it was included to assess divergent validity. Internal consistency for the ideas facet scale is .82 (Costa \& McRae, 1992).

\subsection{Balanced Inventory of Desirability Responding}

Parents completed the Balanced Inventory of Desirability Responding (BIDR; Paulhus, 1991; Paulhus \& Reid, 1991), a 40-item measure of social desirability composed of two factor analytically derived subscales: 1. Self-Deceptive Enhancement (SDE) and 2. Impression Management (IM). Internal consistency (Cronbach's alpha) ranges from $.67-.77$ on the SDE subscale and from .77 - .85 on the IM subscale. The IM subscale was used as a measure of social desirability responding. It was expected that none of the continuity scales would be correlated to the IM subscale.

\subsection{Demographics}

Parents reported demographic data such as child and parent age and sex, parent relationship to child, marital status, parents' educational level and annual household income, and ethnicity. For youth, the following demographic data were collected as part of the Adolescent Self-Report of the Brief Child and Family Phone Interview (BCFPI; Boyle et al., 2009; Cunningham et al., 2009): living situation (e.g., two parents, single parent, other), their own employment/education status, income source, their sex, age, and number of mental health services received during the past 12 months. For clinicians, basic demographic information including sex, educational attainment, profession, and number of years at the agency and in the system was collected. 


\subsection{Case management}

Parents were asked whether or not they had a specific person (case manager) responsible for helping them get and coordinate services for their child and family in the past 12 months. This variable was used to categorize parents into those with and without a case manager.

\subsection{Drop out}

Parents were asked if they had stopped services at any CMH agency/professional before they were completed (i.e., stopped treatment early, stopped attending treatment, dropped out from service). This variable was used to categorize parents into those who dropped out and those who did not.

\subsubsection{Analyses}

\subsubsection{Sample characteristics}

Descriptive statistics of parent, youth and clinician characteristics were tabulated. To assess whether the sample of parents and youth systematically differed from the greater population of possible respondents, the samples were compared to the population of families seen at all accredited CMH agencies in Ontario on key demographic and problem severity variables.

\subsubsection{Preliminary analyses}

Initial item analysis of the $\mathrm{C} 3 \mathrm{MH}$ examined the mean, standard deviation, skewness, and kurtosis of each item. The goal of the preliminary analyses was to evaluate the items, and to identify appropriate items to constitute the final scale. The a priori objective was to develop a concise scale that maintained all necessary content with good psychometric properties. Criteria developed to include/exclude items were based on parsimony, independence of factors, and conceptual meaningfulness (Kleinbaum, Kupper, Muller, \& Nizam, 1978). Items were eliminated if they: (1) had significant correlations with the Impression Management subscale; (2) were endorsed too 
infrequently or by virtually all participants (Jackson, 1970); (3) had mean inter-item correlations $<.15$ or $>.50$ (Briggs \& Cheek, 1986); (3) had low corrected item-total correlations (i.e., < .30) (Nunnally, 1978); (4) or had a correlation with one of the other scales that was greater than with the item's own scale (> .35) (Spector, 1992), and finally, (5) items with a low item efficiency index (IEI) (used in the final stage of item deletion, once the poor items had been deleted; Gati, 1981; Jackson, 1974; Neill \& Jackson, 1976). If an item was considered conceptually meaningful, the decision was made to retain it.

\subsubsection{Construct validity}

Using EQS 6.1 software (Bentler \& Wu, 2003), a confirmatory factor analysis (CFA) was conducted to determine the adequacy of the hypothesized model. The chisquared statistic tests the null hypothesis that the model fits the data. A good fit is indicated by accepting the null hypothesis. This test statistic has been shown to be sensitive to sample size; thus, the model may fit the data well, but the model may be rejected because of large sample size. Additional goodness-of-fit indices used to evaluate the model included: (1) the Non-Normed Fix Index (NNFI), which takes model complexity into account (Byrne, 2006); (2) the Comparative Fit Index (CFI), which considers sample size (Byrne, 2006); and (3) the Incremental Fit Index (IFI; Bollen, 1989), which address both parsimony and sample size. Values $>.90$ are recommended for these comparative or incremental fit indices (Bentler, 1992). The following absolute fit indices were also examined: (4) the standardized root mean square residual (SRMR), which represents the average discrepancy between the observed sample and the hypothesized correlation means (Byrne, 2006); and (5) the Root Mean Square Error of Approximation (RMSEA), which is sensitive to the complexity of the model, and is considered one of the more sensitive indices to model misspecification (Byrne, 2006) (Hu $\&$ Bentler, 1998). Values of $<.05$ for these absolute fit indices indicate a good fit. For RMSEA, Hu and Bentler (1999) have also suggested that $<.06$ indicates a good fit, and MacCallum, Browne and Sugawara (1996) suggested further cutpoints: .08 to .10 indicates a mediocre fit, and > .10 indicates a poor fit. 


\subsubsection{Comparisons between agencies}

Given the clustering of the participants within $\mathrm{CMH}$ agencies, a one-way analysis of variance (ANOVA) was run to compare scale scores between agencies. Only the eight agencies with more than 15 participants were included in this analysis (Cohen, 1992). Agencies were also compared using a one-way random effects intraclass correlation (ICC). A significant positive correlation would indicate a high level of agreement in scores between agencies.

\subsubsection{Reliability}

Internal consistency reliability of scales was assessed using Cronbach's alpha (1951). Three-week test-retest reliability was assessed using ICCs for the seven scales. Intraclass correlations $>.75$ indicate excellent test-retest agreement, .40 -.75 fair-to-good agreement; and <.40 poor agreement (Fleiss, 1981).

\subsubsection{Validity}

Pearson correlation coefficients were used to calculate the convergent and discriminant validity. Using a sample of 300, a significant correlation of $r=.18$, with 80\% power and an alpha of .01 (Faul, Erdfelder, Lang, \& Buchner, 2007) can be detected. Between-group differences for criterion validity were examined using $t$-tests. Outliers ( $>2$ SDs; $n=13$ ) were removed for length of involvement with the agency because of extreme outliers that would have biased the correlations.

\subsubsection{Relationship to demographic characteristics}

Spearman rank correlation coefficients, Point-biserial and Pearson correlations were used to examine the relationship between demographic factors and the $\mathrm{C} 3 \mathrm{MH}$ scales. The False Discovery Rate method (Benjamini \& Hochberg, 1995), which controls the error rate below alpha $=0.05$, and has been shown to balance Type I and Type II errors (Benjamini \& Hochberg, 2000), was used to adjust for multiple comparisons. 


\subsubsection{Results}

\subsubsection{Parent participants}

In total, 364 parents of children 4-18 years who had received help for their child's psychosocial problems participated. Only one parent per family was included in the sample. A sample of this size is considered to be sufficiently large to eliminate subject variance (Comrey, 1988; Guadagnoli \& Velicer, 1988; Nunnally, 1978). The majority of respondents were birth mothers (76\%), and were married or in common-law relationships (71\%). Almost all parent participants self-identified as Caucasian (93\%). Parents' mean age was 43 years $(S D=8$, range $=22-75)$. The target children (i.e., child receiving mental health services) were ages 4 through 18 years $(M=12.1 ; S D=3.5) ; 57 \%$ were male. About half of the families $(52 \%)$ had an annual household income of $>\$ 60,000 \mathrm{CA}$, and most parents (59\%) had some college or university education; in contrast, the population of parents seen at $\mathrm{CMH}$ agencies in Ontario tended to have somewhat lower annual incomes and education. Severity of child problems was comparable to children seen at $\mathrm{CMH}$ agencies in the province of Ontario (see Table 3.2). After removing outliers (13 parents had been involved for $>78$ months), parents were involved with the agency for an average of 19.7 months $(\mathrm{SD}=16.48$, range $=<1-77)$.

\subsubsection{Test-retest participants}

Recruitment for the reliability study was conducted concurrently with the validation study. A sample of 31 participants was mailed the parent questionnaire (C3MH-P) on two occasions approximately 3 weeks apart. There were no significant differences between the test-retest participants and the validation sample on demographic variables.

\subsubsection{Youth participants}

A sample of 57 youth (age 14-18) was also recruited to pilot a youth self-report version of the measure (C3MH-Y). Inclusion and exclusion criteria were identical as stated above. For 14-18 year olds, both the parents and youth were invited to participate. 
Youth were invited either through the mail-out procedure, or through their parents if they were eligible. Youth $(N=57)$ who completed the $\mathrm{C} 3 \mathrm{MH}-\mathrm{Y}$ were primarily female $(75 \%)$, and were on average 15.7 years old $(S D=1.09)$. The majority attended school full-time (96\%) and spoke English as their first language (93\%). Most youth lived either with both parents $(45 \%)$, or with one parent $(36 \%)$; the remainder $(20 \%)$ had another living arrangement (e.g., relatives, guardians, treatment facility, independently, on the street). There were no significant differences in the severity of psychopathology (i.e., BCFPI scores) between the study sample and the sample of youth from Children's Mental Health Ontario (CMHO).

\subsubsection{Clinician participants}

Clinicians $(N=129)$ identified by participants as their "primary clinician" completed the Continuity of Care - Clinician ratings. Clinicians had an average of 12.4 years $(\mathrm{SD}=9.53 ;<1$ to 35$)$ since graduating from their highest degrees. Most clinicians (33\%) had completed a Master's degree either in social work or psychology; $20 \%$ had completed community college; 16\% had completed a Bachelor's Degree; 6\% had completed some graduate work in psychology or social work; $5 \%$ had a MD (a psychiatrist), and $8 \%$ had completed a Ph.D. in psychology or social work. Most (83\%) of the clinicians were female. Clinicians from all 13 agencies from which families were recruited participated, with a range of 2 to 17 clinicians per agency.

\subsubsection{Preliminary analyses for parent-report measure}

Parents rated the 42 core items on the C3MH-P. Initial inter-scale correlations revealed three items that did not correlate with any of the scales. An examination of the item contents revealed that these three items were conceptually different from all other items on the scale in that they assessed beliefs or desires related to continuity, as opposed to the actual experience of continuity. These items, all of which were derived from the Components of Primary Care Index (Flocke, 1997), were: (1) I have wanted this agency to coordinate all the care my child receives; (2) If we are having problems, I would always contact someone at this agency first; and (3) It has been very important for my 
family to see a regular provider. Since the purpose of the scale was to measure the experience of continuity, as opposed to continuity beliefs or expectations, these items were dropped.

Item-level analyses indicated that none of the items had $>1.4 \%$ missing data. Five of the items of the C3MH questionnaire had a "Not Applicable (N/A)" option. Between 8 $-23 \%$ of respondents chose this option. In the CFA, these items were recoded as missing values. Missing data were handled using the Expectation Maximization type of Maximum Likelihood estimation in EQS (Bentler \& Wu, 2003). Only one item significantly correlated with the Impression Management subscale, but the correlation was weak $(r=.11)$. Moreover, the item ("I was asked what I wanted out of treatment for my child/family") was deemed important and was therefore kept. As described below, additional items were dropped based on IEI and CFA results. The IEI considers the corrected item total correlation and the corrected item correlations with all other irrelevant scales.

The final solution resulted in 25 items being retained on five scales; this process involved five iterations (see Appendix CC). In the first iteration, seven items were dropped because of negative IEI values. Two scales were combined because one scale had two items remaining and this scale correlated .90 with the other scale. In the second iteration, three items had negative IEI values. Without these items, two of the scales would have less than three items each. Thus, these items were shifted to other scales based on the item's loading on these scales and their content. In the third iteration, one item with a negative IEI value was dropped. In the fourth iteration, another item with a negative IEI value was dropped. In the fifth iteration, five items were dropped because they were considered either not essential, or redundant with other items, based on similar content (e.g., "Our primary provider knew what upset my child” and "Our primary provider knew what fears my child had") and high item-total correlations (> .80). An examination of the correlation matrix indicates that all items in the $\mathrm{C} 3 \mathrm{MH}-\mathrm{P}$ correlated reasonably well with all others and none of the correlation coefficients was excessively 
large. The average inter-item correlations were within the recommended range of .15 to $.50(M=.45, \mathrm{SD}=.062)$ (Briggs \& Cheek, 1986). Corrected item-total correlations were $>.30$ for all items.

\subsubsection{Preliminary analyses for youth-report measure}

The youth measure began with 38 items. In the pilot-testing phase, 4 of the 42 original items were dropped based on the interviews; youth either could not respond to items, or found the items irrelevant to them. In order to ensure comparability between youth and parent reports, items dropped in the preliminary analyses in the parent measure were also dropped in the youth measure. As a result, the youth-report version analyses began with the same 25 items as the parent version. Item-level analyses indicated that no items had $>5.3 \%$ missing data. Six items had higher correlations with other scales than with the item's own scale (with IEI <0). These items were dropped from further analyses; this process involved four iterations. Careful consideration was given to the item content throughout this process. The resulting pilot $\mathrm{C} 3 \mathrm{MH}-\mathrm{Y}$ had 19 items and three core scales: Management (6 items), Informational (5 items), and Relational continuity (8 items). The Management scale combined items from the parent scales: collaborations and transitions; the Information scale included items from the parent provider knowledge scale; and the Relational scale combined items from the parent scales: relational: interpersonal and relational: consistency.

\subsubsection{Construct validity for parent-report measure}

The individual items were not normally distributed and thus, the Yuan-Bentler scaled statistic (Y-B $\chi^{2}$ ) was used. This statistic is equivalent to the Satorra-Bentler (S-B $\chi^{2}$ ) when the data are incomplete and non-normally distributed (Byrne, 2006). The 5factor model had an excellent fit to the data $\left(\mathrm{Y}-\mathrm{B} \chi^{2}=514.93, p<.001\right.$; NNFI = .93; CFI $=.94 ; \mathrm{IFI}=.94 ; \mathrm{RMSEA}=.046 ; 90 \%$ C.I. $=.039, .053)$. Five alternative nested models were tested and compared with the 5-factor model: 1) a 3-factor model; 2) a 1-factor model; 3) a second-order 3-factor model; 4) a second-order 1-factor model; and 5) a third-order 1-factor model. Of the five alternative models, the second-order models 
demonstrated the better fit (see Appendix CC). The Satorra-Bentler adjusted (Satorra \& Bentler, 2001) $\chi^{2}$ differences values for the comparisons between the 5-factor model and each alternative model were not significant, suggesting that the alternative models were not worse than the 5-factor model (See Appendix DD). Based on the RMSEA and SRMR, however, the 5-factor model was considered to have the best fit.

\subsubsection{Construct validity for youth-report measure}

The 3-factor model resulted in a reasonable fit to the data $\left(\mathrm{Y}-\mathrm{B} \chi^{2}=209.90, p<\right.$ $.001 ; \mathrm{NNFI}=.84 ; \mathrm{CFI}=.86 ; \mathrm{IFI}=.87 ; \mathrm{RMSEA}=.068 ; 90 \%$ C.I. $=.030$, $.095 ;$ see Appendix EE). An alternative 1-factor model was also tested and resulted in a very good fit to the data $\left(\mathrm{Y}-\mathrm{B} \chi^{2}=154.81, n s ; \mathrm{NNFI}=.87 ; \mathrm{CFI}=.88 ; \mathrm{IFI}=.90 ; \mathrm{RMSEA}=.042\right.$; $90 \%$ C.I. $=.000, .076)$. The difference between $\chi^{2}$ values for the 1 - and 3-factor models was not significant, $\left(\Delta \chi^{2}=.26,3 \mathrm{df}, n s\right)$, suggesting that the 1-factor model did not have a worse fit than the 3-factor model. In spite of the comparatively worse fit of the 3 -factor model based on the goodness of fit statistics, the 3-factor model is recommended to provide the ability to compare and contrast youth- and parent-reports. Given that this was a pilot study, these findings will have to be replicated with a larger sample.

\subsubsection{Between agency comparisons}

Given the clustering of the participants within $\mathrm{CMH}$ agencies, a one-way ANOVA was run to compare scale scores between agencies. Levene's test indicated unequal variances for Relational: Interpersonal $(F=2.18, p=.036)$, and Relational: Consistency $(F=2.58, p=.013)$, so Welch's $F$ was used for these variables. There were no significant differences between agencies on any of the scales (see Table 3.6). The intraclass correlation coefficient of the scales across agencies was significant, ICC $=.88$, $F(4,48)=37.87, p<.001$, indicating that there were no differences between agencies across the scales. 


\subsubsection{Item and scale descriptives}

The C3MH yielded response variability that was negatively skewed (i.e., respondents tended to favorably endorse items), which is consistent with outpatient satisfaction surveys (Heflinger et al., 1996; Measelle, Weinstein, \& Martinez, 1998; Rey, Plapp, \& Simpson, 1999; Riley, Stromberg, \& Clark, 2005). Table 3.3 presents the scale descriptives, the interitem correlations, and internal consistencies (Cronbach's alpha) for the C3MH-P. Correlations among scales ranged from .49 to .84 for the C3MH-Y.

\subsubsection{Reliability}

Internal consistencies ranged from .80 to .93 for the C3MH-P (see Table 3.3). The internal consistency of the C3MH-Y was .77, .90, and .93 for the Management, Informational, and Relational scales, respectively. The C3MH-P demonstrated good testretest reliability with ICCs for the five scales ranging from .75 to .92 (see Table 3.4).

\subsubsection{Convergent validity}

(1) Higher satisfaction with services, as measured by the CSQ, was strongly and significantly correlated with all five scales on the C3MH-P (see Table 3.5). (2) There was a small, and significantly negative, correlation between parental depression and the transitions scale. There were no other significant correlations between the measures of parental depression, anxiety and stress, and any of the scales. (3) There was a small, but not statistically significant, correlation between length of time in treatment the provider knowledge scale. (4) The relational continuity scales were moderately to strongly significantly correlated with therapeutic alliance as measured by the parent, and clinician. (5) There were no significant correlations between barriers and continuity. (6) Higher child internalizing problems was positively correlated with provider knowledge and relational consistency. Higher child externalizing problems was negatively correlated with the transitions and relational: interpersonal scales. Impact of child problems on the

family was negatively correlated with transitions and relational: interpersonal. Total child problems and greater child impairment were negatively correlated with the transitions 
scale. (7) Finally, the only significant correlations between the clinician-rated measure of continuity and the continuity scales were between clinician ratings of consistency and parent ratings of provider knowledge and between clinician ratings of overall coordination and parent ratings of relational: interpersonal.

For the C3MH-Y, higher satisfaction with services was significantly correlated ( $p$ $<.001)$ with management continuity $(r=.71)$, informational continuity $(r=.58)$ and relational continuity $(r=.84)$. The relational continuity scale was significantly correlated with therapeutic alliance, $(r=.70)$. See Appendix $\mathrm{HH}$ for convergent and discriminant validity correlations.

\subsubsection{Discriminant validity}

As hypothesized, there were no significant correlations between the $\mathrm{C} 3 \mathrm{MH}-\mathrm{P}$ or the $\mathrm{C} 3 \mathrm{MH}-\mathrm{Y}$ scales and the Impression Management scale of the Balanced Inventory of Desirable Responding (BIDR). There were no significant correlations between the C3MH-P scales and the Ideas subscale of the NEO-PI-R. (Note: The NEO-PI-R was not administered to youth because it is a measure only validated for use with adults.)

\subsubsection{Criterion validity}

Independent samples $t$-tests indicated that there were significant differences between the case management groups on the C3MH-P transitions scale, $t(357)=-3.18, \mathrm{p}$ $<.01, \mathrm{~d}=.34$, provider knowledge scale, $t(357)=-2.43, \mathrm{p}<.01, \mathrm{~d}=.26$, and relational: consistency scale, $t(357)=-3.42, \mathrm{p}<.05, \mathrm{~d}=.36$ (See Figure 3.1). Independent samples t-tests also indicated that there were significant differences between the drop-out groups on the C3MH-P collaborations scale, $t(355)=3.33, \mathrm{p}<.01, \mathrm{~d}=.35$, transitions scale, $t(354)=2.83, \mathrm{p}<.01, \mathrm{~d}=.30$, provider knowledge scale, $t(354)=2.68, \mathrm{p}<.01, \mathrm{~d}=.28$, relational: interpersonal scale, $t(356)=4.45, \mathrm{p}<.001, \mathrm{~d}=.47$, relational: consistency scale, $t(355)=2.83, \mathrm{p}<.01, \mathrm{~d}=.30($ See Figure 3.2$)$.

For the C3MH-Y, there were no significant differences between those with or without a case manager on any of the scales, range of $d$ (standardized effect size) $=.06$ to 
.47. There were significant differences between those youth who indicated having dropped out of treatment versus those who did not on management continuity, $t(9.52)=$ $3.03, p=.013, \mathrm{~d}=.86$, relational continuity $t(53)=2.99, p=.004, \mathrm{~d}=.87$, but not informational continuity, $t(54)=1.66, p=.10, \mathrm{~d}=.45$.

\subsubsection{Relationship to demographic characteristics}

Overall, demographic characteristics were not related to the $\mathrm{C} 3 \mathrm{MH}$ scales, suggesting that parents' responses were generally not related to family composition or features (marital status, relationship to child), socioeconomic status (education, income), or child characteristics (sex, age) (see Appendix II). There were no significant correlations with any of the youth demographic variables (See Appendix JJ).

\subsubsection{Discussion}

Continuity of care in children's mental health has long been recognized as an important component of service delivery, and recent policy and system changes emphasizing service coordination in Ontario's children's mental health system (Government of Ontario, 2011) have increased the need for a tool to assess the experience of continuity of care from the perspective of families in the system. The current study advanced the measurement of continuity of care by developing the Continuity of Care in Children's Mental Health Measure (C3MH). The C3MH was developed based on a review of the literature including existing questionnaires, interviews with parents, youth, and service providers, consultation with researchers and services providers, and pre-testing with parents and youth, and it underwent a rigorous process of testing and piloting for item clarity, reliability, and validity that has been recommended (DeVellis, 2011).

CFA provided support for five dimensions in the C3MH-P: collaboration; transitions; provider knowledge; relational interpersonal, and relational consistency. These dimensions are consistent with the previous literature on continuity of care (see Chapter One). It may be argued that interpersonal continuity (i.e., the quality of the 
relationship) is a consequence, as opposed to a dimension, of continuity. The literature on continuity has consistently included interpersonal continuity (see Saultz \& Albedaiwi, 2004), which has been defined as an ongoing therapeutic relationship, and captures the comfort level, knowledge, trust, and adequacy of communication (Reid et al., 2002). In previous studies with adults in primary care, or mental health care, scales assessing interpersonal continuity have variously been described as patient-provider affiliation (Freeman \& Hughes, 2010), and strength of patient-provider relationship (Reid et al., 2002). Therefore, conceptually, the patient-provider relationship is an integral aspect of interpersonal continuity, which was captured in the C3MH-P. The incremental validity of the interpersonal continuity scale versus existing measures of therapeutic alliance could be tested in future studies to determine if the interpersonal scale is sensitive to interventions designed to enhance continuity.

Three dimensions were supported in the $\mathrm{C} 3 \mathrm{MH}-\mathrm{Y}$ : management, informational, and relational continuity. Test-retest reliability was high and internal consistency was good for the parent- and youth-report versions of the measure. The validity of the C3MH-P was supported based on the analysis of hypothesized relationships with: 1) satisfaction with services; 2) therapeutic alliance; 3) child adjustment measures; and, finally, 4) groups differences (i.e., criterion validity). The only association found for parental measures of stress, anxiety, and depression was between parental depression and the transitions scale. No association was found between time in treatment or between barriers and continuity. Each of these findings will be discussed in turn.

First, a significant and strong positive correlation was found between all continuity scales and satisfaction with services. Previous studies have also found a positive relationship between the processes of care, or improved service delivery, and satisfaction with services (Bickman, 1996; King et al., 2004).

Second, there was a significant positive association between a validated measure of therapeutic alliance and the relational continuity scales, indicating convergent validity. This association was significant for the therapist-rated therapeutic alliance as well. 
Third, a pattern emerged in the association between measure of child adjustment and the continuity scales. Higher severity of child internalizing problems was related to higher ratings of the provider's knowledge of the child, and better consistency of the provider. The finding of a positive association between internalizing problems and provider knowledge and consistency suggests that these children are more likely to see the same provider over time, who, in turn, would get to know the child better. Children with internalizing problems may also be better at forming therapeutic relationships than those with externalizing problems because of their motivation to reduce their distress and their relative lack of difficulty with authority figures (Digiuseppe, Linscott, \& Jilton, 1996; Shirk \& Saiz, 1992; Shirk \& Karver, 2003). This finding is consistent with the finding that children with higher externalizing difficulties had lower continuity scores on the relational: interpersonal scale. Notably, the transitions scale was the only scale to demonstrate negative associations with total problems, child impairment, and impact on the family. This scale also had a negative association with externalizing problems. It is possible that families of a child with more externalizing problems and impairment received lower continuity through transitions as a result of their child's difficulties. These families also likely have more chaotic lives than families with fewer child externalizing problems and impairment, and, as a result, they may experience more difficulty in connecting with services at critical transition periods. This hypothesis is consistent with research findings that children with more severe impairment are more likely to terminate treatment prematurely (Kazdin \& Mazurick, 1994; Kazdin, 1996). These families may have a higher level of needs that are not perceived as being met by the current system. For example, these families may require coordination across multiple providers and relational continuity over longer periods of time, which they may not be receiving. Indeed, Koren (1997) found a negative correlation between service coordination and externalizing problems. While the causal relationship between problem severity and continuity cannot be determined, the negative association suggests that families with higher needs are particularly vulnerable to experiencing discontinuity, especially through transitions. 
The fourth finding that provides evidence for the validity of the $\mathrm{C} 3 \mathrm{MH}$ is expected-group differences. First, there were significant differences between those with and without a case manager across three of the five scales: transitions; provider knowledge; and relational consistency. Having a case manager should affect continuity of care through transitions, and improve provider consistency, which may improve provider knowledge. The finding of no significant differences on the collaborations and relational: interpersonal scales is not surprising, because case management does not necessarily lead to the family being included in the treatment decision-making (collaborations), or to a better therapeutic relationship. As expected, families who dropped out of treatment had lower continuity scores across all scales. The demonstrated difference between these groups is an important strength of this study.

It was hypothesized that higher levels of parental stress, anxiety, and depression would be related to lower levels of continuity. Unlike the study examining the Measure of Processes of Care, which found a relationship to parental stress, anxiety, and depression (King et al., 2004; King et al., 1995), the current study did not find this association. The only significant association that emerged was between higher levels of parental depression and lower scores on the transitions scale. It is clearly important to attend to parental depression when delivering children's mental health services given that these parents are either vulnerable to experiencing discontinuity as a result of their depression, or they may be negatively affected by discontinuity through transitions. Overall, the transitions scale was the most sensitive scale in that it demonstrated the strongest relationships to the validity measures. Thus, this scale is especially important when interpreting continuity scores, as transition points mark a risk for discontinuity.

No relationship was found between time in treatment or barriers and continuity. Although it was expected that longer time in treatment would be associated with higher levels of continuity, continuity of care is likely not a linear processes that increases over time as a result of time in the system. It is likely that families experienced continuity in a similar way that they experience satisfaction (Young, Nicholson, \& Davis, 1995); 
specific agency and individual practices might lead to an experience of greater continuity of care, irrespective of length of involvement with the system. The lack of association between barriers and continuity is not surprising given that the study only included families who had already accessed services.

\subsubsection{Limitations}

There are a number of limitations to the study. First, the cross-sectional design limits conclusions to associative interpretations rather than causal interpretations.

Second, inclusion criteria for the study involved having at least three face-to-face visits. While we considered this to be the minimal amount of services necessary to complete the $\mathrm{C} 3 \mathrm{MH}$ questionnaire, it does introduce a sampling bias as dissatisfied families tend to drop out of treatment early on (Byalin, 1993), or else tend not to participate in studies (Mazor, Clauser, Field, Yood, \& Gurwitz, 2002; Perneger, Chamot, \& Bovier, 2005). Thus, the $\mathrm{C} 3 \mathrm{MH}$ is designed for families that have accessed $\mathrm{CMH}$ services and have had a minimum amount of visits. Instruments that assess access and barriers to CMH services already exist (Cheung \& Dewa, 2007; Davidson \& Manion, 1996; Offord, Boyle, Fleming, \& Blum, 1989) and dropout has been studied extensively in other studies (Kazdin, 1996; Kazdin, Holland, \& Crowley, 1997).

Third, only families who volunteered participated. Parents who volunteer for research studies may take a more active role in their child/family's care, and this may be reflected in higher continuity scale scores. The current sample was more highly educated and had a higher family income compared to all families seen at $\mathrm{CMH}$ agencies in Ontario. There were no significant relations found, however, between education and income and continuity scores across the scales, suggesting that continuity of care is likely not related to these factors. Moreover, there were no significant differences in their child's symptom severity, suggesting that the voluntary sample was representative of all families in terms of presenting problems. 
Finally, the usefulness of this new measure for detecting the level of continuity of care experienced by families across diverse $\mathrm{CMH}$ agencies will require continuous efforts to overcome the challenges of engaging families in questionnaire-based evaluation. Some of these challenges include the amount of time required to engage families willing to complete the questionnaire, and the potential bias introduced in the voluntary nature of participation. One way to overcome this challenge is to include the measure as part of a systemic evaluation protocol. Thus, all families receiving services would complete the measure, which would allow $\mathrm{CMH}$ agencies and policy makers to assess continuity without any bias of voluntary participation.

Results from the current study indicate that the $\mathrm{C} 3 \mathrm{MH}$ is a promising measurement tool that is worth further development for research and practice in children's mental health. 


\section{References}

Adair, C. E., Wild, C. T., Joyce, A., McDougall, G., Gordon, A., Costigan, N., ... Lu, M. (2004). Continuity of mental health services study of Alberta: A research program on continuity of mental health care. Ottawa, ON: Canadian Health Services Research Foundation.

Adamson, J., Gooberman-Hill, R., Woolhead, G., \& Donovan, J. (2004). 'Questerviews': Using questionnaires in qualitative interviews as a method of integrating qualitative and quantitative health services research. Journal of Health Services Research \& Policy, 9, 139-145. doi:10.1258/1355819041403268

Benjamini, Y., \& Hochberg, Y. (1995). Controlling the false discovery rate: A practical and powerful approach to multiple testing. Journal of the Royal Statistical Society. Series B (Methodological), 289-300. Retrieved from http://www.stat.purdue.edu/ doerge/BIOINFORM.D/FALL06/Benjamini and Y FDR.pdf

Benjamini, Y., \& Hochberg, Y. (2000). On the adaptive control of the false discovery rate in multiple testing with independent statistics. Journal of Educational and Behavioral Statistics, 25, 60-83. Retrieved from http://www.unt.edu/rss/class/mike/5030/articles/benjaminihochberg.pdf

Bentler, P. M. (1992). On the fit of models to covariances and methodology to the Bulletin. Psychological Bulletin, 112, 400-404. Retrieved from http://psycnet.apa.org/psycinfo/1993-12081-001

Bentler, P. M., \& Wu, E. J. C. (2003). EQS 6.1 for Windows [Computer software]. Retrieved from http://www.mvsoft.com/pub/EQS 61 QuickStart.pdf

Bickman, L. (1996). A continuum of care: More is not always better. American Psychologist, 51, 689-701. doi:10.1037/0003-066X.51.7.689 
Bollen, K. A. (1989). A new incremental fit index for general structural equation models. Sociological Methods \& Research, 17, 303-316. Retrieved from http://smr.sagepub.com/content/17/3/303.short

Boydell, K. M., Pong, R., Volpe, T., Tilleczek, K., Wilson, E., \& Lemieux, S. (2006). Family perspectives on pathways to mental health care for children and youth in rural communities. Journal of Rural Health, 22, 182-188. doi:10.1111/j.17480361.2006.00029.x

Boyle, M. H., Cunningham, C. E., Georgiades, K., Cullen, J., Racine, Y., \& Pettingill, P. (2009). The Brief Child and Family Phone Interview (BCFPI): 2. Usefulness in screening for child and adolescent psychopathology. Journal of Child Psychology and Psychiatry, 50, 424-431. doi:10.1111/j.1469-7610.2008.01971.x

Brannan, A. M., Sonnichsen, S. E., \& Heflinger, C. A. (1996). Measuring satisfaction with children's mental health services: Validity and reliability of the satisfaction scales. Evaluation and Program Planning, 19, 131-141. doi:10.1016/01497189(96)00004-3

Briggs, S. R., \& Cheek, J. M. (1986). The role of factor analysis in the development and evaluation of personality scales. Journal of Personality, 54, 106-148. doi:10.1111/j.1467-6494.1986.tb00391.x

Byalin, K. (1993). Assessing parental satisfaction with children's mental health services: A pilot study. Evaluation and Program Planning, 16, 69-72. Retrieved from http://www.sciencedirect.com/science/article/pii/0149718993900184

Byrne, B. (2006). Structural equation modeling with EQS: Basic concepts, applications, and programming. Mahwah, NJ: Erlbaum.

Chao, J. (1988). Continuity of care: Incorporating patient perceptions. Family Medicine, 20, 333-337. Retrieved from PM:3266158 
Cheung, A. H., \& Dewa, C. S. (2007). Mental health service use among adolescents and young adults with major depressive disorder and suicidality. Canadian Journal of Psychiatry, 52, 228-232. Retrieved from http://cat.inist.fr/?aModele=afficheN\&cpsidt=18725886

Christakis, D. A., Wright, J. A., Zimmerman, F. J., Bassett, A. L., \& Connell, F. A. (2003). Continuity of care is associated with well-coordinated care. Ambulatory Pediatrics, 3, 82-86. doi:10.1367/1539-4409(2003)003<0082:COCIAW>2.0.CO;2

Cohen, J. (1992). A power primer. Psychological Bulletin, 112, 155-159. Retrieved from http://psycnet.apa.org/journals/bul/112/1/155/

Cohen, S., Kamarck, T., \& Mermelstein, R. (1983). A global measure of perceived stress. Journal of Health and Social Behavior, 24, 385-396. doi:10.2307/2136404

Comrey, A. L. (1988). Factor-analytic methods of scale development in personality and clinical psychology. Journal of Consulting and Clinical Psychology, 56, 754-761. Retrieved from http://psycnet.apa.org/journals/ccp/56/5/754/

Costa, P. T.,Jr., \& McRae, R. R. (1992). The Revised NEO Personality Inventory manual. Odessa, FL: Psychological Assessment Resources.

Cronbach, L. J. (1951). Coefficient alpha and the internal structure of tests. Psychometrika, 16, 297-334. Retrieved from http://www.springerlink.com/index/n435u12541475367.pdf

Cunningham, C. E., Boyle, M. H., Hong, S., Pettingill, P., \& Bohaychuk, D. (2009). The Brief Child and Family Phone Interview (BCFPI): 1. Rationale, development, and description of a computerized children's mental health intake and outcome assessment tool. Journal of Child Psychology and Psychiatry, 50, 416-423. doi:10.1111/j.1469-7610.2008.01970.x 
Davidson, S., \& Manion, I. G. (1996). Facing the challenge: Mental health and illness in Canadian youth. Psychology, Health \& Medicine, 1, 41-56. Retrieved from http://www.tandfonline.com/doi/abs/10.1080/13548509608400005

DeVellis, R. F. (2011). Scale development: Theory and applications. Thousand Oaks, CA: Sage Publications, Inc.

Digiuseppe, R., Linscott, J., \& Jilton, R. (1996). Developing the therapeutic alliance in child—adolescent psychotherapy. Applied and Preventive Psychology, 5, 85-100. Retrieved from http://www.sciencedirect.com/science/article/pii/S0962184996800023

Faul, F., Erdfelder, E., Lang, A. G., \& Buchner, A. (2007). G*Power 3: A flexible statistical power analysis program for the social, behavioral, and biomedical sciences. Behavior Research Methods, 39, 175-191. doi:10.3758/BF03193146

Fleiss, J. L. (1981). Statistical methods for rates and proportions. New York: Wiley.

Flocke, S. A. (1997). Measuring attributes of primary care: Development of a new instrument. Journal of Family Practice, 45, 64-74. Retrieved from ISI:A1997XK68300010

Freeman, G. K., \& Hughes, J. (2010). Continuity of care and the patient experience: An inquiry into the quality of general practice in England. London, England: The King's Fund.

Gati, I. (1981). Properties of the item efficiency index for minimum redundancy item analysis. Educational and Psychological Measurement, 41, 973-978. Retrieved from http://epm.sagepub.com/content/41/4/973.short

Glasgow, R. E., Wagner, E. H., Schaefer, J., Mahoney, L. D., Reid, R. J., \& Greene, S. M. (2005). Development and validation of the patient assessment of chronic illness care (PACIC). Medical Care, 43, 436. Retrieved from 
http://journals.lww.com/lww-

medicalcare/Abstract/2005/05000/Development_and_Validation_of_the_Patient.3.a $\operatorname{spx}$

Goffin, R. D., \& Olson, J. M. (2011). Is it all relative? Comparative judgments and the possible improvement of self-ratings and ratings of others. Perspectives on Psychological Science, 6, 48-60. Retrieved from http://pps.sagepub.com/content/6/1/48.short

Government of Ontario. (2011). Open minds, healthy minds: Ontario's comprehensive mental health and addictions strategy. Retrieved from http://www.health.gov.on.ca/en/common/ministry/publications/reports/mental_healt h2011/mentalhealth.aspx

Guadagnoli, E., \& Velicer, W. F. (1988). Relation to sample size to the stability of component patterns. Psychological Bulletin, 103, 265-275. Retrieved from http://psycnet.apa.org/psycinfo/1988-15800-001

Haggerty, J. L., Reid, R. J., Freeman, G. K., Starfield, B. H., Adair, C. E., \& McKendry, R. (2003). Continuity of care: A multidisciplinary review. British Medical Journal, 327, 1219-1221. doi:10.1136/bmj.327.7425.1219

Hawley, K. M., \& Garland, A. F. (2008). Working alliance in adolescent outpatient therapy: Youth, parent and therapist reports and associations with therapy outcomes. Child Youth Care Forum, 37, 59-74. doi:10.1007/s10566-008-9050-x

Heflinger, C. A. (1996). Measuring service system coordination in managed mental health care for children and youth. Evaluation and Program Planning, 19, 155-163. doi:10.1016/0149-7189(96)00006-7

Heflinger, C. A., Sonnichsen, S. E., \& Brannan, A. M. (1996). Parent satisfaction with children's mental health services in a children's mental health managed care 
demonstration. Journal of Mental Health Administration, 23, 69-79. doi:10.1007/BF02518644

Henry, J. D., \& Crawford, J. R. (2005). The short-form version of the Depression Anxiety Stress Scales (DASS-21): Construct validity and normative data in a large nonclinical sample. British Journal of Clinical Psychology, 44, 227-239. Retrieved from WOS:000229910200007

Holmbeck, G. N., \& Devine, K. A. (2009). Editorial: An author's checklist for measure development and validation manuscripts. Journal of Pediatric Psychology, 34, 691. Retrieved from http://jpepsy.oxfordjournals.org/content/34/7/691.short

Horvath, A. O., \& Greenberg, L. S. (1989). Development and validation of the Working Alliance Inventory. Journal of Counseling Psychology, 36, 223-233. doi:10.1037/0022-0167.36.2.223

Hu, L., \& Bentler, P. M. (1998). Fit indices in covariance structure modeling: Sensitivity to underparameterized model misspecification. Psychological Methods, 3, 424. Retrieved from http://people.cehd.tamu.edu/ okwok/epsy651R/Articles/HuBentler1998.pdf

Jackson, D. N. (1974). Personality research form manual. Port Huron, MI: Research Psychologists Press.

Jackson, D. N. (1970). A sequential system for personality scale development. In C. D. Spielberger (Ed.), Current topics in clinical and community psychology (pp. 61-96). New York: NY: Academic Press.

Kazdin, A. E. (1996). Dropping out of child psychotherapy: Issues for research and implications for practice. Clinical Child Psychology and Psychiatry, 1, 133-156. doi:10.1177/1359104596011012 
Kazdin, A. E., Holland, L., \& Crowley, M. (1997). Family experience of barriers to treatment and premature termination from child therapy. Journal of Consulting and Clinical Psychology, 65, 453-463. Retrieved from ISI:A1997XA22300011

Kazdin, A. E., \& Mazurick, J. L. (1994). Dropping out of child psychotherapy: Distinguishing early and late dropouts over the course of treatment. Journal of Consulting and Clinical Psychology, 62, 1069-1074.

Kincaid, J.P., Fishburne Jr, R.P., Rogers, R.L., \& Chissom. B.S. (1975). Derivation of new readability formulas (automated readability index, fog count and flesch reading ease formula) for navy enlisted personnel. Retrieved from http://www.dtic.mil/cgi-bin/GetTRDoc?AD=ADA006655

King, S., King, G., \& Rosenbaum, P. (2004). Evaluating health service delivery to children with chronic conditions and their families: Development of a refined Measure of Processes of Care (MPOC-20). Children's Health Care, 33, 35-57. doi:10.1207/s15326888chc3301_3

King, S., Rosenbaum, P., \& King, G. (1995). The Measure of Processes of Care: A means to assess family-centred behaviors of health providers. Hamilton, ON: CanChild Centre for Childhood Disability Research.

Kleinbaum, D. G., Kupper, L. L., Muller, K. E., \& Nizam, A. (1978). Applied regression analysis and other multivariable methods. North Scituate, MA: Duxbury Press.

Koren, P. E., Paulson, R. I., Kinney, R. F., Yatchmenoff, D. K., Gordon, L. J., \& DeChillo, N. (1997). Service coordination in children's mental health: An empirical study from the caregiver's perspective. Journal of Emotional and Behavioral Disorders, 5, 162-172. doi:10.1177/106342669700500304

Larsen, D. L., Attkisson, C. C., Hargreaves, W. A., \& Nguyen, T. D. (1979). Assessment of client/patient satisfaction: Development of a general scale. Evaluation and Program Planning, 2, 197-207. doi:10.1016/0149-7189(79)90094-6 
MacCallum, R. C., Browne, M. W., \& Sugawara, H. M. (1996). Power analysis and determination of sample size for covariance structure modeling. Psychological Methods, 1, 130-149. Retrieved from http://psycnet.apa.org/journals/met/1/2/130/

Mazor, K. M., Clauser, B. E., Field, T., Yood, R. A., \& Gurwitz, J. H. (2002). A demonstration of the impact of response bias on the results of patient satisfaction surveys. Health Services Research, 37, 1403-1417. Retrieved from http://onlinelibrary.wiley.com/doi/10.1111/1475-6773.11194/full

Measelle, J. R., Weinstein, R. S., \& Martinez, M. (1998). Parent satisfaction with case managed systems of care for children and youth with severe emotional disturbance. Journal of Child and Family Studies, 7, 451-467. Retrieved from http://www.springerlink.com/index/12qlj1816787205g.pdf

Minore, B., Boone, M., Arthur, A., \& O'Sullivan, J. (2005). Managing continuity of care for children with special needs in rural and remote parts of northern Ontario. Ottawa, ON: Canadian Health Services Research Foundation. Retrieved from www.coespecialneeds.ca/PDF/continuityofcare.pdf

Morrissey, J. P. (1992). An interorganizational network approach to evaluating children's mental health service systems. In L. Bickman \& D. Rog (Eds.), Children's mental health services: Methodological issues (pp. 85-98). San Francisco, CA: Jossey Bass.

Neill, J. A., \& Jackson, D. N. (1976). Minimum redundancy item analysis. Educational and Psychological Measurement, 36, 123-134. Retrieved from http://epm.sagepub.com/content/36/1/123.short

Nunnally, J. (1978). Psychometric theory (2nd ed.). New York: McGraw-Hill.

Offord, D. R., Boyle, M. H., Fleming, J. E., \& Blum, H. M. (1989). Summary of selected results. The Canadian Journal of Psychiatry/La Revue canadienne de psychiatrie, 34, 483-491. Retrieved from http://psycnet.apa.org/psycinfo/1990-04596-001 
Paulhus, D. L. (1991). Measurement and control of response bias. In J. P. Robinson, P. R. Shaver, \& L. S. Wrightsman (Eds.), Measures of personality and social psychological attitudes (pp. 17-59). San Diego: Academic Press. Retrieved from http://doi.apa.org/psycinfo/1991-97206-001

Paulhus, D. L., \& Reid, D. B. (1991). Enhancement and denial in socially desirable responding. Journal of Personality and Social Psychology, 60, 307. doi:10.1037/0022-3514.60.2.307

Perneger, T. V., Chamot, E., \& Bovier, P. A. (2005). Nonresponse bias in a survey of patient perceptions of hospital care. Medical Care, 43, 374. Retrieved from http://journals.lww.com/lwwmedicalcare/Abstract/2005/04000/Nonresponse_Bias_in_a_Survey_of_Patient.8.as $\mathrm{px}$

Reid, R., Haggerty, J., \& McKendry, R. (2002). Defusing the confusion: Concepts and measures of continuity of healthcare. Ottawa, ON: Canadian Health Services Research Foundation. Retrieved from http://www.chsrf.ca/Migrated/PDF/ResearchReports/CommissionedResearch/cr_co ntcare_e.pdf

Rey, J. M., Plapp, J. M., \& Simpson, P. L. (1999). Parental satisfaction and outcome: a 4year study in a child and adolescent mental health service. Australian and New Zealand Journal of Psychiatry, 33, 22-28. Retrieved from http://informahealthcare.com/doi/abs/10.1046/j.1440-1614.1999.00516.x

Riley, S. E., Stromberg, A. J., \& Clark, J. (2005). Assessing parental satisfaction with children's mental health services with the youth services survey for families. Journal of Child and family studies, 14, 87-99. Retrieved from http://www.springerlink.com/index/G27237722440136R.pdf 
Rosenthal, T. C. (2008). The medical home: Growing evidence to support a new approach to primary care. The Journal of the American Board of Family Medicine, 21, 427-440. Retrieved from http://www.jabfp.com/content/21/5/427.full

Satorra, A., \& Bentler, P. M. (2001). A scaled difference chi-square test statistic for moment structure analysis. Psychometrika, 66, 507-514. Retrieved from http://link.springer.com/article/10.1007/BF02296192

Saultz, J. W., \& Albedaiwi, W. (2004). Interpersonal continuity of care and patient satisfaction: A critical review. The Annals of Family Medicine, 2, 445-451. doi:10.1370/afm.91

Shirk, S. R., \& Karver, M. (2003). Prediction of treatment outcome from relationship variables in child and adolescent therapy: A meta-analytic review. Journal of consulting and clinical psychology, 71, 452. Retrieved from http://users.phhp.ufl.edu/rbauer/EBPP/shirk_carver.pdf

Shirk, S. R., \& Saiz, C. C. (1992). Clinical, empirical, and developmental perspectives on the therapeutic relationship in child psychotherapy. Development and Psychopathology, 4, 713-713. Retrieved from http://journals.cambridge.org/production/action/cjoGetFulltext?fulltextid=2541760

Spector, P. E. (1992). Summated rating scale construction: An Introduction. Newbury Park: Sage Publications, Inc.

Stroul, B. A. (1996). Children's mental health: Creating systems of care in a changing society. Balitmore, MD: Paul H. Brookes Publishing Co.

Stroul, B. A., \& Friedman, R. (1986). A system of care for severely emotionally disturbed youth. Washington, DC: Georgetown University, Child and Adolescent Service System Program Technical Assistance Center. 
The Provincial Centre of Excellence for Child and Youth Mental Health at CHEO. (2006). Indicators of Quality for Child and Youth Mental Healthcare in Ontario.

Thornicroft, G., \& Tansella, M. (1999). Translating ethical principles into outcome measures for mental health service research. Psychological Medicine, 29, 761-767. doi:10.1017/S0033291798008034

Tracey, T. J., \& Kokotovic, A. M. (1989). Factor structure of the Working Alliance Inventory. Psychological Assessment, 1, 207-210.

Traugott, M. W. (1987). The importance of persistence in respondent selection for preelection surveys. Public Opinion Quarterly, 51, R-48-57. doi:10.1086/269013

University of South Florida. (2007). System of care practice review -revised: Finding your way in a local system of care. Retrieved from logicmodel.fmhi.usf.edu/resources/PDF/SOCPR-Protocol.pdf

Ware, N. C., Dickey, B., Tugenberg, T., \& McHorney, C. A. (2003). CONNECT: a measure of continuity of care in mental health services. Mental Health Services Research, 5, 209-221. Retrieved from PM:14672500

Wintersteen, M. B., Mensinger, J. L., \& Diamond, G. S.. (2005). Do gender and racial differences between patient and therapist affect therapeutic alliance and treatment retention in adolescents? Professional Psychology: Research and Practice, 36, 400408. doi:10.1037/0735-7028.36.4.400

Young, S. C., Nicholson, J., \& Davis, M. (1995). An overview of issues in research on consumer satisfaction with child and adolescent mental health services. Journal of Child and Family Studies, 4, 219-238. doi:10.1007/BF02234097 
Table 3.1: Definitions of Continuity Scales

\begin{tabular}{|c|c|}
\hline Scale & Definition \\
\hline Management & $\begin{array}{l}\text { "A consistent and coherent approach to the management of a [mental] } \\
\text { health condition that is responsive to a patient's changing needs" } \\
\text { (Haggerty et al., 2003, p.1220). This includes having shared management } \\
\text { plans (which include the child and family), good teamwork, access to } \\
\text { services in the system, and flexibility in adapting care to changes in a } \\
\text { patient's life. }\end{array}$ \\
\hline Collaboration & $\begin{array}{l}\text { Parent/youth working together with staff or staff working with each } \\
\text { other; staff/services are linked within and between providers }\end{array}$ \\
\hline Transitions & $\begin{array}{l}\text { Transitions between staff or from one service including discharge \& } \\
\text { follow-up }\end{array}$ \\
\hline Flexibility & $\begin{array}{l}\text { Services were modified/developed in a way that was consistent with } \\
\text { child/family needs and life circumstances; flexibility to accommodate } \\
\text { changes in needs for services \&/or scheduling }\end{array}$ \\
\hline Informational & $\begin{array}{l}\text { "The use of information on past events and personal circumstances to } \\
\text { make current care appropriate for each individual" (Haggerty et al., 2003, } \\
\text { p.1220). Informational continuity includes both the flow of documented } \\
\text { information about the individual, but also knowledge about the patient's } \\
\text { preferences, values, and context in order to connect care across all } \\
\text { contacts a family has with the agency (e.g., from one clinician to } \\
\text { another). }\end{array}$ \\
\hline $\begin{array}{l}\text { Information } \\
\text { Exchange }\end{array}$ & $\begin{array}{l}\text { How \& extent of information exchanged between two parties; includes } \\
\text { parent to provider or provider to provider }\end{array}$ \\
\hline Provider & How well primary provider knows the child/family or some specific \\
\hline
\end{tabular}




\begin{tabular}{cl}
\hline Scale & Definition \\
\hline Knowledge & aspect of child's life \\
\hline Relational & "An ongoing therapeutic relationship between a patient and one or more \\
& $\begin{array}{l}\text { providers" (Haggerty et al., 2003, p.1220). Relational continuity can be } \\
\text { established with an agency, or group of providers, or with one specific } \\
\text { provider. The relationship provides the patient with a sense of } \\
\text { predictability and coherence. }\end{array}$ \\
\hline Interpersonal & $\begin{array}{l}\text { Perceptions of trust, support; therapeutic alliance that develops over time } \\
\text { Consistency } \\
\text { Over Time \& } \\
\text { Transitions }\end{array}$ \\
\hline
\end{tabular}


Table 3.2: Demographic Characteristics of C3MH Parent Validation Sample

\begin{tabular}{|c|c|c|c|}
\hline \multirow[t]{3}{*}{ Demographic Characteristics } & \multirow{2}{*}{$\begin{array}{l}\text { Study Sample } \\
(\mathrm{N}=364)\end{array}$} & \multirow{2}{*}{$\begin{array}{c}\mathrm{CMHO}^{\mathrm{a}} \\
(\mathrm{N}=18,820)\end{array}$} & \multirow[b]{3}{*}{ Sample vs. CMHO } \\
\hline & & & \\
\hline & $\mathrm{N}(\%)$ & $\mathrm{N}(\%)$ & \\
\hline \multicolumn{4}{|l|}{ Parent Sex } \\
\hline Male & $30(8.2)$ & -- & \\
\hline Female & $334(91.8)$ & -- & \\
\hline Education & & & $\chi^{2}$ \\
\hline Less than high school & $18(4.9)$ & $2062(14.0)$ & $63.15 * * *$ \\
\hline High school graduate & $39(10.7)$ & $2920(19.9)$ & \\
\hline At least some community college/ technical school, or some university & $214(58.8)$ & $7376(50.2)$ & \\
\hline University graduate & $93(25.5)$ & $2327(15.9)$ & \\
\hline Income & & & $\chi^{2}$ \\
\hline
\end{tabular}




\begin{tabular}{|c|c|c|c|}
\hline \multirow[t]{3}{*}{ Demographic Characteristics } & \multirow{2}{*}{$\begin{array}{l}\text { Study Sample } \\
(\mathrm{N}=364)\end{array}$} & \multirow{2}{*}{$\begin{array}{c}\mathrm{CMHO}^{\mathrm{a}} \\
(\mathrm{N}=18,820)\end{array}$} & \multirow[b]{3}{*}{ Sample vs. CMHO } \\
\hline & & & \\
\hline & $\mathrm{N}(\%)$ & $\mathrm{N}(\%)$ & \\
\hline Under $\$ 10,000$ & $7(2.0)$ & $729(5.8)$ & $57.78 * * *$ \\
\hline$\$ 10,000$ to $\$ 19,999$ & $45(13.0)$ & $2316(18.5)$ & \\
\hline$\$ 20,000$ to $\$ 39,999$ & $53(15.4)$ & $2923(23.3)$ & \\
\hline$\$ 40,000$ to $\$ 59,999$ & $60(17.4)$ & $2323(18.5)$ & \\
\hline$\$ 60,000$ and over & $180(52.2)$ & $4253(33.9)$ & \\
\hline Marital Status & & & $\chi^{2}$ \\
\hline Partner or spouse & $222(71.4)$ & $9378(59.6)$ & $13.04 * * *$ \\
\hline Single parent & $89(28.6)$ & $6356(40.4)$ & \\
\hline \multicolumn{4}{|l|}{ Relationship to Child } \\
\hline Birth Mother & $277(76.1)$ & -- & -- \\
\hline
\end{tabular}




\begin{tabular}{|c|c|c|c|}
\hline \multirow[t]{3}{*}{ Demographic Characteristics } & \multirow{2}{*}{$\begin{array}{l}\text { Study Sample } \\
(\mathrm{N}=364)\end{array}$} & \multicolumn{2}{|l|}{$\mathrm{CMHO}^{\mathrm{a}}$} \\
\hline & & $(\mathrm{N}=18,820)$ & \\
\hline & $\mathrm{N}(\%)$ & $\mathrm{N}(\%)$ & Sample vs. CMHO \\
\hline Other & $87(23.9)$ & -- & -- \\
\hline \multicolumn{4}{|l|}{ Race or Color of Respondent } \\
\hline White & $333(92.8)$ & -- & -- \\
\hline \multirow[t]{2}{*}{ Other } & $26(7.2)$ & -- & -- \\
\hline & & & $t$ \\
\hline Child Age $(\mathrm{M} \pm \mathrm{SD})$ & $12.07(3.50)$ & $11.91(3.55)$ & .046 \\
\hline Child Sex & & & $\chi^{2}$ \\
\hline Male & $202(56.9)$ & $13009(56.3)$ & .015 \\
\hline Female & $153(43.1)$ & $10115(43.7)$ & \\
\hline Child Adjustment $(\mathrm{M} \pm \mathrm{SD})$ & & & $t$ \\
\hline
\end{tabular}




\begin{tabular}{lccc}
\hline Demographic Characteristics & Study Sample & $\mathrm{CMHO}^{\mathrm{a}}$ \\
& $(\mathrm{N}=364)$ & $(\mathrm{N}=18,820)$ \\
\hline Internalizing & $\mathrm{N}(\%)$ & $\mathrm{N}(\%)$ & Sample vs. CMHO \\
\cline { 2 - 4 } Externalizing & $68.05(14.70)$ & $63.23(14.65)$ & .33 \\
Total Problem & $70.85(14.91)$ & $68.40(13.36)$ & .16 \\
Functional Impairment & $71.90(12.53)$ & $68.01(12.41)$ & .30 \\
Impact on Family & $72.17(16.30)$ & $67.24(14.61)$ & .31 \\
\hline
\end{tabular}

${ }^{\mathrm{a}} \mathrm{CMHO}=$ Children's Mental Health Ontario data (Brian O’Hara, CMHO, personal communication, August, 2011)

--- indicates that data were not available for the specific variable

$* * * p<.001$ 
Table 3.3: Correlations Between C3MH Parent Scales

\begin{tabular}{|c|c|c|c|c|c|}
\hline & $\begin{array}{l}\text { Management: } \\
\text { Collaborations }\end{array}$ & $\begin{array}{r}\text { Management: } \\
\text { Transitions }\end{array}$ & $\begin{array}{r}\text { Informational: Provider } \\
\text { Knowledge }\end{array}$ & $\begin{array}{r}\text { Relational: } \\
\text { Interpersonal }\end{array}$ & $\begin{array}{r}\text { Relational: } \\
\text { Consistency }\end{array}$ \\
\hline Management: Transitions & .71 & 1 & & & \\
\hline Informational: Provider Knowledge & .67 & .59 & 1 & & \\
\hline Relational: Interpersonal & .59 & .55 & .69 & 1 & \\
\hline Relational: Consistency & .79 & .67 & .69 & .64 & 1 \\
\hline \# of items & 7 & 5 & 5 & 4 & 4 \\
\hline Cronbach's alpha & .83 & .80 & .89 & .93 & .86 \\
\hline Mean & 4.09 & 3.73 & 4.16 & 4.23 & 3.80 \\
\hline Standard Deviation & .63 & .84 & .68 & .77 & .89 \\
\hline Minimum & 1.71 & 1.20 & 1.00 & 1.00 & 1.00 \\
\hline Maximum & 5.00 & 5.00 & 5.00 & 5.00 & 5.00 \\
\hline
\end{tabular}

Note. $N=364 ; 25$ items. All correlations are significant at $p<.001$. 
Table 3.4: Test-retest Reliability of C3MH Means, Standard Deviations, and Intraclass Correlation Coefficients (ICC)

\begin{tabular}{|c|c|c|c|c|}
\hline Sub-scale & Time 1 & Time 2 & $\mathrm{ICC}^{\mathrm{a}}$ & $\mathrm{r}^{\mathrm{a}}$ \\
\hline & $\mathrm{M}(\mathrm{SD})$ & $\mathrm{M}(\mathrm{SD})$ & & \\
\hline Management: Collaborations & $4.30(.56)$ & $4.10(.70)$ & .75 & .65 \\
\hline Management: Transitions & $4.00(.74)$ & $4.09(.64)$ & .87 & .78 \\
\hline Informational: Provider Knowledge & $4.33(.63)$ & $4.41(.49)$ & .79 & .67 \\
\hline Relational: Interpersonal & $4.45(.65)$ & $4.58(.56)$ & .90 & .84 \\
\hline Relational: Consistency & $3.95(.94)$ & $4.02(.79)$ & .92 & .87 \\
\hline
\end{tabular}

Note. $N=30$.

${ }^{a}$ All correlations are significant at $p<.001$ 
Table 3.5: Convergent and Discriminant Validity Correlations for the C3MH-P

\begin{tabular}{|c|c|c|c|c|c|}
\hline & $\begin{array}{l}\text { Management: } \\
\text { Collaborations }\end{array}$ & $\begin{array}{l}\text { Management: } \\
\text { Transitions }\end{array}$ & $\begin{array}{c}\text { Informational: } \\
\text { Provider } \\
\text { Knowledge }\end{array}$ & $\begin{array}{l}\text { Relational: } \\
\text { Interpersonal }\end{array}$ & $\begin{array}{l}\text { Relational: } \\
\text { Consistency }\end{array}$ \\
\hline \multicolumn{6}{|l|}{ Convergent Validity } \\
\hline Depression (DASS-21) & -.053 & $.11^{*}$ & & -.009 & -.018 \\
\hline Anxiety (DASS-21) & .015 & -.009 & & .025 & .092 \\
\hline Stress (DASS-21) & .007 & -.085 & & -.011 & .051 \\
\hline General Stress (PSS) & .004 & -.069 & & .010 & .099 \\
\hline Satisfaction (CSQ) & $.76^{* * * *}$ & $.74 * * *$ & $.63 * * *$ & $.62 * * *$ & $.73 * * *$ \\
\hline Time in treatment & & & .11 & & .055 \\
\hline Barriers & & -.053 & & & .046 \\
\hline $\begin{array}{l}\text { Parent-rated Therapeutic Alliance } \\
\text { (WAI) }\end{array}$ & & & & $.75^{* * *}$ & $.62 * * *$ \\
\hline
\end{tabular}




\begin{tabular}{|c|c|c|c|c|c|}
\hline & $\begin{array}{l}\text { Management: } \\
\text { Collaborations }\end{array}$ & $\begin{array}{l}\text { Management: } \\
\text { Transitions }\end{array}$ & $\begin{array}{c}\text { Informational: } \\
\text { Provider } \\
\text { Knowledge }\end{array}$ & $\begin{array}{l}\text { Relational: } \\
\text { Interpersonal }\end{array}$ & $\begin{array}{l}\text { Relational: } \\
\text { Consistency }\end{array}$ \\
\hline $\begin{array}{l}\text { Clinician-rated Therapeutic Alliance } \\
\text { (WAI) }\end{array}$ & & & & $.39 * * *$ & $.18^{* *}$ \\
\hline Clinician Ratings of Continuity & & & & & \\
\hline Consistency & & & $.15^{*}$ & & -.009 \\
\hline Teamwork & -.056 & & & & \\
\hline Service linkages & & .067 & & & \\
\hline Overall coordination & .007 & .078 & .061 & $.14^{*}$ & .081 \\
\hline Child adjustment (BCFPI) & & & & & \\
\hline Internalizing & .10 & -.016 & $.17 * *$ & .077 & $.11^{*}$ \\
\hline Externalizing & -.077 & $-.14 * *$ & .024 & $-.11 *$ & .02 \\
\hline Total Problem & .013 & $-.12 *$ & .092 & -.023 & .086 \\
\hline
\end{tabular}




\begin{tabular}{|c|c|c|c|c|c|}
\hline & $\begin{array}{l}\text { Management: } \\
\text { Collaborations }\end{array}$ & $\begin{array}{c}\text { Management: } \\
\text { Transitions }\end{array}$ & $\begin{array}{c}\text { Informational: } \\
\text { Provider } \\
\text { Knowledge }\end{array}$ & $\begin{array}{c}\text { Relational: } \\
\text { Interpersonal }\end{array}$ & $\begin{array}{l}\text { Relational: } \\
\text { Consistency }\end{array}$ \\
\hline Child Impairment & -.048 & $-.12 *$ & -.014 & -.09 & -.014 \\
\hline Impact on Family & -.11 & $-.25 * * *$ & -.086 & $-.18 * *$ & -.086 \\
\hline \multicolumn{6}{|l|}{ Discriminant Validity } \\
\hline \multicolumn{6}{|l|}{ Social Desirability (BIDR) } \\
\hline Impression Management & .07 & .04 & .06 & .002 & .05 \\
\hline IDEAS scale (NEO-PI-R) & .07 & .02 & .08 & .07 & .08 \\
\hline
\end{tabular}

Note. $\mathrm{N}=355$.

$* p<.05$

$* * p<.01$

$* * * p<.001$

blank cell $=$ not tested as no relations between scales were hypothesized 
Table 3.6: C3MH Parent Scale Comparisons between Agencies with $\mathbf{n}>15$

\begin{tabular}{|c|c|c|c|c|}
\hline Scale & $d f 1$ & $d f 2$ & $F$ & $p$ \\
\hline Management: Collaboration & 7 & 318 & 1.26 & .270 \\
\hline Management: Transitions & 7 & 317 & .70 & .675 \\
\hline Informational: Provider Knowledge & 7 & 318 & 1.34 & .232 \\
\hline Relational: Interpersonal $^{\mathrm{a}}$ & 7 & 112.62 & 1.09 & .377 \\
\hline Relational: Consistency ${ }^{\mathrm{a}}$ & 7 & 111.99 & 2.03 & .057 \\
\hline
\end{tabular}

${ }^{a}$ Used Welch's $F$ because of inequality of variances

$N=326 ; 8$ agencies. 


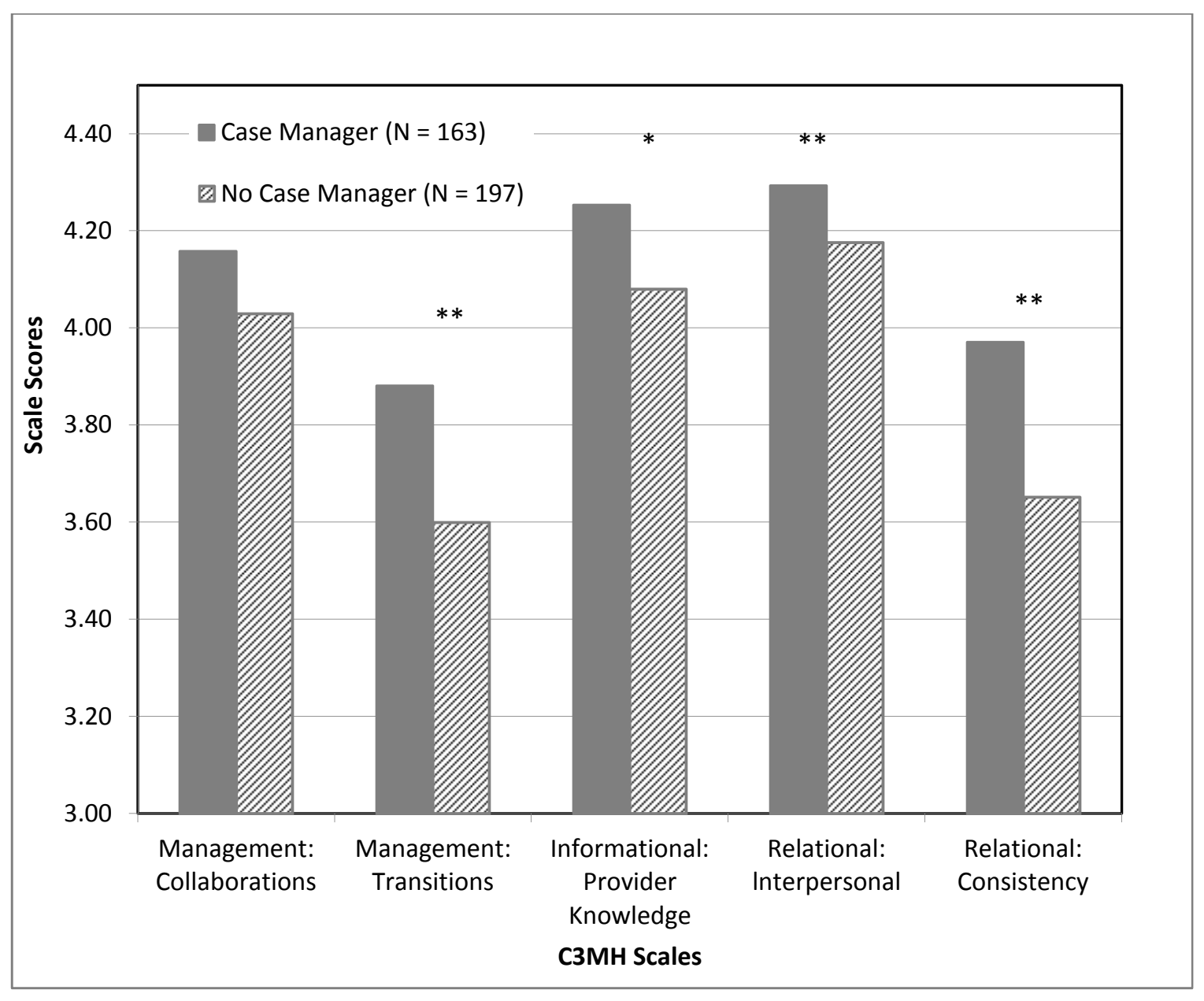

Figure 3.1: Mean Scale Scores by Group: Case Manager vs. No Case Manager

Note. Mean scale scores were compared using $t$-tests for two groups: those with and without a case manager.

$$
\begin{aligned}
& * p<.05 \\
& * * p<.01
\end{aligned}
$$




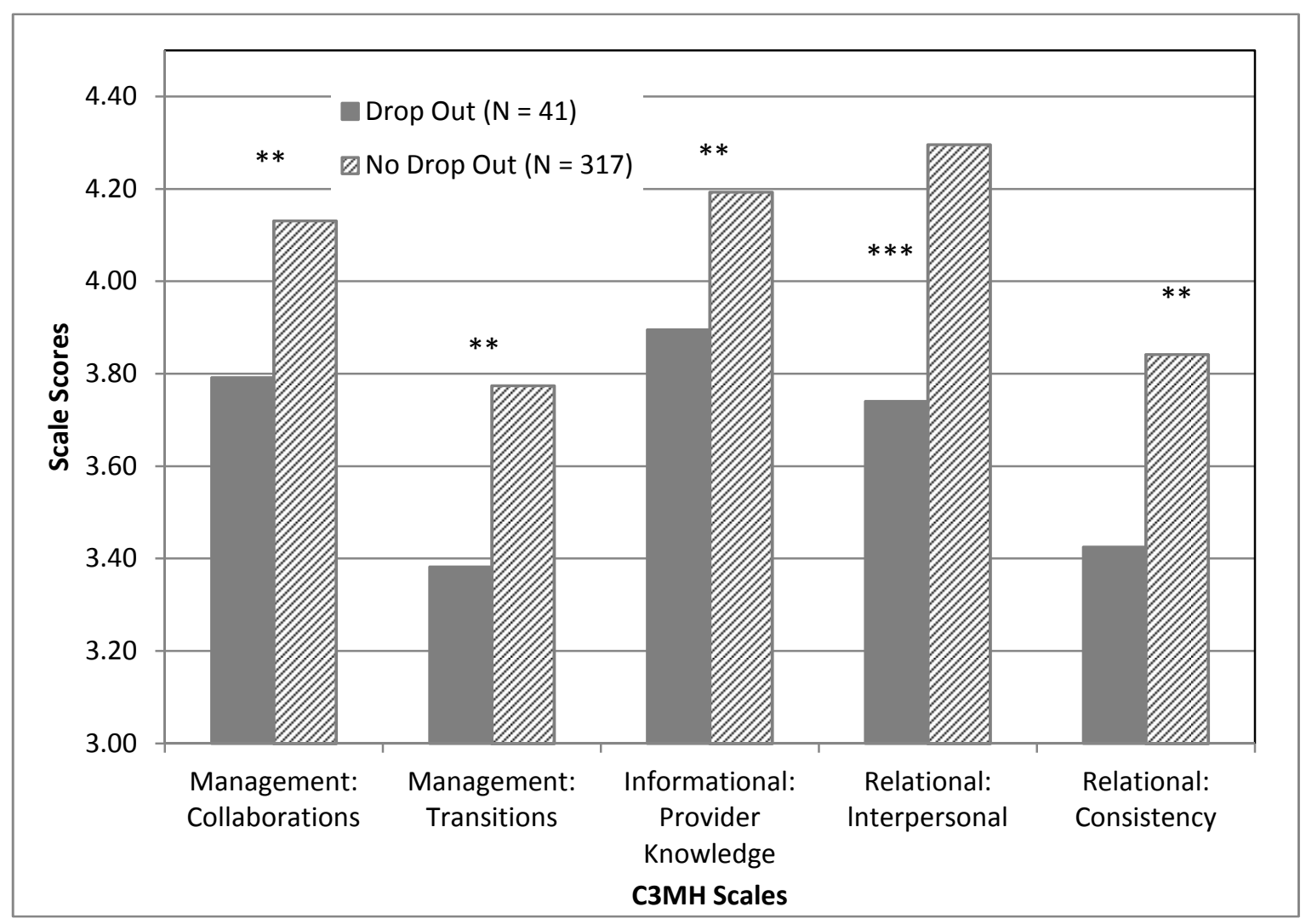

Figure 3.2: Mean Scale Scores by Group: Drop Out vs. No Drop Out

Note. Mean scale scores were compared using $t$-tests for two groups: those who had dropped out and those who had not. Parents were asked if they had stopped services at the agency before they were completed (i.e., stopped treatment early, stopped attending treatment, dropped out from service). Those who responded 'yes' were classified in the 'drop out' group.

$* * p<.01$

$* * * p<.001$ 


\section{Chapter 4}

\section{General Discussion}

The goal of this dissertation was to understand continuity of care from the perspective of parents and youth receiving children's mental health services, and to develop and validate a new measure of continuity of care in children's mental health. Theoretical constructs of continuity of care have been dominated by adult health services research (Miller et al., 2009). This dissertation therefore contributes to the theoretical understanding of continuity of care in children's mental health, an area that has not been explored to the extent of other areas of health services research.

In the general introduction (Chapter One), the history of continuity of care, including definitions and measurement of this concept, was reviewed across the medical, adult mental health, pediatrics, and children's mental health literatures. A series of studies were conducted to address the following objectives: (1) to describe parent, youth, and service provider perspectives on continuity of care; (2) to develop and validate a parent-report measure of continuity of care (C3MH-P) and (3) to pilot a youth-report measure $(\mathrm{C} 3 \mathrm{MH}-\mathrm{Y})$. The results of these studies will be discussed, including implications and future research directions.

In the first study, described in Chapter Two, parents, youth, and service providers involved with children's mental health services, were interviewed in a qualitative study using a semi-structured interview. Findings from this study affirmed the broad categories of relational, informational, and management continuity described by Reid et al. (2002), and included additional sub-themes unique to children's mental health, such as family and child involvement in treatment, and cross-sector coordination. These findings enrich our understanding of continuity as framed in the literature by expanding upon previous models and adapting them to the complex field of children's mental health. In particular, these studies added the concepts of family participation and collaboration, and 
highlighted specific transition points in children's mental health care that create a risk of discontinuity.

Overall, parents, youth, and service providers consistently valued continuity of care as an essential process of children's mental health care. Transitions emerged as a particular risk for discontinuity, especially at intake, when a family changed clinicians, or when a family returned for services. These transitions particularly affected relational continuity, as families and youth generally expressed a desire to continue with the same provider, although this was not always possible. In general, however, it was clear that individual efforts at the level of the service provider to bridge gaps helped to ease transitions and improve continuity, which families appreciated. The consequences of discontinuity included dissatisfaction, having to repeat their story, and parents taking the lead in coordinating services for their families. These consequences are key findings from this study that contribute to our understanding of potential psychological implications of discontinuity. Psychologically, a consistent core of personnel gives a patient a sense of predictability and coherence in their care (Haggerty et al., 2003); conversely, discontinuity, experienced as gaps, especially at transition points, can lead to a sense of incoherence and disorder. Sense of coherence, which Antonovsky (1979) defines as "The extent to which one has a pervasive, enduring though dynamic, feeling of confidence that one's environment is predictable and that things will work out as well as can reasonably be expected" (p.123), has been strongly related to perceived health and mental health (Eriksson \& Lindström, 2006). Thus, increased continuity of services through consistent personnel may lead to better-perceived mental health through an increased sense of coherence.

The second study, described in Chapter Three, involved creating the C3MH-P questionnaire and validating it using a sample of 364 parents recruited from 13 children's mental health $(\mathrm{CMH})$ agencies. In addition, a youth-report measure (C3MH-Y) was created and piloted with 57 youth (see Chapter Three). Quotes from the qualitative interviews (e.g., "I had to repeat my history every time we needed help") were used to generate items for the $\mathrm{C} 3 \mathrm{MH}$ questionnaire. For the $\mathrm{C} 3 \mathrm{MH}-\mathrm{P}$, after eliminating poor 
items based on item-level analyses and factor analysis, five scales were supported with an excellent fit using confirmatory factor analysis, and suitable internal consistency and testretest reliability were demonstrated. Overall, most of the hypothesized relationships between the scales and expected measures emerged. The $\mathrm{C} 3 \mathrm{MH}$ scales were related to: satisfaction with services, having a case manager, and dropping out of treatment. The relational continuity scales were related to therapeutic alliance, and the transitions scale was negatively related to parental depression and child problem severity, impairment, and impact of problems on the family. Notably, family characteristics and demographic variables did not influence parents' or youths' perceptions of continuity, which is an important finding, given that these factors may be expected to affect continuity of care.

\subsection{Transitions as a Sentinel Scale}

The combined results of these studies indicate that transitions are a specific risk to continuity, and that measurement of continuity at transition points is particularly sensitive to discontinuity and its relationship to expected outcomes, such as problem severity, parental depression, and impact of the problems on the family. Certainly, when services are functioning in a smooth and coordinated manner, continuity becomes more difficult to measure from the perspective of the patient. It is when this coordination breaks down and negatively impacts the patient that lack of continuity becomes more evident (Freeman \& Hughes, 2010). Successful transitions enhance continuity, while poorly executed transitions undermine continuity (Ware, Dickey, Tugenberg, \& McHorney, 2003). Thus, transition points become a means of exploring potential discontinuities (Freeman et al., 2007). Continuity across transitions was part of the Maudsley Continuing Care Study (Johnson, Prosser, Bindman, \& Szmukler, 1997), as well as the CONNECT study (Ware et al., 2003). The analyses presented as part of the dissertation indicate that the transitions scale, included in the core measure that all parents complete, is a particularly sensitive scale, and can therefore be viewed as a "sentinel," or a key indicator, of continuity of care. In the CONNECT scale, transitions were included as modules administered only to patients who had experienced particular transitions in the preceding year. A similar "modular" approach was also taken as part of 
the development of the $\mathrm{C} 3 \mathrm{MH}$, in which only parents and youth who had experienced particular transitions completed particular modules (i.e., discharge, change in providers, and involvement in other sectors). The description and analyses of these modules is the focus of a parallel line of research and as such is not included this dissertation.

\subsection{Family Participation and Collaboration}

Family participation emerged as an important theme in the qualitative study, and, as such, a scale for the $\mathrm{C} 3 \mathrm{MH}$ (i.e., collaboration scale) was developed to assess his element of continuity. Items include: "I felt involved in decisions about my child's care;" and "I was asked what I wanted out of treatment for my child/family". The link between family participation and service coordination in children's mental health has been demonstrated in a previous study that found that families with higher participation tended to view services as more coordinated (Koren et al., 1997). Families who participate in services may play an active role in increasing continuity, but they may also have greater opportunity to observe coordination efforts that they may have otherwise missed (Koren et al., 1997). In general, family participation in care is a key principle of family-centred services and the system of care philosophy in children's mental health (Friesen \& Koroloff, 1990; Hernandez et al., 2001). Thus, its emergence as a theme in the qualitative study, and its support as a scale in the $\mathrm{C} 3 \mathrm{MH}$, is consistent with children's mental health service principles and previous research. The inclusion of family participation in the conceptualization of continuity of care is a unique contribution of this dissertation to the construct of continuity, which has been primarily based on adult services and has not included this theme. Findings from these studies can be applied to family-centred models of care, which emphasize building care around children and families (MacKean, Thurston, \& Scott, 2005), and include service coordination strategies such as the provision of key workers (Sloper, Greco, Beecham, \& Webb, 2006). Consistent with the findings of a study on continuity of care for children with chronic health conditions, parents in the qualitative study reported actively coordinating their child's care, which merits recognition and support (Miller et al., 2009). The inclusion of a key worker to help coordinate services for families may be more appropriate for some families than others, 
and would have to be discussed between families and service providers to determine the most appropriate service-level intervention that meets the families needs.

\subsection{Significance of the Dissertation}

In children's mental health, recent policy and related system reform efforts have emphasized the need to improve the coordination of services and to include service users in this process (Government of Ontario, 2011). The results of this dissertation support the renewed emphasis on service coordination and collaboration and the need to include parents and youth in the discussion aimed at understanding and evaluating the children's mental health system (Lebow, 1982; Young, Nicholson, \& Davis, 1995).

In 2003, Adair and colleagues provided a brief history of the concept of continuity of care, and identified optimal characteristics of a continuity of care measure (Adair, 2003). The current instrument, which is the only continuity of care measure developed specifically for children's mental health, fulfills all of their criteria. The C3MH is (1) a multidimensional instrument, with (2) good psychometric properties, developed from (3) the patient and family perspective and experience of continuity of care. Furthermore, it has utility across service interfaces across multiple levels of the service delivery system (Adair, 2003).

Theoretically, this dissertation contributed to the literature on continuity of care by affirming that the constructs of relational, informational, and management continuity were applicable to this population, but the analyses of both studies revealed a more complex conceptualization of continuity, while also examining its correlates and consequences. Specifically, these studies added the concepts of family participation and collaboration, and highlighted specific transition points in children's mental health care that create a risk of discontinuity. The development of "modules" that address continuity between sectors, which is a unique contribution to the field, is ongoing and part of the larger research program. 
Overall, this dissertation addresses the first two aspects of the "triple challenge" proposed by Wierdsma and colleagues (2009): "to clarify the concept, to develop comprehensive measures, and to design and test effective interventions that will improve continuity of mental health care" (p.56). The third challenge, to test effective interventions that will improve continuity of care, is the subject of future research.

\subsection{Limitations}

Before discussing future research directions, it is necessary to review some limitations of the studies conducted for this dissertation. First, the nature of the study sample should be addressed. Only families who had already received at least three faceto-face visits were recruited from participating $\mathrm{CMH}$ agencies in Ontario and only those who volunteered went on to participate. Given the inclusion criteria of having at least three face-to-face visits, these studies did not assess access to mental health services, which is an important area of research. In order to measure continuity of services, families had to have experienced services, so the decision was made to focus on these families instead of families who had not accessed care. Access to services continues to be an important area of research that has been investigated previously (Cheung \& Dewa, 2007; Davidson \& Manion, 1996; Offord, Boyle, Fleming, \& Blum, 1989), but was not the focus of these studies.

Families were recruited exclusively through participating CMH agencies. Ideally, families' experiences of continuity would be assessed from the point at which they begin their current episode of mental health service use, regardless of the point of entry into the "system." The logistics of such as study, however, are untenable. It is possible that families who accessed services through other sectors, such as child welfare, or education, may have been systematically different than families in these studies. Koren (1997), for example, found that for families in the United States whose plans were the responsibility of a child welfare agency, service coordination tended to be viewed as better than for families working with $\mathrm{CMH}$ agencies or educational organizations. It is noted that child welfare agencies tend to have strong case management components, which may explain 
this difference. Thus, it is possible that families recruited from different service sectors may have reported different levels of continuity.

Families voluntarily participated in the study. These families may have taken a more active role in their care, which may result in higher continuity scores. The study sample of voluntary participants was more educated and had higher income compared to all families seen at $\mathrm{CMH}$ agencies in Ontario. It is possible that these families had systematically different perceptions of continuity. Within the sample, however, no differences emerged on the continuity scales for education or income, suggesting that the sociodemographic differences in the current sample may not have systematically biased the findings. There were no differences between the samples on child psychopathology, which is important, given the associations between continuity and problem severity.

Finally, the sample was recruited from 13 agencies in Ontario, which included both rural and urban populations. Continuity of care has broad relevance for jurisdictions outside of Ontario. Therefore, these instruments should be validated with larger and more varied samples in other provinces, as well as in the United States. Notably, there were no significant differences between the agencies included in the validation study, which provides some evidence for the applicability of the instrument across CMH agencies within Ontario.

The instrument itself requires a Grade 7 reading level. Although this is the recommended level for questionnaires, we acknowledge that this excludes parents and youth from participating if they have difficulty reading at this level and may also be problematic for individuals for whom English is a second language. It is possible that this questionnaire may be administered with the support of someone who can read the instrument aloud to parents or youth and record their responses. A note of caution is warranted in this respect as the instrument was validated using only self-report, and a response bias would be introduced if the person aiding the respondent were affiliated with the agency. For example, parents and youth may not be comfortable disclosing their perceptions of the services if a staff member of the agency is recording their responses. In addition, the questionnaire was designed in the English language, which also excludes 
parents and youth who do not read English. The development of a new instrument typically involves first developing the measure in a primary language, and future studies examine the validity of other language versions of the instrument. Ideally, this instrument will undergo validation with versions in other languages.

\subsection{Future Research}

The current studies represent a first step in the process of developing and validating the $\mathrm{C} 3 \mathrm{MH}$. There are two primary avenues for future research using the $\mathrm{C} 3 \mathrm{MH}$. First, the youth measure, which demonstrated promising findings in the pilot study, should be validated using a large sample of youth. Other validation studies for the $\mathrm{C} 3 \mathrm{MH}$ parent measure should include large samples from other jurisdictions, as well as other language versions, such as French (in Canada) and Spanish (in the United States). The second avenue of future research involves using the $\mathrm{C} 3 \mathrm{MH}$ as an evaluation tool to determine whether service-level reforms, which are aimed at improving service coordination, are in fact impacting continuity of care from the perspective of service users (see, for example, Durbin, Goering, Streiner, \& Pink, 2006). For example, the community-led Service Collaboratives (CAMH, 2012), which are lead by the Centre for Addiction and Mental Health in order to advance Ontario's Comprehensive Mental Health and Addictions Strategy (Government of Ontario, 2011), are focused on improving access and coordination between the various sectors providing services to children and youth. Understanding and evaluating these efforts will require the use of tools such as the $\mathrm{C} 3 \mathrm{MH}$. For example, matched comparisons can be made between sites that have implemented initiatives to improve continuity versus those that have not using the $\mathrm{C} 3 \mathrm{MH}$.

A broad avenue of future research in the area of health services research remains examining the link between service delivery and clinical improvement. Numerous studies, including the Fort Bragg study, have repeatedly failed to show an impact of system-level reforms to increase integration and coordination on clinical outcomes (Bickman, 1996; Goldman, Morrissey, \& Ridgely, 1994; Hamner, Lamberg, \& Bickman, 1997; Lehman, Postrado, Roth, McNary, \& Goldman, 1994; Weisz, Han, \& Valeri, 
1997). As such, the focus on improving service delivery has been proposed as an ethical principle (Thornicroft \& Tansella, 1999), independent of its potential relation to individual outcomes. As Ware et al. (2003) suggest, it is necessary to examine the basic question of what outcomes should be expected from mental health services and what aspects of care will contribute positively to these outcomes. While the principle of providing a good continuum of care, especially in order to overcome historical fragmentation of services remains important, future research should examine the link between good continuity of care (measured using multidimensional, validated instruments from the patient or family perspective) and clinical outcomes. Such research should take into account the use of evidence-based interventions at the individual level (Weisz et al., 1997), such that system reforms designed to improve continuity of care do not become an "impressive structure" built on a "weak foundation" (Bickman, 1996, p.695), as has been suggested to have occurred in the Fort Bragg study. 


\section{References}

Adair, C. E. (2003). History and measurement of continuity of care in mental health services and evidence of its role in outcomes. Psychiatric Services, 54, 1351-1356. doi:10.1176/appi.ps.54.10.1351

Antonovsky, A. (1979). Health, stress, and coping. San Francisco, CA: Jossey-Bass.

Bickman, L. (1996). A continuum of care: More is not always better. American Psychologist, 51, 689-701. doi:10.1037/0003-066X.51.7.689

CAMH. (2012). System improvements through service collaboratives. Retrieved from http://everykid.on.ca/wp-content/uploads/2012/07/SISC-Brochure-FINAL.pdf

Cheung, A. H., \& Dewa, C. S. (2007). Mental health service use among adolescents and young adults with major depressive disorder and suicidality. Canadian Journal of Psychiatry, 52, 228-232. Retrieved from http://cat.inist.fr/?aModele=afficheN\&cpsidt=18725886

Davidson, S., \& Manion, I. G. (1996). Facing the challenge: Mental health and illness in Canadian youth. Psychology, Health \& Medicine, 1, 41-56. Retrieved from http://www.tandfonline.com/doi/abs/10.1080/13548509608400005

Durbin, J., Goering, P., Streiner, D. L., \& Pink, G. (2006). Does systems integration affect continuity of mental health care? Administration and Policy in Mental Health and Mental Health Services Research, 33, 705-717. doi:10.1007/s10488-006-00876

Eriksson, M., \& Lindström, B. (2006). Antonovsky's sense of coherence scale and the relation with health: A systematic review. Journal of Epidemiology and Community Health, 60, 376-381. Retrieved from http://www.ncbi.nlm.nih.gov/pmc/articles/PMC2563977/ 
Freeman, G.K., Woloshynowych, M. Baker, R., Boulton, M., Guthrie, J. Car, B., ... Tarrant, C. (2007). Continuity of care 2006: What have we learned since 2000 and what are policy imperatives now. Report for the national co-ordinating center for NHS Service Delivery and Organisation $R \& D(N C C S D O)$. Retrieved from http://www.sdo.nihr.ac.uk/files/project/138-final-report.pdf

Freeman, G. K., \& Hughes, J. (2010). Continuity of Care and the Patient Experience: An Inquiry into the Quality of General Practice in England. London, England: The King's Fund.

Friesen, B. J., \& Koroloff, N. M. (1990). Family-centered services: Implications for mental health administration and research. The Journal of Behavioral Health Services and Research, 17, 13-25. Retrieved from http://www.springerlink.com/index/0j8t2487v8010k22.pdf

Goldman, H. H., Morrissey, J. P., \& Ridgely, M. S. (1994). Evaluating the Robert Wood Johnson Foundation program on chronic mental illness. The Milbank Quarterly, 3747. Retrieved from http://www.jstor.org/stable/10.2307/3350337

Government of Ontario. (2011). Open Minds, Healthy Minds: Ontario's Comprehensive Mental Health and Addictions Strategy. Retrieved from http://www.health.gov.on.ca/en/common/ministry/publications/reports/mental_healt h2011/mentalhealth.aspx

Haggerty, J. L., Reid, R. J., Freeman, G. K., Starfield, B. H., Adair, C. E., \& McKendry, R. (2003). Continuity of care: a multidisciplinary review. British Medical Journal, 327, 1219-1221. doi:10.1136/bmj.327.7425.1219

Hamner, K. M., Lamberg, E. W., \& Bickman, L. (1997). Children's mental health in a continuum of care: Clinical outcomes at 18 months for the Fort Bragg demonstration. The Journal of Behavioral Health Services and Research, 24, 465471. Retrieved from http://www.springerlink.com/index/C064336912311Q70.pdf 
Hernandez, M., Gomez, A., Lipien, L., Greenbaum, P. E., Armstrong, K. H., \& Gonzalez, P. (2001). Use of the system-of-care practice review in the national evaluation: Evaluating the fidelity of practice to system-of-care principles. Journal of Emotional and Behavioral Disorders, 9, R-43-52. doi:10.1177/106342660100900105

Johnson, S., Prosser, D., Bindman, J., \& Szmukler, G. (1997). Continuity of care for the severely mentally ill: Concepts and measures. Social Psychiatry and Psychiatric Epidemiology, 32, 137-142. Retrieved from ISI:A1997WT90200003

Koren, P. E., Paulson, R. I., Kinney, R. F., Yatchmenoff, D. K., Gordon, L. J., \& DeChillo, N. (1997). Service coordination in children's mental health: An empirical study from the caregiver's perspective. Journal of Emotional and Behavioral Disorders, 5, 162-172. doi:10.1177/106342669700500304

Lebow, J. (1982). Pragmatic decisions in the evaluation of consumer satisfaction with mental health treatment. Evaluation and Program Planning, 5, 349-356. Retrieved from http://www.sciencedirect.com/science/article/pii/0149718982900076

Lehman, A. F., Postrado, L. T., Roth, D., McNary, S. W., \& Goldman, H. H. (1994). Continuity of care and client outcomes in the Robert Wood Johnson Foundation program on chronic mental illness. The Milbank Quarterly, 105-122. Retrieved from http://www.jstor.org/stable/10.2307/3350340

MacKean, G. L., Thurston, W. E., \& Scott, C. M. (2005). Bridging the divide between families and health professionals' perspectives on family $\square$ centred care. Health Expectations, 8, 74-85. Retrieved from http://www.researchgate.net/publication/8020412_Bridging_the_divide_between_fa milies_and_health_professionals'_perspectives_on_familycentred_care/file/9fcfd50d385527181b.pdf

Miller, A. R., Condin, C. J., McKellin, W. H., Shaw, N., Klassen, A. F., \& Sheps, S. (2009). Continuity of care for children with complex chronic health conditions: 
Parents' perspectives. BMC Health Services Research, 9, 242. Retrieved from http://www.biomedcentral.com/1472-6963/9/242/

Offord, D. R., Boyle, M. H., Fleming, J. E., \& Blum, H. M. (1989). Summary of selected results. The Canadian Journal of Psychiatry/La Revue canadienne de psychiatrie,. Retrieved from http://psycnet.apa.org/psycinfo/1990-04596-001

Reid, R., Haggerty, J., \& McKendry, R. (2002). Defusing the confusion: Concepts and measures of continuity of healthcare. Ottawa, ON: Canadian Health Services Research Foundation. Retrieved from http://www.chsrf.ca/Migrated/PDF/ResearchReports/CommissionedResearch/cr_co ntcare_e.pdf

Sloper, P., Greco, V., Beecham, J., \& Webb, R. (2006). Key worker services for disabled children: What characteristics of services lead to better outcomes for children and families? Child: Care, Health and Development, 32, 147-157. Retrieved from http://eprints.whiterose.ac.uk/archive/00000973/01/sloperp1_keywk_cchd.pdf

Thornicroft, G., \& Tansella, M. (1999). Translating ethical principles into outcome measures for mental health service research. Psychological Medicine, 29, 761-767. doi:10.1017/S0033291798008034

Ware, N. C., Dickey, B., Tugenberg, T., \& McHorney, C. A. (2003). CONNECT: A measure of continuity of care in mental health services. Mental Health Services Research, 5, 209-221. Retrieved from PM:14672500

Weisz, J. R., Han, S. S., \& Valeri, S. M. (1997). More of what? Issues raised by the Fort Bragg study. American Psychologist, 52, 541-545. doi:10.1037/0003066X.52.5.541

Wierdsma, A., Mulder, C., de Vries, S., \& Sytema, S. (2009). Reconstructing continuity of care in mental health services: a multilevel conceptual framework. Journal of Health Services Research \& Policy, 14, 52-57. doi:10.1258/jhsrp.2008.008039 
Young, S. C., Nicholson, J., \& Davis, M. (1995). An overview of issues in research on consumer satisfaction with child and adolescent mental health services. Journal of Child and Family Studies, 4, 219-238. Retrieved from http://www.springerlink.com/index/L8G51K574N46462M.pdf 


\section{Appendices}

\section{Appendix A: Definitions}

\begin{tabular}{|c|c|c|}
\hline Author(s) & Year & Definition of Continuity \\
\hline Byrd J.T. & $(1972)$ & "Appropriate care and treatment in accord with the needs of the client." \\
\hline Bass R.D. \& Windle C. & $(1972)$ & $\begin{array}{l}\text { "Relatedness between present and past care in conformity with client's therapeutic needs." Operationally, } \\
\text { continuity of care exists when: " } 1 \text {. there are no obstacles to a client remaining in or moving between services in } \\
\text { conformity with his therapeutic needs; } 2 \text {. administrative mechanisms relate present and past care by providing a) } \\
\text { stable client-caretaker relationships; b) necessary written and verbal communication among staff within and } \\
\text { between the center's services; and c) contacts with clients who appear to be dropping out of treatment or lost } \\
\text { during transfer between treatment persons or services." }\end{array}$ \\
\hline Hansen, M.F. & $(1975)$ & $\begin{array}{l}\text { Three elements: 1. "A continuing relationship between a physician or health professional and a patient"; } 2 . \\
\text { "Continuity of data or information"; 3. "The actual accomplishment of care itself." }\end{array}$ \\
\hline Hennen B.K. & $(1975)$ & $\begin{array}{l}\text { Four dimensions of "continuity of environment": 1) chronological - "Those aspects of health applied to changes } \\
\text { over time, such as individual human development and family development." 2) geographical - "the provision of } \\
\text { primary care regardless of the site." 3) interdisciplinary - "those aspects of continuity that cross the traditional } \\
\text { clinical disciplines." 4) interpersonal -“Includes doctor-patient relationships, interpersonal family relationships, } \\
\text { and interprofessional relationships." }\end{array}$ \\
\hline
\end{tabular}




Author(s) Year Definition of Continuity

McGuire H.D.

Cook, R.L.

Test M.A.

Bachrach, L

Eriksson E.A., Mattsson L.

Brody S.J.
(1976) “...[A]n uninterrupted succession of care, a planned effort on the part of providers to assure patients continuity of services, if not by the same individual on all occasions, at least by health professionals who are familiar with the patient's condition and treatment program. This also implies uninterrupted succession when the patient's needs require a transfer to another source of care..."

(1979) "Continuity involves (1) patient participation in the planning, implementation, evaluation, and revision of his/her nursing care based on reliable information; and (2) the continuous flow of relevant information about the patient between appropriate health-team members."

(1979) Dimensions of continuity: 1. "Cross-sectional care" - "at any given point in a chronically mentally ill person's treatment, the person must be involved in a system of care that is comprehensive (in meeting unmet needs) and integrated." 2. "Longitudinal continuity" - "care that is continuous and integrated over time."

(1981) "Continuity of care may be understood as a process involving the orderly, uninterrupted movement of patients among the diverse elements of the service delivery system." Dimensions of continuity: temporal (longitudinal), individual (patient-centred), cross-sectional (comprehensive), flexibility (not a linear progression), relationship (between patient and providers), accessibility, and communication (between patient and providers)

(1983) "The extent to which the same provider is seen during a sequence of visits."

(1986) "Continuity of care embraces all providers with as many of the services delivered in concert or separately as required." 


\begin{tabular}{|c|c|c|}
\hline Author(s) & Year & Definition of Continuity \\
\hline Torrey E.F. & (1986) & $\begin{array}{l}\text { "A process involving the orderly, uninterrupted movement of patients among the diverse elements of the service } \\
\text { delivery system." }\end{array}$ \\
\hline Bachrach, L. & (1987) & $\begin{array}{l}\text { "Continuity of care means that the patient will be able to receive all of the different services that he or she needs, } \\
\text { even though the service system is fragmented and even though many different service delivery agencies must be } \\
\text { involved in his or her treatment." It also means that "the service system must be accessible to the patient, accessible } \\
\text { in many different ways" including psychological access, financial access, geographic access and access over long } \\
\text { periods. }\end{array}$ \\
\hline
\end{tabular}

Baker F., Vischi T.

Shegda L.M., McCorkle R.

Brekke J.S., Test M.A.
(1989) Seven dimensions of continuity: "1) longitudinal - client treatment matches client progress even if care givers, treatment modalities or treatment sites change; 2 ) individualized - client care is planned for and with particular clients and their families; 3 ) comprehensive - the full range of services needed by a patient are made available; 4) flexible - the services provided to a client change as that individual's needs change; 5) personal - clients can rely on relationships with a person or persons interested in them as individuals; 6) accessible - service delivery to a client is experienced as free of barriers; 7) informative - continuity of information exists through open communications between client and service providers"

(1990) "Coordinated process of activities that involves the client and health care providers working together to facilitate the transition of health care from one institution, agency or individual to another."

(1992) 2 dimensions: "cross-sectional "continuity refers to the need at any one point in time for the client to be involved in a system of care that is comprehensive and integrated." "Longitudinal continuity means care that is continuous and integrated over time." 


\begin{tabular}{lll}
\hline Author(s) $\quad$ Year $\quad$ Definition of Continuity \\
\hline
\end{tabular}

Rosenbaum P.L., King S.M.,

Cadman D.T.

Van Achterberg, T., Stevens,

F.C., Crebolder, H.F., et al.

Bickman, L.
(1992) Continuity and consistency of care: "Provide continuity over time such that the same professionals act as regular providers of care. Link information from one visit to another and one professional/caregiver to another."

Coordination of care: "Recognize the need for services from other sources and make referral. Ensure information is shared among those involved in the child's care. Act as liaison with school, specialists, agencies and others involved in caregiving by providing necessary link or follow-up of required services."

(1996) "Interdisciplinary continuity can be seen as continuity in complex, multidisciplinary services. Appropriate referrals and coordination of services are examples of interdisciplinary continuity. Interpersonal continuity involves the quality and the endurance of relationships between clients and care providers. ...Informational continuity refers to the completeness of information available to and documented by care givers, thus preventing unnecessary or duplicate care or treatment."

(1996) Continuum of care: "availability (and accessibility) to the full range and level of mental health services required to meet the changing needs of children with mental health disorders." Continuity of care: "The delivery of coordinated services on an individualized basis." 


\begin{tabular}{lll}
\hline Author(s) $\quad$ Year $\quad$ Definition of Continuity \\
\hline
\end{tabular}

Alegria M., Pescosolido B.A.,

Santo D., et al.

Elder W.G.

Johnson S., Prosser D.,

Bindman J.

Meijer W.J., Vermeij D.J.B.
(1997) "Single provider continuity occurs when 1) one provider is seen in three of more visits within a six month period, 2) for the same problem (as defined by the respondent) and 3) without a gap of more than two months within that period unless the problem is reported to be solved." "Multiple provider continuity occurs when 1) at least one member in a team of providers is seen in three or more visits within a six month period, 2) for the same problem (as defined by the respondent), 3) without a gap of more than two months within that period unless the problem is reported to be solved and 4) with an explicit referral or sharing of information among the providers." "System continuity is the situation in which 1) 3 or more visits occur within a six month period, 2) for the same problem (as defined by the respondent), 3) without a gap of more than two months within that period, 4) within the same system (public or private) of care." "Sector continuity represents the situation where there are 1) 3 or more visits occur within a six month period, 2) for the same problem (as defined by the respondent), 3) without a gap of more than two months within that period unless the problem is reported to be solved and 4) within the same sector of care."

(1997) Continuity of care: "continuous relationship with a provider or clinic throughout an episode of care." Continuum of care: "matching patient need with appropriate type and intensity of care over trajectory of illness."

(1997) Cross-sectional aspects: "continuity between service providers, comprehensiveness, and accessibility." Longitudinal aspects: "continuity of contact (does the service stay in contact with the patient), continuity of provider, continuity through discharges and transfers, implementation of service plans."

(1997) "Continuity of care implies continuity of caregiver or coordination among practitioners, among organizations, and over time." 


\begin{tabular}{lll}
\hline Author(s) $\quad$ Year $\quad$ Definition of Continuity \\
\hline
\end{tabular}

Citro R., Ghosh S., Churgin

P.G.

Saarento O., Öiesvold T.,

Sytema S., et al.

Brekke J.S., Ansel M., Long J., et al.

Preston C., Cheater F., Baker

R., et al.

Sytema S., Burgess P.

Ware N.C., Tugenberg T.,

Dickey B., et al.
(1998) "The delivery of care in an uninterrupted and coordinated manner and in accordance with the patient's needs."

(1998) "The degree to which the service system links episodes of treatment into a seamless, uninterrupted whole, in conformity with the needs of the patient." "Continuity of care is a multidimensional concept including integration and coordination of services, communication among the various service providers and the stability of patientcaregiver relationship over time."

(1999) Longitudinal continuity - "the extent to which clients are involved in treatment continuously over time without gaps in service." Service intensity - "the number of service contacts or total duration of service contacts over a specified period."

(1999) "Receiving care from a particular professional throughout the care process, and receiving consistent, coordinated care from different staff working together."

(1999) 2 dimensions: Cross-sectional continuity is "the comprehensiveness and accessibility of services required to meet the range of needs of long term patients." Longitudinal continuity includes "continuity of service provision (sustained contact with services), continuity of service provider (i.e. patients receive services across time from the same staff), and continuity through discharges and transfers (i.e. flexible and rapid transfer between care levels according to varying needs of patients)."

(1999) "Management and treatment of [severe conditions that are chronic and debilitating] over time." Continuum of care: "a system of interventions with multiple components of varying intensity." 


Author(s)
Chien C.F., Steinwachs D.M.,

Lehman A., et al

Sparbel K.J., Anderson M.A.

Donaldson M.

Reid, R. et al.

Haggerty, J.L. et al.
Year Definition of Continuity

(2000) Continuity of care is "longitudinal care that is integrated and coordinated over time." Provider continuity is "seeing the same provider...for all mental health care over time."

(2000) "Continuity of care is a series of connected patient-care events both within a health care institution and among multiple settings. It requires coordination and linkages across time, settings, providers, and consumers of health care."

(2001) "The degree to which health care activities are structured to increase information available to a clinician and to increase the likelihood of goal alignment between the patient and the clinician."

(2002) "Continuity of care is how one patient experiences care over time as coherent and linked; this is the result of good information flow, good interpersonal skills, and good coordination of care."

(2003) "For patients and their families, the experience of continuity is the perception that the providers know what has happened before, that different providers agree on a management plan, and that a provider who knows them will care for them in the future" 


\begin{tabular}{|c|c|c|}
\hline Author(s) & Year & Definition of Continuity \\
\hline $\begin{array}{l}\text { Freeman G., Woloshynowych, } \\
\text { R.B., Boulton M., Guthrie, B., } \\
\text { Car, J. et al. }\end{array}$ & (2007) & $\begin{array}{l}\text { A multi-aspect definition of continuity with six elements: "1.The experience of a coordinated and smooth } \\
\text { progression of care from the patient's point of view (experienced continuity). To achieve this central element the } \\
\text { service needs: } 2 \text {. Excellent information transfer following the patient (continuity of information). 3. Effective } \\
\text { communication between professionals and services and with patients (cross-boundary and team continuity). 4. To } \\
\text { be flexible and adjust to the needs of the individual patient over time (flexible continuity). } 5 \text {. Care from as few } \\
\text { professionals as possible, consistent with other needs (longitudinal continuity). } 6 \text {. To provide one or more named } \\
\text { individual professionals with whom the patient can establish and maintain a therapeutic relationship (relational or } \\
\text { personal continuity)." }\end{array}$ \\
\hline $\begin{array}{l}\text { Wierdsma, Mulder, de Vries, } \\
\text { and Systema }\end{array}$ & (2009) & $\begin{array}{l}\text { "COC is interpreted as the degree to which episodes of treatment are linked in a seamless, uninterrupted whole, in } \\
\text { conformity with patients' needs [...] this definition of continuity captures four core elements: (a) continuous care, } \\
\text { i.e. episodes are linked; (b) care of an individual patient, i.e. treatment is not an attribute of the service system; (c) } \\
\text { cross-boundary care, i.e. episodes of treatment are linked in a seamless whole; and (d) care recorded objectively, } \\
\text { i.e. in conformity with patients' manifest needs" (p.53). }\end{array}$ \\
\hline
\end{tabular}

Note. See Reid et al. (2002) for a comprehensive summary of definitions of continuity of care to 2002. 


\section{Appendix A References}

Alegria, M., Pescosolido, B. A., Santos, D., \& Vera, M. (1997). Can we conceptualize and measure continuity of care in individual episodes. Sociological Focus, 30, 113 129.

Bachrach, L. L. (1981). Continuity of care for chronic mental patients: A conceptual analysis. American Journal of Psychiatry, 138, 1449-1456. Retrieved from PM:7294213

Bachrach, L. L. (1987). Continuity of care. New Directions in Mental Health Services, $35,63-73$.

Baker, F., \& Vischi, T. (1989). Continuity of care and the control of costs: Can case management assure both? Journal of Public Health Policy, 10, 204-213. doi: $10.2307 / 3342680$

Bass, R. D., \& Windle, C. (1972). Continuity of care: An approach to measurement. American Journal of Psychiatry, 129, 196-201. Retrieved from ISI:A1972N099600013

Bickman, L. (1996). A continuum of care: More is not always better. American Psychologist, 51, 689-701. doi:10.1037/0003-066X.51.7.689

Brekke, J. S., Ansel, M., Long, J., Slade, E., \& Weinstein, M. (1999). Intensity and continuity of services and functional outcomes in the rehabilitation of persons with schizophrenia. Psychiatric Services, 50, 248-256. Retrieved from PM:10030485

Brekke, J. S., \& Test, M. A. (1992). A model for measuring the implementation of community support programs: results from three sites. Community Mental Health Journal, 28, 227-247. doi:10.1007/BF00756819 
Brody, S. J. (1986). Continuity of care: The new-old health requirement. Michigan Hospitals, 22, 17. Retrieved from http://europepmc.org/abstract/MED/10311728

Byrd, J. T. (1972). An analysis of continuity of care in a community mental health center.

Chien, C. F., Steinwachs, D. M., Lehman, A., Fahey, M., \& Skinner, E. A. (2000). Provider continuity and outcomes of care for persons with schizophrenia. Mental Health Services Research Ment Health Serv Res Ment Health Serv.Res, 2, 201-211.

Citro, R., Ghosh, S., \& Churgin, P. G. (1998). Modeling and evaluation of continuity of care in a staff model HMO. M D Computing, 15, RINGER VERLAG 175 FIFTH AVE, NEW YORK, NY 10010 USA-298-306. Retrieved from ISI:000075718300004

Cook, R. L. (1979). Continuity of care: cliche or viable nursing concept? Nursing Lteeadership, 2, 21. Retrieved from http://www.ncbi.nlm.nih.gov/pubmed/259928

Donaldson, M. S. (2001). Continuity of care: A reconceptualization. Medical Care Research and Review, 58, 255-290. doi:10.1177/107755870105800301

Elder, W. G. (1997). Who has the "relationship" in managed care? Professional Psychology-Research and Practice, 28, 405-406. doi:10.1037/07357028.28.4.405.b

Eriksson, E. A., \& Mattsson, L. G. (1983). Quantitative measurement of continuity of care: Measures in use and an alternative approach. Medical Care, 21, 858-875. Retrieved from ISI:A1983RG93200002

Freeman, G.K., Woloshynowych, M., Baker, R., Boulton, M., Guthrie, B., Car, J., ... Tarrant. C. (2007). Continuity of care 2006: What have we learned since 2000 and what are policy imperatives now. Report for the national co-ordinating center for NHS Service Delivery and Organisation $R \& D(N C C S D O)$. Retrieved from http://www.sdo.nihr.ac.uk/files/project/138-final-report.pdf 
Haggerty, J. L., Reid, R. J., Freeman, G. K., Starfield, B. H., Adair, C. E., \& McKendry, R. (2003). Continuity of care: a multidisciplinary review. British Medical Journal, 327, 1219-1221. doi:10.1136/bmj.327.7425.1219

Hansen, M. F. (1975). Continuity of care in family practice. Part 3: Measurement and evaluation of continuity of care. Journal of Family Practice, 2, 439-444.

Hennen, B. K. (1975). Continuity of care in family practice. Part 1: Dimensions of continuity. Journal of Family Practice, 2, 371-372.

Johnson, S., Prosser, D., Bindman, J., \& Szmukler, G. (1997). Continuity of care for the severely mentally ill: Concepts and measures. Social Psychiatry and Psychiatric Epidemiology, 32, 137-142. Retrieved from ISI:A1997WT90200003

Mcguire, H. D. (1976). Continuing health care: Better continuity needed. Hospitals, 50, 87-91. Retrieved from ISI:A1976BM33200011

Meijer, W. J., \& Vermeij, D. J. B. (1997). A comprehensive model of cooperation between caregivers related to quality of care. International Journal for Quality in Health Care, 9, 23-33. doi:10.1093/intqhc/9.1.23

Preston, C., Cheater, F., Baker, R., \& Hearnshaw, H. (1999). Left in limbo: Patients' views on care across the primary/secondary interface. Quality in Health Care, 8 , 16-21. doi:10.1136/qshc.8.1.16

Reid, R., Haggerty, J., \& McKendry, R. (2002). Defusing the confusion: Concepts and measures of continuity of healthcare. Ottawa, ON: Canadian Health Services Research Foundation. Retrieved from http://www.chsrf.ca/Migrated/PDF/ResearchReports/CommissionedResearch/cr_co ntcare_e.pdf

Rosenbaum, P. L., King, S. M., \& Cadman, D. T. (1992). Measuring processes of caregiving to physically disabled children and their families. I: Identifying relevant 
components of care. Developmental Medicine and Child Neurology, 34, 103-114. doi:10.1111/j.1469-8749.1992.tb14976.x

Saarento, O., Oiesvold, T., Sytema, S., Gostas, G., Kastrup, M., Lonnerberg, O., ... Hansson, L. (1998). The Nordic Comparative Study on Sectorized Psychiatry: Continuity of care related to characteristics of the psychiatric services and the patients. Social Psychiatry and Psychiatric Epidemiology Soc Psychiatry Psychiatr Epidemiol, 33, 521-527. Retrieved from ISI:000076405800001

Shegda, L. M., \& McCorkle, R. (1990). Continuing care in the community. Journal of Pain Symptom Management, 5, 279-286. doi:10.1016/0885-3924(90)90044-K

Sparbel, K. J. H., \& Anderson, M. A. (2000). Integrated literature review of continuity of care: Part 1, Conceptual issues. Journal of Nursing Scholarship, 32, 17-24. doi:10.1111/j.1547-5069.2000.00017.x

Sytema, S., \& Burgess, P. (1999). Continuity of care and readmission in two service systems: A comparative Victorian and Groningen case-register study. Acta Psychiatrica Scandinavica, 100, 212-219. doi:10.1111/j.1600-0447.1999.tb10848.x

Test, M. A. (1979). Continuity of care in community treatment. New Directions for Mental Health Services, 1979, 15-23. Retrieved from http://onlinelibrary.wiley.com/doi/10.1002/yd.23319790203/abstract

Torrey, E. F. (1986). Continuous treatment teams in the care of the chronic mentally-ill. Hospital and Community Psychiatry, 37, 1243-1247. Retrieved from ISI:A1986F109900008

Van, A.,T., Stevens, F. C. J., Crebolder, H. F. J. M., DeWitte, L. P., \& Philipsen, H. (1996). Coordination of care: Effects on the continuity and quality of care. International Journal of Nursing Studies, 33, 638-650. doi:10.1016/S00207489(96)00021-1 
Ware, N. C., Tugenberg, T., Dickey, B., \& McHorney, C. A. (1999). An ethnographic study of the meaning of continuity of care in mental health services. Psychiatric Services, 50, 395-400. Retrieved from ISI:000078959400013

Wierdsma, A., Mulder, C., de Vries, S., \& Sytema, S. (2009). Reconstructing continuity of care in mental health services: a multilevel conceptual framework. Journal of Health Services Research \& Policy, 14, 52-57. doi:10.1258/jhsrp.2008.008039 
Appendix B: Summary of Relevant Measures of Continuity of Care

\begin{tabular}{|c|c|c|c|c|c|}
\hline Measure & $\begin{array}{l}\text { Description (Type of } \\
\text { Instrument/Response } \\
\text { Categories) }\end{array}$ & Populations/Setting & $\begin{array}{l}\text { Psychometric } \\
\text { Properties }\end{array}$ & $\begin{array}{l}\text { Dimensions of } \\
\text { Continuity }\end{array}$ & $\begin{array}{l}\text { Outcomes Related to } \\
\text { Continuity }\end{array}$ \\
\hline $\begin{array}{l}\text { Perception of } \\
\text { Continuity } \\
\text { Scale (Chao } \\
\text { 1988) }\end{array}$ & $\begin{array}{l}\text { Self-administered } \\
\text { questionnaire describes the } \\
\text { ongoing physician patient } \\
\text { relationship; } 23 \text { items } \\
\text { divided into two subscales } \\
\text { "structural elements" and } \\
\text { "interpersonal elements" }\end{array}$ & Primary care & $\begin{array}{l}\text { Good internal } \\
\text { consistency } \\
\text { reliability } \\
\text { Cronbach's alpha } \\
=.86 ; \\
\text { Interpersonal scale } \\
\text { has significant face } \\
\text { validity. }\end{array}$ & $\begin{array}{l}\text { Two factors: } \\
\text { - } \quad \text { Structure of health } \\
\text { care delivery } \\
\text { - } \quad \text { Interpersonal } \\
\text { subscale }\end{array}$ & $\begin{array}{l}\text { Highly related to patient } \\
\text { satisfaction }\end{array}$ \\
\hline
\end{tabular}




\begin{tabular}{|c|c|c|c|c|c|}
\hline Measure & $\begin{array}{l}\text { Description (Type of } \\
\text { Instrument/Response } \\
\text { Categories) }\end{array}$ & Populations/Setting & $\begin{array}{l}\text { Psychometric } \\
\text { Properties }\end{array}$ & $\begin{array}{l}\text { Dimensions of } \\
\text { Continuity }\end{array}$ & $\begin{array}{l}\text { Outcomes Related to } \\
\text { Continuity }\end{array}$ \\
\hline $\begin{array}{l}\text { Measure of } \\
\text { Processes of } \\
\text { Care Scale } \\
\text { (MPOC; } \\
\text { King, } \\
\text { Rosenbaum } \\
\text { and King, } \\
\text { 1995) }\end{array}$ & $\begin{array}{l}\text { Response categories: } \\
\text { "Indicate how much this } \\
\text { event or situation happens to } \\
\text { you”: 7-point scale from } 7 \\
\text { 'To a Great Extent' to } 1 \\
\text { 'Never'; includes } 0 \text { N/A }\end{array}$ & $\begin{array}{l}\text { Parents of children with } \\
\text { disabilities involved in } \\
\text { ambulatory treatment } \\
\text { centres }\end{array}$ & $\begin{array}{l}\text { Test-retest } \\
\text { reliabilities range } \\
\text { from } .78 \text { - .88 for } \\
\text { the } 5 \text { scales; } \\
\text { internal } \\
\text { consistency } \\
\text { reliabilities range } \\
\text { from } .81 \text { - .96; } \\
\text { good evidence of } \\
\text { MPOC's validity, } \\
\text { especially related } \\
\text { to its content and } \\
\text { constructs }\end{array}$ & 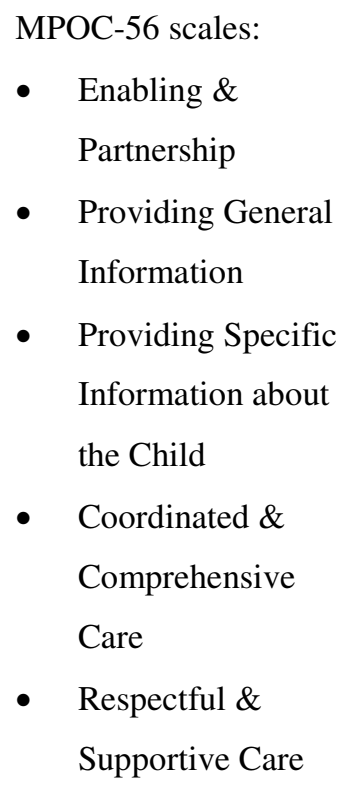 & $\begin{array}{l}\text { MPOC significant predictor } \\
\text { of parent's well-being (i.e., } \\
\text { less distress and depression) } \\
\text { (King et al., 1999) and of } \\
\text { satisfaction as measured by } \\
\text { the Client Satisfaction } \\
\text { Questionnaire (King, } \\
\text { Rosenbaum and King, 1995) }\end{array}$ \\
\hline
\end{tabular}




\begin{tabular}{|c|c|c|c|c|c|}
\hline Measure & $\begin{array}{l}\text { Description (Type of } \\
\text { Instrument/Response } \\
\text { Categories) }\end{array}$ & Populations/Setting & $\begin{array}{l}\text { Psychometric } \\
\text { Properties }\end{array}$ & $\begin{array}{l}\text { Dimensions of } \\
\text { Continuity }\end{array}$ & $\begin{array}{l}\text { Outcomes Related to } \\
\text { Continuity }\end{array}$ \\
\hline $\begin{array}{l}\text { Service } \\
\text { Coordination } \\
\text { Scale } \\
\text { (DeChillo \& } \\
\text { Lebow, } \\
\text { 1992) } \\
\text { adapted by }\end{array}$ & $\begin{array}{l}18 \text { items administered to } \\
\text { parents; reduced to } 9 \text { items; } \\
\text { 5-point scales ranging from } \\
\text { not at all to very much }\end{array}$ & $\begin{array}{l}266 \text { Caregivers whose } \\
\text { children have severe } \\
\text { emotional disabilities } \\
\text { (ages 5-18 years) }\end{array}$ & $\begin{array}{l}\text { Service } \\
\text { Coordination score } \\
\text { alpha coefficient }= \\
.88, \text { indicating a } \\
\text { high level of } \\
\text { internal } \\
\text { consistency }\end{array}$ & - Coordination & $\begin{array}{l}\text { Service coordination } \\
\text { associated with overall } \\
\text { satisfaction and } \\
\text { comprehensiveness }\end{array}$ \\
\hline
\end{tabular}




\begin{tabular}{|c|c|c|c|c|c|}
\hline Measure & $\begin{array}{l}\text { Description (Type of } \\
\text { Instrument/Response } \\
\text { Categories) }\end{array}$ & Populations/Setting & $\begin{array}{l}\text { Psychometric } \\
\text { Properties }\end{array}$ & $\begin{array}{l}\text { Dimensions of } \\
\text { Continuity }\end{array}$ & $\begin{array}{l}\text { Outcomes Related to } \\
\text { Continuity }\end{array}$ \\
\hline $\begin{array}{l}\text { Components of } \\
\text { Primary } \\
\text { Care Index } \\
\text { (CPCI; } \\
\text { Flocke, } \\
\text { 1997) }\end{array}$ & $\begin{array}{l}\text { 20-item self-report } \\
\text { questionnaire; Response } \\
\text { format: 5-point Likert-type } \\
\text { scale, ranging from } 1 \text { = } \\
\text { strongly disagree to } 5= \\
\text { strongly agree, with neutral } \\
\text { as central option }\end{array}$ & $\begin{array}{l}\text { Patients in primary care } \\
\text { setting; } N=2899 \\
\text { patients in original scale } \\
\text { development sample }\end{array}$ & $\begin{array}{l}\text { Internal } \\
\text { consistency } \\
\text { reliabilities of the } 4 \\
\text { factors ranged } \\
\text { from } .68-.79, \\
\text { which is } \\
\text { considered good. }\end{array}$ & $\begin{array}{l}\text { Four consistent factors: } \\
\text { - Interpersonal } \\
\text { Communication } \\
\text { - } \text { Accumulated } \\
\text { Knowledge } \\
\text { - Coordination of } \\
\text { Care } \\
\text { - } \quad \text { Preference to see } \\
\text { regular physician }\end{array}$ & $\begin{array}{l}\text { Each CPCI scale scores } \\
\text { significantly associated with } \\
\text { patient satisfaction with the } \\
\text { visit; Christakis et al (2003) } \\
\text { found COC index was } \\
\text { associated with Coordination } \\
\text { of Care scale from CPCI } \\
\text { using a pediatric sample } \\
\text { (parent-report) }\end{array}$ \\
\hline
\end{tabular}




\begin{tabular}{|c|c|c|c|c|c|}
\hline Measure & $\begin{array}{l}\text { Description (Type of } \\
\text { Instrument/Response } \\
\text { Categories) }\end{array}$ & Populations/Setting & $\begin{array}{l}\text { Psychometric } \\
\text { Properties }\end{array}$ & $\begin{array}{l}\text { Dimensions of } \\
\text { Continuity }\end{array}$ & $\begin{array}{l}\text { Outcomes Related to } \\
\text { Continuity }\end{array}$ \\
\hline $\begin{array}{l}\text { Alberta } \\
\text { Continuity } \\
\text { of Services } \\
\text { Scale for } \\
\text { Mental } \\
\text { Health } \\
\text { (ACSS-MH; } \\
\text { Adair et al., } \\
\text { 2004); }\end{array}$ & $\begin{array}{l}\text { Part A: 43-item multi- } \\
\text { dimensional measure } \\
\text { completed by mental health } \\
\text { care patients; 5-point scale } \\
\text { ranging from 'strongly } \\
\text { disagree' to 'strongly } \\
\text { agree'. Part B: } \\
\text { Observer/chart rating } \\
\text { completed by clinician; } 17 \\
\text { items with } 4-5 \text { categorical } \\
\text { responses per item }\end{array}$ & $\begin{array}{l}\text { Sample used in } \\
\text { developing the scale } \\
\text { ranged from more } \\
\text { acutely ill patients who } \\
\text { had recently entered the } \\
\text { mental health system to } \\
\text { patients with chronic } \\
\text { illness and long-term } \\
\text { involvement }\end{array}$ & $\begin{array}{l}\text { Good internal } \\
\text { consistency ( } .92, \\
.86, \text { and } .78) \text { and } \\
\text { split-half reliability } \\
(.88, .83 \text {, and } .77) \\
\text { for the patient- } \\
\text { rated scales; Good } \\
\text { internal } \\
\text { consistency (.60 to } \\
.95) \text { and reasonable } \\
\text { interrater reliability } \\
\text { for observer-rated } \\
\text { scale }\end{array}$ & $\begin{array}{l}\text { Three subscales: } \\
\text { - } \quad \text { System } \\
\text { fragmentation } \\
\text { (perceived } \\
\text { discontinuity } \\
\text { among services) } \\
\text { - Relationship base, } \\
\text { and } \\
\text { Responsive } \\
\text { treatment }\end{array}$ & $\begin{array}{l}\text { Better continuity associated } \\
\text { with higher community costs } \\
\text { and lower hospital costs, } \\
\text { improved quality of life, } \\
\text { community functioning and } \\
\text { satisfaction with services }\end{array}$ \\
\hline
\end{tabular}




\begin{tabular}{|c|c|c|c|c|c|}
\hline Measure & $\begin{array}{l}\text { Description (Type of } \\
\text { Instrument/Response } \\
\text { Categories) }\end{array}$ & Populations/Setting & $\begin{array}{l}\text { Psychometric } \\
\text { Properties }\end{array}$ & $\begin{array}{l}\text { Dimensions of } \\
\text { Continuity }\end{array}$ & $\begin{array}{l}\text { Outcomes Related to } \\
\text { Continuity }\end{array}$ \\
\hline $\begin{array}{l}\text { CONNECT } \\
\text { (Ware, 2003) }\end{array}$ & $\begin{array}{l}\text { 70-item fixed response } \\
\text { interview designed for } \\
\text { administration by lay } \\
\text { interviewers; 5-point scales. } \\
\text { If respondent endorses any } \\
\text { of } 5 \text { questions about } \\
\text { changes in the previous } 12 \\
\text { months (e.g., therapist who } \\
\text { left, change in housing), } \\
\text { then corresponding module } \\
\text { administered. }\end{array}$ & $\begin{array}{l}\text { Developed for use with } \\
\text { adults diagnosed with } \\
\text { serious mental illness; } \\
\text { field test had } 400 \text { people } \\
\text { with serious mental } \\
\text { illness complete } \\
\text { CONNECT }\end{array}$ & $\begin{array}{l}5 \text { of } 13 \text { scales met } \\
.80 \text { criterion for } \\
\text { internal } \\
\text { consistency; } \\
\text { remainder } \\
\text { approached the } \\
\text { standard with } \\
\text { Cronbach alpha } \\
\text { coefficients of .70 } \\
\text { or above; 2-week } \\
\text { test-retest } \\
\text { reliability indicated } \\
\text { fair-to-good } \\
\text { agreement }\end{array}$ & $\begin{array}{l}13 \text { scales and one } \\
\text { single-item indicator; } 4 \\
\text { dimensions from factor } \\
\text { analysis: } \\
\text { - Knowledge } \\
\text { - Availability } \\
\text { - Coordination } \\
\text { - } \quad \text { Flexibility }\end{array}$ & $\begin{array}{l}\text { 1) Clinical outcomes: low } \\
\text { but statistically sig. negative } \\
\text { correlations between } \\
\text { CONNECT availability } \\
\text { scales and several symptom } \\
\text { indicators (e.g., depression/ } \\
\text { anxiety) 2) Quality of life: } \\
\text { modest but consistent } \\
\text { relationship; 3) Satisfaction: } \\
\text { 12 CONNECT scales and } \\
\text { general coordination item } \\
\text { associated with satisfaction }\end{array}$ \\
\hline
\end{tabular}




\begin{tabular}{|c|c|c|c|c|c|}
\hline Measure & $\begin{array}{l}\text { Description (Type of } \\
\text { Instrument/Response } \\
\text { Categories) }\end{array}$ & Populations/Setting & $\begin{array}{l}\text { Psychometric } \\
\text { Properties }\end{array}$ & $\begin{array}{l}\text { Dimensions of } \\
\text { Continuity }\end{array}$ & $\begin{array}{l}\text { Outcomes Related to } \\
\text { Continuity }\end{array}$ \\
\hline $\begin{array}{l}\text { University of } \\
\text { South } \\
\text { Florida's } \\
\text { System of } \\
\text { Care } \\
\text { Practice } \\
\text { Review - } \\
\text { Revised } \\
\text { (SOCPR-R; } \\
\text { University of } \\
\text { South } \\
\text { Florida, } \\
\text { 2007; } \\
\text { Hernandez et } \\
\text { al., 2001) }\end{array}$ & $\begin{array}{l}\text { Semi-structured interview; } \\
\text { qualitative }\end{array}$ & $\begin{array}{l}\text { Sites (children's mental } \\
\text { health centers) } \\
\text { implementing a system } \\
\text { of care (SOC) for at } \\
\text { least } 5 \text { years compared } \\
\text { to sites using a } \\
\text { traditional service } \\
\text { delivery model }\end{array}$ & $\begin{array}{l}\text { Integration and } \\
\text { Coordination } \\
\text { subdomain } \\
\text { reliability: .80 }\end{array}$ & $\begin{array}{l}\text { Integration and } \\
\text { Coordination ( } 1 \text { of } 11 \\
\text { subdomains of } \\
\text { SOCPR) }\end{array}$ & $\begin{array}{l}\text { Overall study found that } \\
\text { SOC sites scored high than } \\
\text { non-SOC sites in all domains } \\
\text { of the SOCPR, including } \\
\text { subdomain of integration } \\
\text { and coordination. }\end{array}$ \\
\hline
\end{tabular}




\section{Appendix C: Study 1 Interview Protocol: Parents / Youth}

We are doing research on the continuity of care provided through your local children's mental health center. As part of this study, we are interviewing parents/youth to obtain their perspective and experience of continuity of care. You have been asked to participate because you have already received services from an agency on at least two occasions and may be involved with multiple service providers.

1. Tell me about your experiences at [agency name]

Probes:

- What was it like to seek help for the first time at [agency name]?

- What helped?

- What got in the way?

2. How are appointments handled at [agency name]?

Probes:

- What was the process like when you first made contact with the agency?

- What happens if you have to cancel or reschedule?

- What would you do if a problem arose?

- How frequent is your contact with the agency?

3. Let's talk about the group of people who help you and your family.

Probes:

- Who is involved in helping your family?

- Have you been seeing the same person?

- How has that been for you?

- How has your relationship changed over time?

- How has this relationship affected how you feel?

- How has it affected your child/parent?

- Does [provider] have all the information about you that is important to your care?

4. Have you every received services from more than one service provider at the same time?

Probes:

- How did that work?

- How did they connect and share information?

- How were you involved in the process?

- What was the process like for you?

4a.) Has your family physician been involved in this process?

- Tell me about their involvement

- How did they connect with the agency/school/others? 
4b.) Has a psychiatrist been involved?

- Tell me about their involvement

- How did they connect with the agency/family physician/others?

4c.) Has a pediatrician been involved?

- Tell me about their involvement

- How did they connect with the agency/family physician/others?

4d.) Has the school been involved in this process?

- Tell me about their involvement

- How did they connect with the agency/family physician/others?

- Does it seem like all of the people you've mentioned are working together to help your family? Explain:

5. Could you tell me what services [agency] has provided to you/your child?

Probes:

- How were you involved in these services?

- Was there ever a transition from one service to another?

- What was the outcome of receiving this service?

6. Have your needs been comprehensively met?

Probes:

- What worked well for you in receiving services?

- What were the problems you encountered?

- Are there barriers to accessing diagnostic services, specialists and other recommended services?

- What are the barriers to accessing services and supports?

Anything else you would like to add?

Any further comments about continuity of care. 


\section{Appendix D: Study 1 Interview Protocol: Service Providers}

We are doing research on the continuity of care provided through your children's mental health agency. As part of this study, we are interviewing clinical staff to obtain their perspective of continuity of care. In answering these questions, consider the services you provide in general and the structure of the service system in which you work.

1. Tell me about the intake process at your agency

Probes:

- What is it like for families when they first contact you for help?

- What works about this system?

- What would you change?

2. How are appointments handled at [agency name]?

Probes:

- What happens if you have to cancel or reschedule?

- If a client needed to cancel or reschedule, what would they need to do?

- How frequent is your contact with the family?

3. To what extent do clients consistently see the same staff?

Probes:

- Have the individual care providers changed for any of your clients?

- Have you taken over as the primary service provider or referred your clients on to another provider in your center? How did this work? Examples?

- In general, how satisfied are parents/caregivers with the frequency and regularity of contact?

- If changes occur, to what extent are they due to: (a) staff turnover; (b) client's request; or (c) service provider's request?

- What strategies are employed to manage transitions in caregivers?

4. To what extent is there integration and coordination between you and other service providers?

Probes:

- Have you ever offered services to a client receiving services from other providers at the same time? Explain:

- When clients receive a range of services, from your center as well as other organizations, to what extent are these services coordinated (e.g. between psychiatrists, psychologists and family physicians when pharmacological intervention is required)? Do you have concerns about this issue? What works? What would you change?

- How is the child or family involved in the communication that occurs among and between you and other service providers/informal helpers? Explain:

5. How are treatment plans developed?

Probes: 
- Who was involved in implementing the treatment plan? Who kept it going?

- How does parental involvement affect their children's adherence to the plan?

6. To what extent can you access a comprehensive array of services?

Probes:

- Are there barriers to accessing diagnostic services, specialists and other services?

- How do you communicate with any of the other service providers or family helpers?

- Do current practices fit with your expectations?

Anything else you would like to add?

Any further comments about continuity of care. 


\section{Appendix E: Study 1 Recruitment Handout}

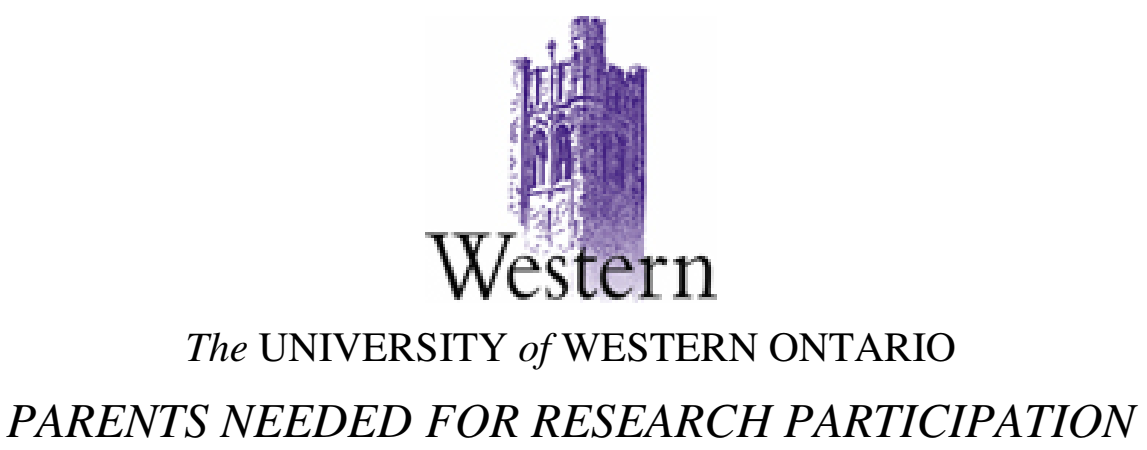

\section{Do you have a child between the ages of $\mathbf{4}$ and 17 years old?}

Have you attended at least two face-to-face appointments at (agency)?

Researchers from the University of Western Ontario are conducting a study on parents' experience of continuity of care in children's mental health.

\section{What does it involve?}

- First, a researcher will contact you to tell you all the details of the study.

- If you decide to participate, you will meet with the researcher at this agency and complete an interview that takes about $1-1.5$ hours.

- Participation is voluntary and you are free to refuse to participate.

\section{Are you interested?}

- Fill out the following information and return this sheet to the receptionist

- A researcher will be in contact with you in about two weeks

Parent Name:

First Last

Phone number:

Home Work

Child Name:

Child Date of Birth:

\section{YYYY/MM/DD}

Child Gender: $\square$ Boy $\quad \square$ Girl

This research is being conducted through the UWO Departments of Psychology and Family Medicine. Participation in the study will in no way affect the services that are offered through the [agency name]. 


\title{
Appendix F: Informed Consent Telephone Script for Parents
}

\author{
Continuity of Care in Children's Mental Health: Parent, Youth and Professional Perspectives
}

Hello, may I please speak to (Participant name)? Hello my name is (RA Name), I am working with Dr. Graham Reid and his colleagues on a research project at The University of Western Ontario. When you contacted (agency), you agreed to allow someone to call you about participating in a research study. (Agency) passed along your name to me.

Is this a good time to discuss the study, or is there a better time to call back?

\section{We mailed a letter describing the study to you last week. Let me review the study briefly and then I will answer any questions you may have.}

The purpose of this research is to gain a better understanding of how parents and youth experience care in children's mental health as coherent and linked. In particular, we are interested in how parents and youth experience continuity of care over time within an agency as well as across different services sectors (i.e., school, family physician, child welfare, youth justice, and children's mental health) and on how this continuity might impact child, parent, and family wellbeing.

If you agree to participate in this study, you will complete an interview with me at (agency) that will take approximately 1-1.5 hours. We can book the interview at a time when you are already going to the center for an appointment or at another time that fits with your schedule. In appreciation for your assistance with this study, you will receive a \$20 gift certificate for participating.

The information you provide us is very important. For this reason we will tape record your interview in case there are details that I miss. All tape-recorded information will be erased after the study is complete. Transcribed information will be kept in a locked filing cabinet at the University of Western Ontario for up to 7 years.

The interview will ask you about your experiences in receiving services at (agency), specifically, what it was like to first seek help, and your experiences of care and coordination within (agency). We are also interested in your experience of care across different sectors and how different providers have met your needs. The information you tell us is confidential to our research team and will not be shared with the children's agency. The second part is a standard series of questions that you would be asked to complete if your child starts treatment at (agency). This information remains confidential to (agency) and to our research team.

Participating in this study is your choice. You may refuse to participate or withdraw from this study at any time. You may refuse to answer any questions. Whatever you decide will have no effect on your or your child's care.

Do you have any questions?

Do you consent to participate in this study? $\square$ Yes $\square$ No

If Yes: What day would you like to schedule the interview for? 
If No: To help us in designing future studies, it would be very helpful if we could know why you decided not to participate. If you do not wish to tell me this information, just say so.

Name of Child:

Name of Parent/Guardian:

Signature of Research Assistant: Date: 


\section{Appendix G: Study 1 Consent to Participate - Parents/Youth}

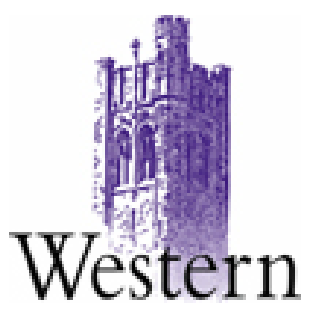

\section{The UNIVERSITY of WESTERN ONTARIO}

Continuity of Care in Children's Mental Health: Parent, Youth and Professional Perspectives

\section{If you agree to give researchers permission for an interview, please read, sign and date the following consent form:}

This is to certify that $I$, agree to be interviewed as part of The University of Western Ontario study entitled "Continuity of Care in Children's Mental Health: Parent, Youth and Professional Perspectives." I have read the Letter of Information, have had the nature of the study explained to me and I agree to participate. All questions have been answered to my satisfaction.

\section{I give permission to the researchers to audiotape the interview}

\section{I do not give permission to the researchers to audiotape the interview}

In addition, please check one of the following:

\section{AGREE to have the Brief Child and Family Phone Interview data for my child released to this research team.}

$\square \quad$ I DO NOT AGREE to have the Brief Child and Family Phone Interview data for my child released to this research team.

Participant Signature Date

If participant is under age 18 years:

Parent Signature Date Date 


\section{Appendix H: Study 1 Consent to Participate - Professionals}

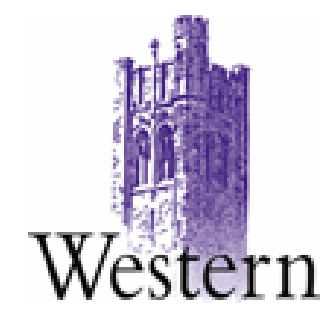

\section{The UNIVERSITY of WESTERN ONTARIO}

Continuity of Care in Children's Mental Health: Parent, Youth and Professional Perspectives

If you agree to give researchers permission for an interview, please read, sign and date the following consent form:

This is to certify that I, agree to be interviewed as part of The University of Western Ontario study entitled "Continuity of Care in Children's Mental Health: Parent, Youth and Professional Perspectives". I have read the Letter of Information, have had the nature of the study explained to me and I agree to participate. All questions have been answered to my satisfaction.

I give permission to the researchers to audiotape the interview

I do not give permission to the researchers to audiotape the interview

Participant Signature Date

Researcher Signature Date 


\title{
Appendix I: Study 1 Letter of Information: Parents
}

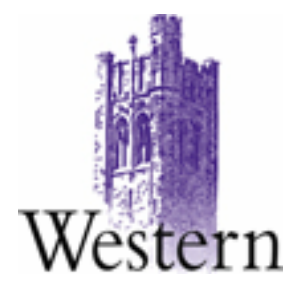

\author{
The UNIVERSITY of WESTERN ONTARIO
}

\author{
Continuity of Care in Children's Mental Health: Parent, Youth and Professional Perspectives \\ Juliana Tobon, Ph.D. Candidate Psychology Co-Principal Investigator \\ Dr. Graham J. Reid Psychology \& Family Medicine Co-Principal Investigator \\ Dr. Judith B. Brown Family Medicine \& Social Work Co-Investigator
}

\section{Purpose}

The purpose of this study is to interview parents, youth, and service providers to obtain their perspective and experience of continuity of care. You are being invited to participate because you have indicated that you have received services from an agency on at least two occasions and may be involved with multiple service providers. This study has been supported by (contact person) on behalf of (agency). Approximately 20 parents, 12 youth, and 10 professionals will be interviewed.

\section{Procedure}

The researchers ask that you assist in this study by consenting to an interview, which will last approximately 90 minutes. The interview is about your experience in receiving services through the children's mental health system and the continuity of these services within the agency and across sectors. You will be asked questions about who is involved in helping your family, what your relationship is like, and how you have experienced care as coordinated over time and across different providers. In appreciation of your time, you will be compensated with a $\$ 20$ gift certificate of your choice. 


\section{Voluntary Participation}

Your participation in the research is voluntary and you may refuse to participate, refuse to answer any questions or decide to withdraw from the study at any time. Following the end of the project, you can request a written summary of the results from the researchers, Graham J. Reid, Ph.D., Juliana Tobon, M.Sc., and Judith B. Brown, Ph.D., The University of Western Ontario.

\section{Confidentiality and Privacy}

To ensure confidentiality, the interview will be held in a private office at the agency. To assist in documenting the interviews, we also ask that you give consent to audio taping of the interview, which will then be transcribed. This will be done with the understanding that all field notes, tapes and transcripts will be secured in locked cabinets at the University of Western Ontario, for a period of seven years after completion of the study, after which time it will be destroyed. You may stop the recording device at any time during the interview. Transcriptions will have identifiers replaced with study identifiers [i.e., female, parent 1 (FP1)]. Your answers will be confidential and you will not be identified in any written reports or subsequent presentation of results. Representatives of the University of Western Ontario Health Sciences Research Ethics Board may contact you or require access to your study-related records to monitor the conduct of the research.

\section{Risks and Discomforts}

Participating in this study may make you think about factors pertaining to your child's mental health care that you had not thought about before. It is possible that thinking about your child's care may upset you. The interviewer will listen to your concerns supportively. You may end the interview at any time. Participation in this study will not affect you or your child's access to services. Parents' views will not be identified with workers and care of your child will not be adversely affected by any criticism that you may make as a parent.

\section{Contact Information}

This letter is for you to keep. If you have any questions please contact Dr. Graham Reid, at [phone number]. If you have any questions about the conduct of this study or your rights as a research participant, you may contact The Office of Research Ethics, The University of Western Ontario, [phone number]. 


\title{
Appendix J: Study 1 Letter of Information: Youth
}

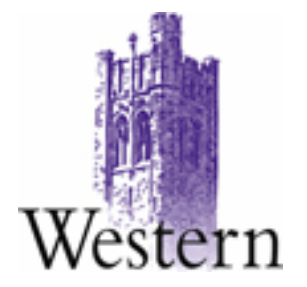

\section{The UNIVERSITY of WESTERN ONTARIO}

\section{Continuity of Care in Children's Mental Health: Parent, Youth and Professional Perspectives}

\author{
Juliana Tobon, Ph.D. Candidate Psychology Co-Principal Investigator \\ Dr. Graham J. Reid Psychology \& Family Medicine Co-Principal Investigator \\ Dr. Judith B. Brown Family Medicine \& Social Work Co-Investigator
}

\section{Purpose}

The purpose of this study is to interview parents, youth, and service providers to obtain their perspective and experience of continuity of care. You are being invited to participate because you have indicated that you have already received services from an agency on at least two occasions and may be involved with multiple service providers. This study has been supported by (contact person) on behalf of (agency). Approximately 20 parents, 12 youth, and 10 professionals will be interviewed.

\section{Procedure}

The researchers ask that you assist in this study by consenting to an interview, which will last approximately 90 minutes. The interview is about your experience in receiving services through the children's mental health system and the continuity of these services within the agency and across sectors. You will be asked questions about who is involved in helping your family, what your relationship is like, and how you have experienced care as coordinated over time and across different providers. In appreciation of your time, you will be compensated with a $\$ 20$ gift certificate of your choice.

\section{Voluntary Participation}

Your participation in the research is voluntary and you may refuse to participate, refuse to answer any questions or decide to withdraw from the study at any time. Following the end of the project, you can request a written summary of the results from the researchers, Graham J. Reid, Ph.D., Juliana Tobon, M.Sc., and Judith B. Brown, Ph.D. The University of Western Ontario. 


\section{Confidentiality and Privacy}

To ensure confidentiality, the interview will be held in a private office at the agency. To assist in documenting the interviews, we also ask that you give consent to audio taping of the interview, which will then be transcribed. This will be done with the understanding that all field notes, tapes and transcripts will be secured in locked cabinets at the University of Western Ontario, for a period of seven years after completion of the study, after which time it will be destroyed. You may stop the recording device at any time during the interview. Transcriptions will have identifiers replaced with study identifiers [i.e., female, youth 1 (FY1)]. Your answers will be confidential and you will not be identified in any written reports or subsequent presentation of results. Representatives of the University of Western Ontario Health Sciences Research Ethics Board may contact you or require access to your study-related records to monitor the conduct of the research.

\section{Risks and Discomforts}

Participating in this study may make you think about factors pertaining to your mental health care that you had not thought about before. It is possible that thinking about your care may upset you. The interviewer will listen to your concerns supportively. You may end the interview at any time. Participation in this study will not affect your access to services. Your views will not be identified with workers and your care will not be adversely affected by any criticism that you may make.

\section{Contact Information}

This letter is for you to keep. If you have any questions please contact Dr. Graham Reid, at [phone number]. If you have any questions about the conduct of this study or your rights as a research participant, you may contact The Office of Research Ethics, The University of Western Ontario, [phone number]. 


\title{
Appendix K: Study 1 Letter of Information: Professionals
}

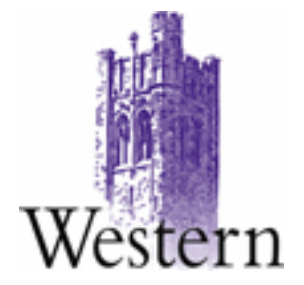

\section{The UNIVERSITY of WESTERN ONTARIO}

\section{Continuity of Care in Children's Mental Health: Parent, Youth and Professional Perspectives}

\author{
Juliana Tobon, Ph.D. Candidate Psychology Co-Principal Investigator \\ Dr. Graham J. Reid Psychology \& Family Medicine Co-Principal Investigator \\ Dr. Judith B. Brown Family Medicine \& Social Work Co-Investigator
}

\section{Purpose}

The purpose of this study is to interview parents, youth, and service providers to obtain their perspective and experience of continuity of care. You are being invited to participate because you provide direct services to families at a children's mental health center.

\section{Procedure}

The researchers ask that you assist in this study by consenting to an interview, which will last approximately 90 minutes. The interview is about your experience in offering services through the children's mental health system and the continuity of these services within the agency and across sectors. You will be asked questions such as how appointments are handled at your agency, how services are linked and coordinated within the agency and across sectors, how treatment plans are developed and the extent to which clients see the same staff. In appreciation of your time, you will be compensated with a $\$ 20$ gift certificate of your choice.

\section{Voluntary Participation}

Your participation in the research is voluntary and you may refuse to participate, refuse to answer any questions or decide to withdraw from the study at any time. Following the end of the project, you can request a written summary of the results from the researchers, Graham J. Reid, Ph.D., Juliana Tobon, M.Sc., and Judith B. Brown, Ph.D., The University of Western Ontario. 


\section{Confidentiality and Privacy}

To ensure confidentiality, the interview will be held in a private office at the agency. To assist in documenting the interviews, we also ask that you give consent to audio taping of the interview, which will then be transcribed. This will be done with the understanding that all field notes, tapes and transcripts will be secured in locked cabinets at the University of Western Ontario, for a period of seven years after completion of the study, after which time it will be destroyed. You may stop the recording device at any time during the interview. Transcriptions will have identifiers replaced with study identifiers [i.e., service provider 1 (SP1)]. Your answers will be confidential and you will not be identified in any written reports or subsequent presentation of results. Representatives of the University of Western Ontario Health Sciences Research Ethics Board may contact you or require access to your study-related records to monitor the conduct of the research.

\section{Risks and Discomforts}

There is no apparent harm to you in taking part in this study. Your views will not be identifiable or linked with your agency.

\section{Contact Information}

This letter is for you to keep. If you have any questions please contact Dr. Graham Reid, at [phone number]. If you have any questions about the conduct of this study or your rights as a research participant, you may contact The Office of Research Ethics, The University of Western Ontario, [phone number]. 


\title{
Appendix L: Study 1 Ethics Approval
}

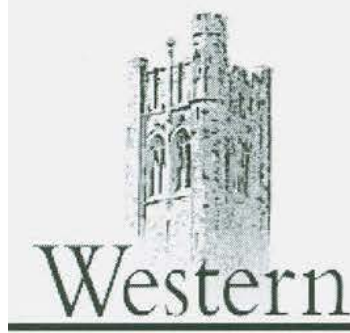

\section{Office of Research Ethics}

The University of Western Ontario

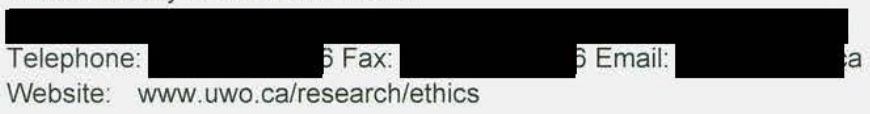

\section{Use of Human Subjects - Ethics Approval Notice}

\author{
Principal Investigator: Dr. G.J. Reid \\ Review Number: $16309 E$ \\ Review Level: Expedited \\ Review Date: July 08, 2009 \\ Protocol Title: Continuity of Care in Children's Mental Health: Parent, Youth and Professional \\ Perspectives
}

Department and Institution: Psychology, University of Western Ontario

Sponsor: INTERNAL RESEARCH FUND-UWO

Ethics Approval Date: July 29, $2009 \quad$ Expiry Date: December 31, 2009

Documents Reviewed and Approved: UWO Protocol, Letter of Information (parents), Letter of Information (youth), Letter of Information (professionals), Advertisement, Consent - Interview (Parent/youth), Consent - Interview (Professionals), Telephone script.

Documents Received for Information:

This is to notify you that The University of Western Ontario Research Ethics Board for Health Sciences Research Involving Human Subjects (HSREB) which is organized and operates according to the Tri-Council Policy Statement: Ethical Conduct of Research Involving Humans and the Health Canada/ICH Good Clinical Practice Practices: Consolidated Guidelines; and the applicable laws and regulations of Ontario has reviewed and granted approval to the above referenced study on the approval date noted above. The membership of this REB also complies with the membership requirements for REB's as defined in Division 5 of the Food and Drug Regulations.

The ethics approval for this study shall remain valid until the expiry date noted above assuming timely and acceptable responses to the HSREB's periodic requests for surveillance and monitoring information. If you require an updated approval notice prior to that time you must request it using the UWO Updated Approval Request Form.

During the course of the research, no deviations from, or changes to, the protocol or consent form may be initiated without prior written approval from the HSREB except when necessary to eliminate immediate hazards to the subject or when the change(s) involve only logistical or administrative aspects of the study (e.g. change of monitor, telephone number). Expedited review of minor change(s) in ongoing studies will be considered. Subjects must receive a copy of the signed information/consent documentation.

Investigators must promptly also report to the HSREB:

a) changes increasing the risk to the participant(s) and/or affecting significantly the conduct of the study;

b) all adverse and unexpected experiences or events that are both serious and unexpected;

c) new information that may adversely affect the safety of the subjects or the conduct of the study.

If these changes/adverse events require a change to the information/consent documentation, and/or recruitment advertisement, the newly revised information/consent documentation, and/or advertisement, must be submitted to this office for approval.

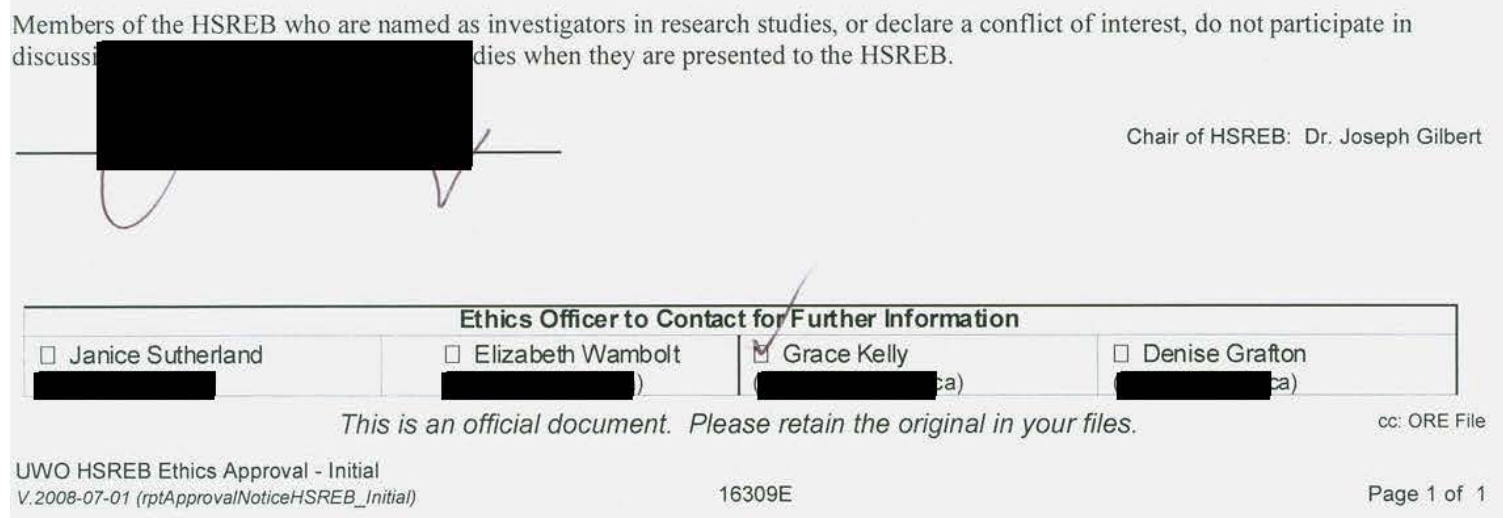




\section{Appendix M: Study 2 Recruitment Form}

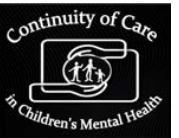

PARENTS NEEDED FOR RESEARCH PARTICIPATION

Western

Have you had at least 3 face-to-face appointments with staff from

[Agency]?

Dr. Graham Reid and researchers from Western University,

in partnership with [Agency],

are doing a study about parents' experience of continuity of care in children's mental health.

\section{${ }^{*}$ What does it involve?}

- First, a researcher will contact you by phone to tell you about the study.

- Participation is voluntary and you can refuse to participate.

- If you choose to participate, you will be sent a questionnaire that will take about 1 hour to complete.

- Please see the enclosed Letter of Information for more details, including confidentiality and compensation.

*Are you interested in hearing about the study?

$\square$ Yes $\rightarrow$ please complete the form below

$\square$ No Thanks $\rightarrow$ can you please tell us why:

$\square$ I have not had 3 face-to-face appointments

$\square$ My child is under 4 years of age

$\square$ My child is over 18 years of age

I am involved in another research study

$\square$ I have already been asked about this study

$\square$ Not interested

$\square$ Other:

Please complete if interested.

Child/Youth's Name:

First Last

Child/Youth's Date of Birth:

YYYY/MM/DD

Parent's Name:

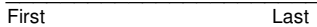

Phone number:

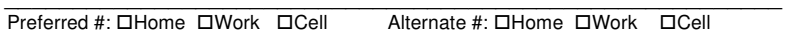

Child/Youth's Gender: aBoy $\quad$ aGirl

Best time to call: $\quad$ व8am - noon $\quad$ anoon $-4 p m \quad \square 4 p m-8 p m$

Please return your completed form to Western University

in the stamped envelope provided.

This form can also be completed online at [website].

Thank you! 


\section{Appendix N: Study 2 Telephone Script}

Informed Consent Telephone Script for Parents

Continuity of Care in Children's Mental Health: Development of a Measure

Today's date (month-dd-yyy): _ _ Time call starts:

Interviewer's Initials:

Hello, may I please speak to (Participant name)?

Hello my name is (RA Name). I am working with Dr. Graham Reid and his colleagues on a research project at The University of Western Ontario. Recently at (agency), you provided your contact information to allow someone to call you about participating in a research study. (Agency) passed along your name to me.

Is this a good time to tell you about the research, or is there a better time to call back?

Let me review our study briefly, and then I will answer any questions you may have.

You were invited to be a part of this research study because you have been in contact with one of 5 children's agencies in Southern Ontario participating in this study. The purpose of this study is to find out how [parents/youth] experience continuity of care in the children's mental health system. This means how you experience care as coordinated over time and across services. It is important to understand your experiences because it is the goal of children's agencies in Ontario to provide coordinated services to families, but this has not been measured from the perspective of families. Your participation will help us to understand how families experience care and will ultimately help agencies to improve their services.

If you agree to participate in this study, you will receive a package either in the mail or through email that will take about 60 minutes to complete. You would answer questions related to your experience receiving services in the previous year at [agency] as well as at any other agencies, with your child's school, with child welfare, and with the medical sector, if they were involved in your care. You will also be asked about the severity of your child's problems, your stress levels, your satisfaction with services, and demographic questions because we want to understand how continuity of care is related to these areas. The information you tell us is confidential to our research team and will not be shared with the children's agency. In appreciation of your time, you will be compensated with a $\$ 20$ gift certificate to your choice of Tim Hortons, Starbucks, Chapters, or McDonald's.

Along with the questionnaire, you would receive a consent form asking for your permission to contact the primary clinician with which you are involved so that he/she can complete a brief measure about your continuity of care. The clinician would not see the information you provide to use through the survey. You would also indicate your permission for the agency to release your 
visit dates to our research team so that we have an accurate record of the length of your involvement with the agency.

Participating in this study is your choice. You may refuse to participate or withdraw from this study at any time. You may refuse to answer any questions. Whatever you decide will have no effect on your/your child's care.

Do you have any questions?

Do you consent to participate in this study? $\square$ Yes $\square$ No

If No: To help us in designing future studies, it would be very helpful if we could know why you decided not to participate. If you do not wish to tell me this information, just say so.

Reason not interested:

If Yes: Thank-you for your interest in participating in this important study.

Before we continue, I am going to make sure that you meet our study criteria.

Has your child had at least three face to face visits at [agency]?

Has your child been diagnosed with a developmental delay, or autism spectrum disorder?

Is your child between the ages of 4 and 18 years?

Are you comfortable with a grade 7 reading level in English?

If parent ineligible:

Unfortunately, it looks like we won't be able to include you in this study because we are looking for families who meet a certain criteria. Thank you so much for your time.

If parent eligible:

You meet our study criteria, so I will need to collect some additional information from you so you can participate in the study.

Can you verify your child's name?

What is your relationship to the child:

Mother

Father

Step-mom

Step-dad

Adoptive mom

Adoptive dad

Grandmother

Grandfather 
Foster mom

Foster dad

What is your preference for receiving the Continuity of Care package?

Email

Mail

If email: What is your email address:

Verify:

What is your mailing address (collect for all participants):

Address 1:

Address 2:

City:

Postal Code:

Are you planning to move in the next year?

Yes

No

If "yes", when?:

What is your gift card preference?

Tim Hortons

Chapters

Starbucks

McDonald's

Thanks again for agreeing to participate. Your participation will help us understand and improve services at [agency] and in the children's mental health system.

You should expect to receive the survey package in [your inbox/the mail] within the next 4-6 weeks. We ask that you complete the package at your earliest convenience, when you have an hour free from distractions. We will send you reminders to complete the package after 1 week, 3 weeks, and 7 weeks.

Once we receive your survey package, we will mail out the gift card of your choice. Thanks for your time.

Any additional call comments/preferences:

Time call ends: 


\section{Appendix O: Study 2 Consent for Parents}
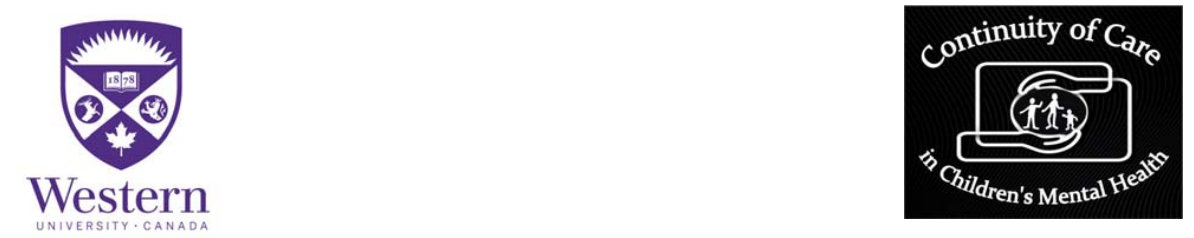

Please return this consent form along with the completed questionnaire using the stamped addressed envelope provided. The letter of information is for you to keep.

I have read the Letter of Information, have had the nature of the study explained to me and I agree to participate. All questions have been answered to my satisfaction.

$\square$ I AGREE to have visit dates and program names for my child released to this research team.

$\square$ I DO NOT AGREE to have visit dates and program names for my child released to this research team.

$\square$ I AGREE to have my child's clinician at [Agency] release the Continuity of Care: Clinician Scales and the Therapeutic Alliance Measure to this research team.

Name of your child's clinician at [AGENCY]:

$\square$ I DO NOT AGREE to have my child's clinician release the Continuity of Care: Clinician Scales and the Therapeutic Alliance Measure to this research team.

Name of your child:

Youth signature

(for children age 12 and older):

Parent/guardian's name:

Parent/guardian's

signature:

Date: 


\section{Appendix P: Study 2 Consent for Youth}
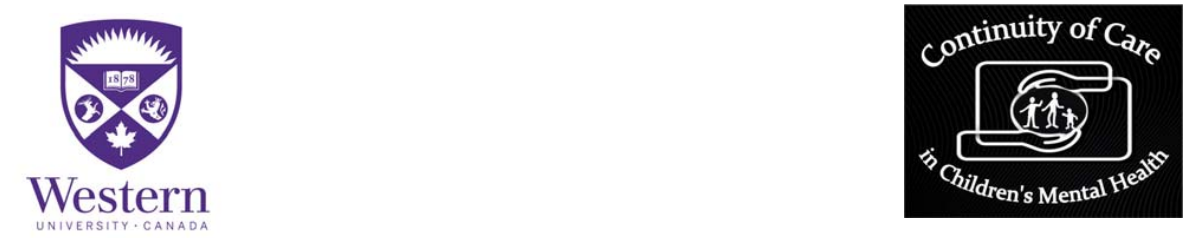

Please return this consent form along with the completed questionnaire using the stamped addressed envelope provided. The letter of information is for you to keep.

I have read the Letter of Information, have had the nature of the study explained to me and I agree to participate. All questions have been answered to my satisfaction.

$\square$ I AGREE to have my visit dates and program names released to this research team.

$\square$ I DO NOT AGREE to have visit dates and program names released to this research team.

$\square$ I AGREE to have my clinician at [Agency] release the Continuity of Care: Clinician Scales and the Therapeutic Alliance Measure to this research team.

Name of your clinician at [AGENCY]:

$\square$ I DO NOT AGREE to have my clinician release the Continuity of Care: Clinician Scales and the Therapeutic Alliance Measure to this research team.

Your name:

Your signature

(for youth age 14 and older):

Parent/guardian's name:

Parent/guardian's

signature:

Date: 


\title{
Appendix Q: Study 2 Letter of Information for Parents
}

Care

\author{
Continuity of Care in Children's Mental Health \\ Western University \\ [address] \\ [phone number] [website]
}

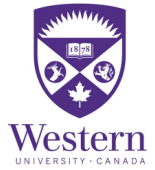

\section{PARENT LETTER OF INFORMATION}

Investigators:

Graham J. Reid, Ph.D.

Juliana Tobon, M.Sc.

Shannon Stewart, Ph.D

Barrie Evans, Ph.D.

Judith B. Brown, Ph.D.

Richard Goffin, Ph.D.
Psychology \& Family Medicine, UWO

Psychology, UWO

Child and Parent Resource Institute

Thames Valley District School Board

Family Medicine, UWO

Psychology, UWO

\author{
Principal Investigator \\ Co-Investigator \\ Co-Investigator \\ Co-Investigator \\ Co-Investigator \\ Co-Investigator
}

Purpose:

The purpose of this research is to find out how parents experience continuity of care in the children's mental health system. We are also interested in looking at how continuity of care is related to the amount of time in treatment, parental stress levels, and satisfaction with services. You were invited to be a part of this study because you contacted one of several children's agencies in Southern Ontario participating in this study.

\section{Procedures:}

First, you will receive a questionnaire by email or in the mail that will take about 45 minutes to complete. The questionnaire will ask you about your experience of continuity of care within the agency, between providers, between agencies, and between other providers, such as your child's school and your family doctor. Second, along with the questionnaire, you will receive 6 other measures that will take approximately 30 minutes to complete.

Finally, along with the questionnaires, there will be a consent form asking your permission for the agency to share your visit dates with our research team so that we get a measure of your service use. You will also indicate your consent for your primary clinician to complete their rating of your continuity of care and a therapeutic relationship measure, and to indicate whether you have had any involvement with the education, primary care and child welfare sectors for services.

The information you tell us is confidential to our research team and will not be shared with the agency. In appreciation of your time, you will be compensated with a $\$ 20$ gift certificate of your choice from Tim Hortons, Starbucks, Chapters, or McDonalds.

If you are interested in the results of the study, we will provide you with a one-page summary of the findings once the study is complete. 
Risks and Discomforts:

This study may make you think about things you have not thought about before. It is possible that reflecting on issues related to your child's mental health care might cause you distress or emotional upset. You may choose not to fill out the questionnaires at any time. In addition, you will be provided with a list of community resources to contact if you become upset or distressed while you complete the questionnaires. Otherwise, there are no known risks related to being in this study. You may not benefit directly from being in this study. The information from this study may be used to help develop new procedures and questionnaires to help families and children like yours.

\section{Voluntary Participation:}

Participation in this study is voluntary. You may refuse to participate and you may refuse to answer any questions or withdraw from the study at any time with no effect on your child's care. Completion and return of the questionnaire indicates your consent to participate in the study.

Confidentiality and Privacy:

All information obtained for the study is confidential. All forms have a code number to ensure confidentiality. Identifying information such as your name will be kept separate from your answers. Only the principal investigators (Dr. Reid and Ms. Tobon) and research assistants will have access to your identifying information. The rest of the research team will not have access to your name or other identifying information. All forms are stored in a locked filing cabinet for security. Information in this study is only for research. When the study results are presented or published your name or your child's name will never be used. Although we recruited you from a children's centre in the community, the research team is based at the Western University in the Departments of Psychology and Family Medicine. Information gathered for this project will not be shared with staff at the children's mental health center. The clinician that you identify during the telephone screening will be aware of your participation, but will not have access to your responses. Some of the information gathered for the research study may overlap with information gathered as part of clinical services at the center you have contacted. Therefore, it is possible that there will be some overlap in the information provided.

Representatives of the Western University Health Sciences Research Ethics Board may contact you or require access to your study-related records to monitor the conduct of the research.

\section{Contact Information:}

This letter is for you to keep. If you have any questions about this project, please call Dr. Graham Reid at [phone number]. If you have any questions about the conduct of this study or your rights as a research subject you may contact the Director, Office of Research Ethics, Western University, [phone number], email: [email address] Dr. David Hill, Scientific Director, Lawson Health Research Institute at [phone number].

Dr. Graham Reid, C. Psych.

Associate Professor, Psychology \& Family Medicine and Paediatrics 


\section{Appendix R: Study 2 Letter of Information for Youth}

$\underbrace{\text { Continuity }}_{\text {Care }}$

\author{
Continuity of Care in Children's Mental Health \\ Western University \\ [address] \\ [phone number] [website]
}

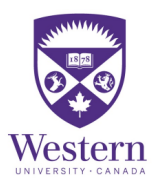

\section{YOUTH LETTER OF INFORMATION}

Investigators:

Graham J. Reid, Ph.D.

Juliana Tobon, M.Sc.

Shannon Stewart, Ph.D.

Barrie Evans, Ph.D.

Judith B. Brown, Ph.D.

Psychology \& Family Medicine, UWO

Principal Investigator Psychology, UWO

Child and Parent Resource Institute

Thames Valley District School Board

Co-Investigator

Family Medicine, UWO

Co-Investigator

Co-Investigator

Richard Goffin, Ph.D.

Psychology, UWO

Co-Investigator

Co-Investigator

Purpose:

The purpose of this research is to find out how youth experience continuity of care in the children's mental health system. We are also interested in looking at how continuity of care is related to the amount of time in treatment, stress levels, and satisfaction with services. You were invited to be a part of this study because you contacted one of several children's agencies in Southern Ontario participating in this study.

\section{Procedures:}

First, you will receive a questionnaire by email or in the mail that will take about 45 minutes to complete. The questionnaire will ask you about your experience of continuity of care within the agency, between providers, between agencies, and between other providers, such as your school and your family doctor. Second, along with the questionnaire, you will receive 6 other measures that will take approximately 30 minutes to complete.

Finally, along with the questionnaires, there will be a consent form asking your permission for the agency to share your visit dates with our research team so that we get a measure of your service use. You will also indicate your consent for your primary clinician to complete their rating of your continuity of care and a therapeutic relationship measure, and to indicate whether you have had any involvement with the education, primary care and child welfare sectors for services.

The information you tell us is confidential to our research team and will not be shared with the agency. In appreciation of your time, you will be compensated with a $\$ 20$ gift certificate of your choice from Tim Hortons, Starbucks, Chapters, or McDonalds.

If you are interested in the results of the study, we will provide you with a one-page summary of the findings once the study is complete.

Risks and Discomforts:

This study may make you think about things you have not thought about before. It is possible that reflecting on issues related to your mental health care might cause you distress or emotional upset. You may choose not to fill out the questionnaires at any time. In addition, you will be provided with a list of community resources to contact if you become upset or distressed while you complete the questionnaires. Otherwise, there are no known risks related to being in this study. You may not benefit directly from being in this study. The information from this study may be used to help develop new procedures and questionnaires to help families and children like yours. 
Voluntary Participation:

Participation in this study is voluntary. You may refuse to participate and you may refuse to answer any questions or withdraw from the study at any time with no effect on your care. Completion and return of the questionnaire indicates your consent to participate in the study.

Confidentiality and Privacy:

All information obtained for the study is confidential. All forms have a code number to ensure confidentiality. Identifying information such as your name will be kept separate from your answers. Only the principal investigators (Dr. Reid and Ms. Tobon) and research assistants will have access to your identifying information. The rest of the research team will not have access to your name or other identifying information. All forms are stored in a locked filing cabinet for security. Information in this study is only for research. When the study results are presented or published your name or your name will never be used. Although we recruited you from a children's centre in the community, the research team is based at the University of Western Ontario in the Departments of Psychology and Family Medicine. Information gathered for this project will not be shared with staff at the children's mental health center. The clinician that you identify during the telephone screening will be aware of your participation, but will not have access to your responses. Some of the information gathered for the research study may overlap with information gathered as part of clinical services at the center you have contacted. Therefore, it is possible that there will be some overlap in the information provided.

Representatives of The University of Western Ontario Health Sciences Research Ethics Board may contact you or require access to your study-related records to monitor the conduct of the research.

\section{Contact Information:}

This letter is for you to keep. If you have any questions about this project, please call Dr. Graham Reid at [phone number]. If you have any questions about the conduct of this study or your rights as a research subject you may contact the Director, Office of Research Ethics, The University of Western Ontario, [phone number], [email] Dr. David Hill, Scientific Director, Lawson Health Research Institute at [phone number].

Dr. Graham Reid, C. Psych.

Associate Professor, Psychology \& Family Medicine and Paediatrics 


\title{
Appendix S: Study 2 Thank-You Letter Parents/Youth
}

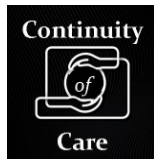

\author{
Continuity of Care in Children's Mental Health \\ Western University \\ [address] \\ [phone number] [website]
}

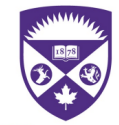

Western

[Date]

Dear [Participant],

Thank you very much for taking the time to complete our questionnaire. With the information you provided us, we can better understand how children's mental health services currently work and how they can improve.

As a token of our appreciation, please find enclosed a $\$ 20$ gift card.

Thank you again for your time and effort,

Dr. Graham Reid, C. Psych.

Principal Investigator

Associate Professor

Psychology \& Family Medicine

The University of Western Ontario

$\begin{array}{lll}\text { Juliana Tobon, M.Sc. } & \text { Psychology, UWO } & \text { Co-Investigator } \\ \text { Shannon Stewart, Ph.D. } & \text { Child and Parent Resource Institute } & \text { Co-Investigator } \\ \text { Barrie Evans, Ph.D. } & \text { Thames Valley District School Board } & \text { Co-Investigator } \\ \text { Judith B. Brown, Ph.D. } & \text { Family Medicine, UWO } & \text { Co-Investigator } \\ \text { Richard Goffin, Ph.D. } & \text { Psychology, UWO } & \text { Co-Investigator }\end{array}$




\title{
Appendix T: Study 2 Thank-You Letter Clinician
}

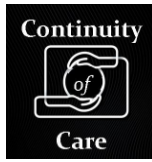

\author{
Continuity of Care in Children's Mental Health \\ Western University \\ [address] \\ [phone number] [email]
}

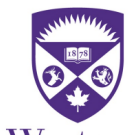

Western

[Date]

Dear [Participant],

Thank you very much for taking the time to complete our clinician questionnaire. With the information you provided us, we can better understand how children's mental health services currently work and how they can improve.

As a token of our appreciation, please find enclosed a $\$ 5$ gift card.

Thank you again for your time and effort,

Dr. Graham Reid, C. Psych.

Principal Investigator

Associate Professor

Psychology \& Family Medicine

The University of Western Ontario

Juliana Tobon, M.Sc.

Shannon Stewart, Ph.D.

Barrie Evans, Ph.D.

Judith B. Brown, Ph.D.

Richard Goffin, Ph.D.
Psychology, UWO

Child and Parent Resource Institute

Thames Valley District School Board

Family Medicine, UWO

Psychology, UWO
Co- Investigator

Co-Investigator

Co-Investigator

Co-Investigator

Co-Investigator 


\section{Appendix U: Study 2 Ethics Approval}

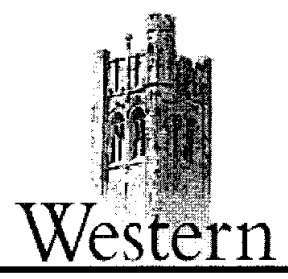

Principal Investigator: Dr. G.J. Reid

Review Number: 17294E

Review Date: July 21, 2010

Office of Research Ethics

The University of Western Ontario

Telephone:

Website:

Use of Human Subjects - Ethics Approval Notice

Department and Institution: Psychology, University of Western Ontario

Sponsor: CIHR-CANADIAN INSTITUTE OF HEALTH RESEARCH

Ethics Approval Date: August 24, 2010

Expiry Date: October 31, 2012

Documents Reviewed and Approved: UWO Protocol, Letter of Information and Consent (Parents), Letter of Information and Consent (Youth), Telephone Script.

Documents Received for Information:

This is to notify you that The University of Western Ontario Research Eth ics Board for Health Sciences Research Involving Human Subjects (HSREB) which is organized and operates according to the Tri-Council Policy Statement: Ethical Conduct of Research Involv ing Humans and the Health Canada/ICH Good Clinical Practice Practices: Consolidated Guidelines; and the applicable laws and regulations of Ontario has reviewed and granted approval to the above referenced study on the approval date noted above. The membership of this REB also complies with the membersh ip requirements for REB's as defined in Division 5 of the Food and Drug Regulations.

The ethics approval for this study shall remain valid until the expiry date noted above assuming timely and acc eptable responses to the HSREB's periodic requests for surve illance and monitoring information. If you require an updated approval notice prior to that time you must request it using the UWO Updated Approval Request Form.

During the course of the research, no deviations from, or changes to, the protocol or consent form may be in itiated without prior written approval from the HSREB except when necessary to elimina te immediate hazards to the subject or when the change( $s$ ) involve only $\log$ istical or admini strative aspects of the study (e.g. change of mon itor, telephone number). Exped ited re vie w of minor change(s) in ongoing studies will be considered. Subjects must receive a copy of the signed information/consent documentation.

Investigators must promptly also report to the HSREB:

a) changes increasing the risk to the participant(s) and/or affecting significantly the conduct of the study;

b) all adverse and unexpected experiences or events that are both serious and unexpected;

c) new information that may adversely affect the safety of the subjects or the conduct of the study.

If these changes'adverse events require a change to the information/consent doc umentation, and/or recruitment advertisement, the ne wly revised information/consent documentation, and/or ad vertisement, must be submitted to this office for approval.

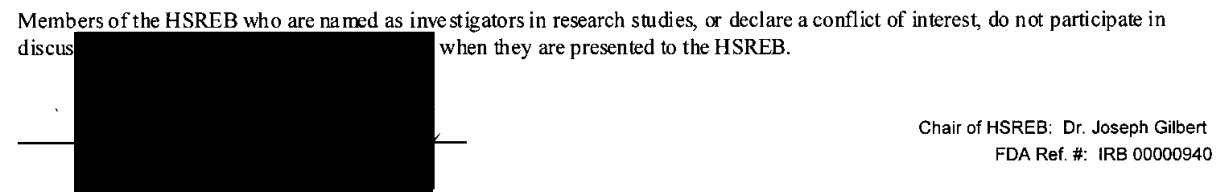

\begin{tabular}{|c|c|c|c|}
\hline \multicolumn{4}{|c|}{ Ethics Officer to Contact for Further Information } \\
\hline U Janice Sutherland & Elizabeth Wambolt & Grace Kelly & Denise Grafton \\
\hline
\end{tabular}

UWO HSREB Ethics Approval - Initial

V.2008-07-0t (rotApprovalNoticeHSREB_initial) 
Appendix V: Demographic Characteristics of C3MH Test-Retest Sample

\begin{tabular}{|c|c|c|c|}
\hline Demographic Characteristics & $\begin{array}{c}\text { Test-Retest } \\
\text { (TRT) Sample } \\
(N=30)\end{array}$ & $\begin{array}{c}\text { Study } \\
\text { Sample } \\
(N=334)\end{array}$ & \\
\hline & $\mathrm{N}(\%)$ & $\mathrm{N}(\%)$ & $\begin{array}{l}\text { TRT vs. } \\
\text { Sample }\end{array}$ \\
\hline Parent Sex & & & $\chi^{2}$ \\
\hline Male & $3(10.0)$ & $27(8.1)$ & .13 \\
\hline Female & $27(90.3)$ & $307(91.9)$ & \\
\hline Education & & & $\chi^{2}$ \\
\hline Less than high school & 0 & $18(5.4)$ & 6.70 \\
\hline High school graduate & $5(16.7)$ & $34(10.2)$ & \\
\hline $\begin{array}{l}\text { Some community college/ technical } \\
\text { school, or some university }\end{array}$ & $13(43.3)$ & $201(60.2)$ & \\
\hline University graduate & $12(40.0)$ & $81(24.3)$ & \\
\hline Income & & & $\chi^{2}$ \\
\hline Under $\$ 10,000$ & 0 & $7(2.2)$ & .72 \\
\hline$\$ 10,000$ to $\$ 19,999$ & $4(13.3)$ & $41(13.0)$ & \\
\hline$\$ 20,000$ to $\$ 39,999$ & $5(16.7)$ & $48(15.2)$ & \\
\hline$\$ 40,000$ to $\$ 59,999$ & $5(16.7)$ & $55(17.5)$ & \\
\hline
\end{tabular}




\begin{tabular}{|c|c|c|c|}
\hline Demographic Characteristics & $\begin{array}{c}\text { Test-Retest } \\
\text { (TRT) Sample } \\
(N=30)\end{array}$ & $\begin{array}{c}\text { Study } \\
\text { Sample } \\
(N=334)\end{array}$ & \\
\hline & $\mathrm{N}(\%)$ & $\mathrm{N}(\%)$ & $\begin{array}{l}\text { TRT vs. } \\
\text { Sample }\end{array}$ \\
\hline$\$ 60,000$ and over & $16(53.3)$ & $164(52.1)$ & \\
\hline Marital Status & & & $\chi^{2}$ \\
\hline Partner or spouse & $23(76.7)$ & $227(68.2)$ & .93 \\
\hline Single parent & $7(23.3)$ & $106(31.8)$ & \\
\hline Relationship to Child & & & $\chi^{2}$ \\
\hline Birth Mother & $21(70.0)$ & $78(23.4)$ & .67 \\
\hline Other & $9(30.0)$ & $256(76.6)$ & \\
\hline Race or Color of Respondent & & & $\chi^{2}$ \\
\hline White & $29(100)$ & $304(92.1)$ & 2.46 \\
\hline Other & $0(0)$ & $26(7.9)$ & \\
\hline
\end{tabular}


Appendix W: Demographic Characteristics of C3MH-Y Validation Sample

Demographic Characteristics

Study Sample

$\mathrm{CMHO}^{\mathrm{a}}$

$(\mathrm{N}=54) \quad(\mathrm{N}=3,565)$

N $(\%) \quad$ N $(\%) \quad$ Sample vs.

$\mathrm{CMHO}$

Youth Sex

Male

$14(24.6)$

Female

$43(75.4)$

Child Age $(\mathrm{M} \pm \mathrm{SD})$

$15.71(1.09)$

$--$

Present Living Situation

Two parents

25 (44.6)

Single parent

$20(35.7)$

Other (e.g., Relatives, guardians,

$11(19.7)$

treatment facility, own place, street)

Primary Language

English

$52(92.9)$

Other

$--$

School Attendance

Full time

$54(96.4)$ 


\begin{tabular}{|c|c|c|c|}
\hline \multirow[t]{2}{*}{ Demographic Characteristics } & Study Sample & \multicolumn{2}{|l|}{$\mathrm{CMHO}^{\mathrm{a}}$} \\
\hline & $(\mathrm{N}=54)$ & $(\mathrm{N}=3,565)$ & \\
\hline & $\mathrm{N}(\%)$ & $\mathrm{N}(\%)$ & Sample vs. \\
\hline & & & $\mathrm{CMHO}$ \\
\hline Part time & $1(1.8)$ & -- & \\
\hline Other & $1(1.8)$ & -- & \\
\hline Child Adjustment $(\mathrm{M} \pm \mathrm{SD})$ & & & $t$ \\
\hline Internalizing & $67.90(13.16)$ & $58.69(12.28)$ & .69 \\
\hline Externalizing & $62.44(9.85)$ & $60.86(11.34)$ & .16 \\
\hline Total Problem & $67.51(10.89)$ & $60.93(11.36)$ & .60 \\
\hline Functional Impairment & $67.93(13.45)$ & $63.73(12.10)$ & .31 \\
\hline
\end{tabular}

${ }^{\text {a }} \mathrm{CMHO}=$ Children's Mental Health Ontario data (Brian O'Hara, CMHO, personal communication, August, 2011) 


\section{Appendix X: C3MH-P Item Descriptives}

\begin{tabular}{|c|c|c|c|c|c|c|c|}
\hline $\begin{array}{l}\text { Item } \\
\text { ID }^{\mathrm{a}}\end{array}$ & $\begin{array}{c}\text { Final Questionnaire Item } \\
\text { Number }\end{array}$ & Mean & SD & $\begin{array}{l}\text { Skewness } \\
\text { (z-score) }\end{array}$ & $\begin{array}{l}\text { Kurtosis } \\
\text { (z-score) }\end{array}$ & Min & Max \\
\hline \multicolumn{8}{|c|}{ Management: Collaboration } \\
\hline \multicolumn{8}{|c|}{ Sample Item: I felt involved in decisions about my child's care } \\
\hline 7 & B9 & 3.67 & 1.02 & -3.61 & -1.74 & 1 & 5 \\
\hline 37 & B16 & 4.06 & 0.92 & -8.14 & 4.08 & 1 & 5 \\
\hline 49 & B19 & 4.04 & 0.85 & -8.78 & 7.21 & 1 & 5 \\
\hline 71 & B21 & 4.08 & 0.87 & -9.54 & 7.98 & 1 & 5 \\
\hline 88 & B27 & 3.59 & 1.05 & -3.29 & -1.64 & 1 & 5 \\
\hline
\end{tabular}

Management: Transitions

Sample Item: There was a smooth process to link my child and family with additional services as needs arose

\begin{tabular}{cccccccc}
\hline 9 & B10 & 4.01 & 1.01 & -6.78 & 0.48 & 1 & 5 \\
48 & B18 & 3.39 & 1.12 & -2.55 & -2.17 & 1 & 5 \\
75 & B15 & 3.80 & 1.19 & -7.33 & 0.02 & 1 & 5 \\
127 & B28 & 3.61 & 1.18 & -5.81 & -1.59 & 1 & 5 \\
\hline
\end{tabular}

Management: Flexibility

Sample Item: My child/family's care changed as our needs changed

\begin{tabular}{llllllll}
\hline 1 & B1 & 4.01 & 0.88 & -8.01 & 5.30 & 1 & 5 \\
\hline
\end{tabular}




\begin{tabular}{cccccccc}
\hline $\begin{array}{c}\text { Item } \\
\text { ID }\end{array}$ & $\begin{array}{c}\text { Final Questionnaire Item } \\
\text { Number }\end{array}$ & Mean & SD & Skewness & Kurtosis & Min & Max \\
& & & & $(z$-score $)$ & $(z$-score $)$ & \\
14 & B3 & 3.94 & 0.90 & -6.62 & 2.21 & 1 & 5 \\
17 & B11 & 4.52 & 0.59 & -7.94 & 5.49 & 2 & 5 \\
18 & B12 & & & & & & \\
47 & B17 & 4.03 & 0.96 & -6.56 & 1.59 & 1 & 5 \\
77 & B20 & 3.71 & 0.96 & -3.68 & -1.10 & 1 & 5 \\
\hline
\end{tabular}

Informational: Information exchange

Sample Item: The staff who worked with my child... knew about the care my child received at other places

\begin{tabular}{lccccccc}
\hline 11 & B2 & 3.97 & 0.96 & -6.51 & 1.05 & 1 & 5 \\
51 & B14 & 3.69 & 1.12 & -6.49 & -0.35 & 1 & 5 \\
76 & B22 & 4.16 & 0.90 & -11.37 & 10.14 & 1 & 5 \\
126 & B13 & 4.18 & 0.85 & -7.30 & 2.74 & 1 & 5 \\
\hline
\end{tabular}

Informational: Provider Knowledge

Sample Item: Our primary provider knew my child's strengths

\begin{tabular}{lccccccc}
\hline 34 & B7 & 3.99 & 0.91 & -4.96 & 0.10 & 1 & 5 \\
52 & B36 & 4.21 & 0.75 & -8.07 & 7.13 & 1 & 5 \\
53 & B37 & 4.22 & 0.77 & -8.24 & 6.55 & 1 & 5 \\
55 & B38 & 4.02 & 0.91 & -8.52 & 5.48 & 1 & 5 \\
\hline
\end{tabular}




\begin{tabular}{cccccccc}
\hline $\begin{array}{c}\text { Item } \\
\text { ID }\end{array}$ & $\begin{array}{c}\text { Final Questionnaire Item } \\
\text { Number }\end{array}$ & Mean & SD & Skewness & Kurtosis & Min & Max \\
& & & & $(z$-score $)$ & $(z$-score $)$ & \\
\hline 56 & B39 & 4.01 & 0.89 & -7.81 & 4.74 & 1 & 5 \\
57 & B40 & 4.03 & 0.86 & -5.58 & 0.92 & 1 & 5 \\
58 & B41 & 4.16 & 0.81 & -8.07 & 5.24 & 1 & 5 \\
59 & B42 & 4.18 & 0.79 & -7.73 & 5.33 & 1 & 5 \\
64 & B43 & 3.77 & 1.03 & -4.53 & -1.37 & 1 & 5 \\
\hline
\end{tabular}

Relational: Interpersonal

Sample Item: The staff who worked with my child... took the time to establish a good relationship with my child

\begin{tabular}{lcccccccc}
\hline 31 & B5 & 4.32 & 0.79 & -9.95 & 7.36 & 1 & 5 \\
79 & B23 & 4.44 & 0.73 & -10.98 & 9.24 & 1 & 5 \\
82 & B44 & 4.18 & 0.82 & -7.41 & 3.41 & 1 & 5 \\
94 & B46 & 4.15 & 0.90 & -8.81 & 4.84 & 1 & 5 \\
96 & B47 & 4.28 & 0.81 & -9.33 & 6.15 & 1 & 5 \\
97 & B48 & 4.19 & 0.87 & -9.97 & 7.78 & 1 & 5 \\
101 & B49 & 4.26 & 0.83 & -9.61 & 7.27 & 1 & 5 \\
\hline
\end{tabular}

Relational: Consistency over time \& transitions

Sample Item: I could count on our primary provider to help my family when we were in need

\begin{tabular}{llllllll}
\hline 16 & B4 & 3.95 & 1.05 & -6.31 & 0.08 & 1 & 5 \\
\hline
\end{tabular}




\begin{tabular}{cccccccc}
\hline $\begin{array}{c}\text { Item } \\
\text { ID }\end{array}$ & $\begin{array}{c}\text { Final Questionnaire Item } \\
\text { Number }\end{array}$ & Mean & SD & Skewness & Kurtosis & Min & Max \\
& & & & & & \\
& $(z$-score $)$ & $(z$-score $)$ & & \\
\hline 33 & B6 & 4.03 & 0.94 & -6.57 & 1.39 & 1 & 5 \\
36 & B8 & 3.19 & 1.22 & -0.01 & -4.60 & 1 & 5 \\
83 & B45 & & & & & & \\
89 & B25 & 4.00 & 0.97 & -7.76 & 3.49 & 1 & 5 \\
91 & B26 & 3.72 & 1.13 & -5.30 & -1.50 & 1 & 5 \\
92 & B24 & 4.40 & 0.76 & -11.89 & 12.35 & 1 & 5 \\
\hline
\end{tabular}

NOTE: $N=364 ; 42$ items

${ }^{a}$ Item ID is a unique identifier that was maintained through all versions of the questionnaire and can be used to link the parent items to the youth items. 


\section{Appendix Y: C3MH-P Social Desirability Correlations, Item Efficiency Index and CFA Factor Loadings}

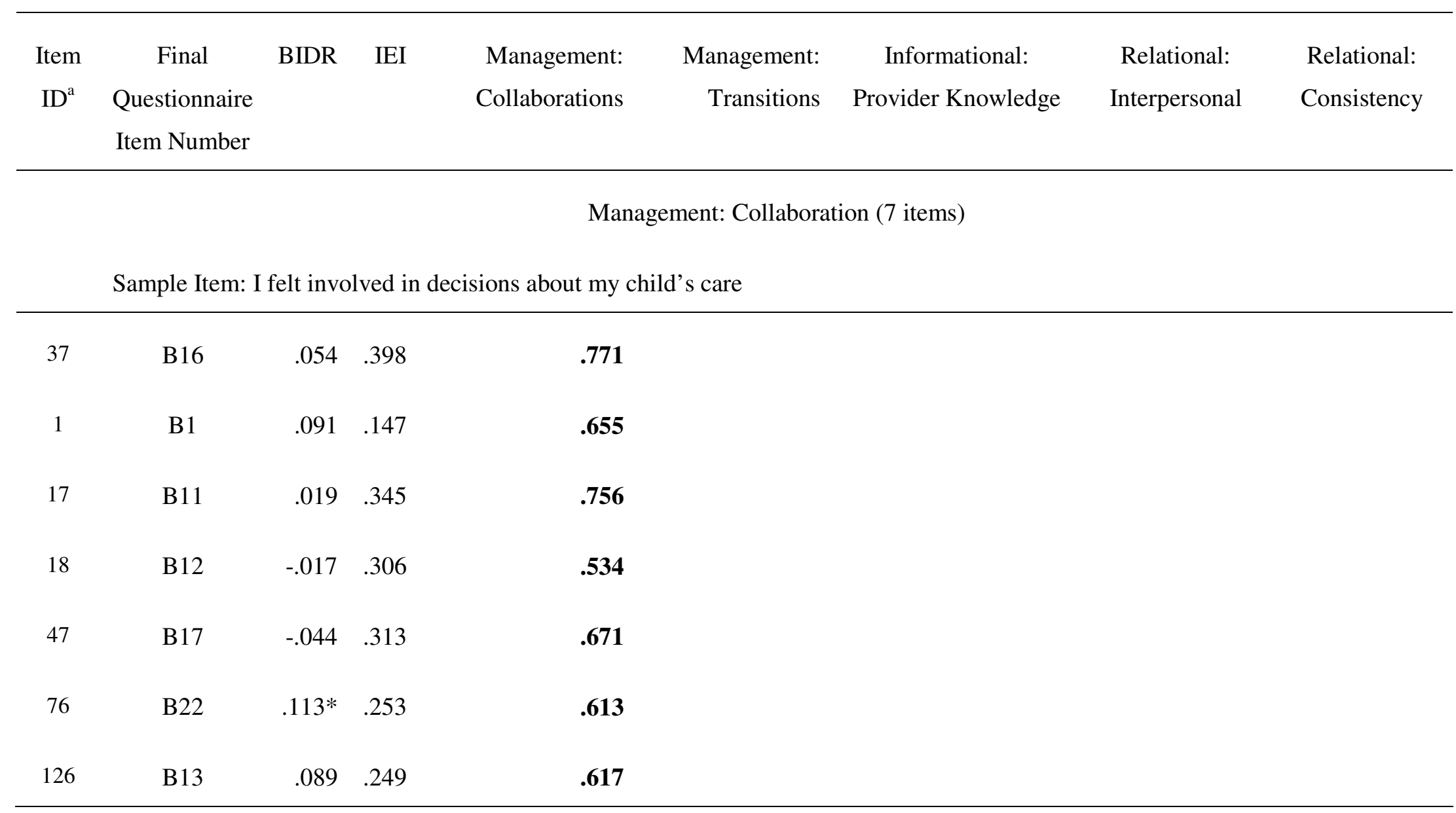




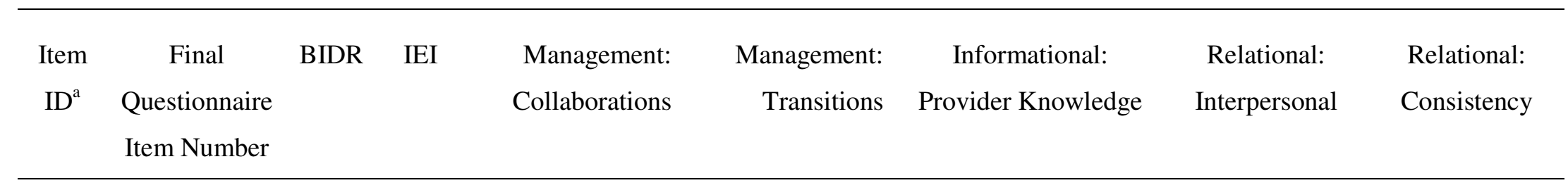

Management: Transitions (5 items)

Sample Item: There was a smooth process to link my child and family with additional services as needs arose

\begin{tabular}{lcccc}
\hline 9 & B10 & .079 & .181 & $\mathbf{. 7 1 7}$ \\
48 & B18 & -.047 & .354 & $\mathbf{. 7 4 4}$ \\
75 & B15 & .023 & .429 & $\mathbf{. 7 7 3}$ \\
127 & B28 & .040 & .360 & $\mathbf{. 5 7 1}$ \\
51 & B14 & .019 & .219 & $\mathbf{. 5 2 2}$ \\
\hline
\end{tabular}

Informational: Provider Knowledge (5 items)

Sample Item: Our primary provider knew my child's strengths

\begin{tabular}{lllll}
\hline 52 & B36 & -.008 & .563 & $\mathbf{. 8 2 2}$
\end{tabular}




\begin{tabular}{|c|c|c|c|c|c|c|c|c|}
\hline $\begin{array}{l}\text { Item } \\
\text { ID }^{\mathrm{a}}\end{array}$ & $\begin{array}{l}\text { Final } \\
\text { Questionnaire } \\
\text { Item Number }\end{array}$ & BIDR & IEI & $\begin{array}{l}\text { Management: } \\
\text { Collaborations }\end{array}$ & $\begin{array}{r}\text { Management: } \\
\text { Transitions }\end{array}$ & $\begin{array}{c}\text { Informational: } \\
\text { Provider Knowledge }\end{array}$ & $\begin{array}{c}\text { Relational: } \\
\text { Interpersonal }\end{array}$ & $\begin{array}{l}\text { Relational: } \\
\text { Consistency }\end{array}$ \\
\hline 53 & B37 & .020 & .426 & & & .837 & & \\
\hline 55 & B38 & .089 & .501 & & & .817 & & \\
\hline 58 & B41 & .072 & .536 & & & .839 & & \\
\hline 59 & B42 & .079 & .436 & & & .657 & & \\
\hline
\end{tabular}

Relational: Interpersonal (4 items)

Sample Item: The staff who worked with my child... took the time to establish a good relationship with my child

\begin{tabular}{rrrrrrr}
\hline 31 & B5 & .016 & .339 & & $\mathbf{. 7 4 7}$ \\
94 & B46 & .011 & .668 & $\mathbf{9 1 6}$ & \\
97 & B48 & -.002 & .716 & $\mathbf{9 4 8}$ & \\
101 & B49 & -.016 & .702 & $\mathbf{9 1 5}$ & \\
\hline
\end{tabular}




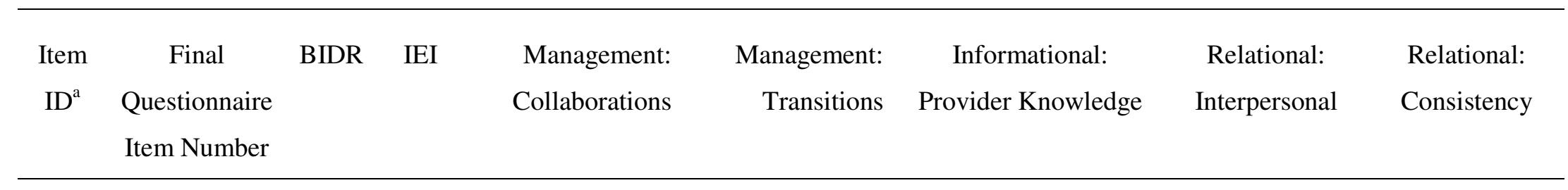

Relational: Consistency over time \& transitions (4 items)

Sample Item: I could count on our primary provider to help my family when we were in need

\begin{tabular}{llllll}
\hline 16 & B 4 & .081 & .414 & $\mathbf{. 8 5 8}$ \\
33 & B6 & .004 & .457 & $\mathbf{8 1 8}$ \\
36 & B8 & .048 & .419 & $\mathbf{. 6 5 4}$ \\
83 & B 45 & .029 & .285 & $\mathbf{8 3 2}$ \\
\hline
\end{tabular}

NOTE: $N=364 ; 25$ items. Factor loadings were obtained from the confirmatory factor analysis.

${ }^{a}$ Item ID is a unique identifier that was maintained through all versions of the questionnaire and can be used to link the parent items to the youth items.

Blank cells $=$ item was not modeled to load on the factors 


\section{Appendix Z: C3MH-P Factor Correlations}

\begin{tabular}{|c|c|c|c|c|c|}
\hline & $\begin{array}{l}\text { Management: } \\
\text { Collaborations }\end{array}$ & $\begin{array}{l}\text { Management: } \\
\text { Transitions }\end{array}$ & $\begin{array}{r}\text { Informational: } \\
\text { Provider } \\
\text { Knowledge }\end{array}$ & $\begin{array}{l}\text { Relational: } \\
\text { Interpersonal }\end{array}$ & $\begin{array}{r}\text { Relational } \\
\text { Consistency }\end{array}$ \\
\hline $\begin{array}{l}\text { Management: } \\
\text { Transitions }\end{array}$ & .89 & & & & \\
\hline $\begin{array}{l}\text { Informational: } \\
\text { Provider } \\
\text { Knowledge }\end{array}$ & .77 & .72 & & & \\
\hline $\begin{array}{l}\text { Relational: } \\
\text { Interpersonal }\end{array}$ & .61 & .61 & .73 & & \\
\hline $\begin{array}{l}\text { Relational: } \\
\text { Consistency }\end{array}$ & .93 & .85 & .80 & .68 & \\
\hline
\end{tabular}

Note. $N=364 ; 25$ items. Factor correlations were obtained from the confirmatory factor analysis. 


\section{Appendix AA: C3MH-Y Item Descriptives}

\begin{tabular}{|c|c|c|c|c|c|c|c|}
\hline Item ID $^{\mathrm{a}}$ & $\begin{array}{c}\text { Youth Questionnaire } \\
\text { Item Number }\end{array}$ & Mean & SD & $\begin{array}{l}\text { Skewness } \\
\text { (z-score) }\end{array}$ & $\begin{array}{l}\text { Kurtosis } \\
\text { (z-score) }\end{array}$ & Min & $\operatorname{Max}$ \\
\hline \multicolumn{8}{|c|}{ Management: Collaboration } \\
\hline \multicolumn{8}{|c|}{ Sample Item: I felt involved in decisions about my care } \\
\hline 7 & B9 & 3.51 & 1.00 & -1.65 & -0.10 & 1 & 5 \\
\hline 37 & B15 & 3.91 & 1.01 & -3.23 & 1.63 & 1 & 5 \\
\hline 49 & B17 & 4.02 & 0.81 & -4.03 & 4.83 & 1 & 5 \\
\hline 71 & B19 & 3.79 & 1.00 & -3.94 & 2.69 & 1 & 5 \\
\hline 88 & B25 & 3.40 & 0.84 & -1.65 & 1.75 & 1 & 5 \\
\hline
\end{tabular}

Management: Transitions

Sample Item: The staff who worked with me... helped me get services from other staff

\begin{tabular}{cccccccc}
\hline 9 & B10 & 3.27 & 1.23 & -0.44 & -1.10 & 1 & 5 \\
127 & B26 & 3.75 & 0.98 & -3.66 & 1.84 & 1 & 5 \\
\hline
\end{tabular}

Management: Flexibility

Sample Item: My care changed as my needs changed

\begin{tabular}{lccccccc}
\hline 1 & B1 & 3.84 & 1.05 & -3.53 & 1.82 & 1 & 5 \\
14 & B3 & 3.70 & 1.13 & -3.10 & 0.60 & 1 & 5 \\
17 & B11 & 4.41 & 0.74 & -4.34 & 3.74 & 2 & 5 \\
18 & B12 & 3.96 & 0.96 & -2.82 & 1.35 & 1 & 5
\end{tabular}




\begin{tabular}{cccccccc}
\hline Item ID $^{\mathrm{a}}$ & $\begin{array}{c}\text { Youth Questionnaire } \\
\text { Item Number }\end{array}$ & Mean & SD & $\begin{array}{c}\text { Skewness } \\
(z \text {-score })\end{array}$ & $\begin{array}{c}\text { Kurtosis } \\
(z \text {-score })\end{array}$ & Min & Max \\
\hline 47 & B16 & 3.81 & 1.11 & -2.60 & -0.09 & 1 & 5 \\
77 & B18 & 3.91 & 1.01 & -3.58 & 1.94 & 1 & 5 \\
\hline
\end{tabular}

Informational: Information exchange

Sample Item: The staff who worked with me... knew about the care I received at other places

\begin{tabular}{rrrrrrrr}
\hline 11 & B2 & 4.09 & 0.87 & -4.79 & 6.19 & 1 & 5 \\
51 & B14 & 3.51 & 1.17 & -1.28 & -1.10 & 1 & 5 \\
76 & B20 & 4.26 & 0.72 & -3.28 & 2.83 & 2 & 5 \\
126 & B13 & 4.13 & 0.78 & -2.36 & 1.18 & 2 & 5 \\
\hline
\end{tabular}

Informational: Provider Knowledge

Sample Item: My primary provider knew my strengths

\begin{tabular}{rrrrrrrrr}
\hline 34 & B7 & 3.82 & 0.98 & -1.79 & -0.14 & 1 & 5 \\
52 & B34 & 3.98 & 0.94 & -4.11 & 3.61 & 1 & 5 \\
53 & B35 & 4.18 & 0.83 & -4.16 & 4.70 & 1 & 5 \\
55 & B36 & 4.05 & 0.94 & -2.89 & 1.21 & 1 & 5 \\
56 & B37 & 3.91 & 1.05 & -2.19 & -0.39 & 1 & 5 \\
57 & B38 & 3.84 & 1.01 & -3.14 & 1.46 & 1 & 5 \\
58 & B39 & 4.20 & 0.84 & -4.81 & 5.69 & 1 & 5 \\
59 & B40 & 4.02 & 0.90 & -3.47 & 2.48 & 1 & 5
\end{tabular}




\begin{tabular}{cccrrrrrr}
\hline Item ID $^{\mathrm{a}}$ & $\begin{array}{c}\text { Youth Questionnaire } \\
\text { Item Number }\end{array}$ & Mean & SD & $\begin{array}{c}\text { Skewness } \\
(z \text {-score })\end{array}$ & $\begin{array}{c}\text { Kurtosis } \\
(z \text {-score })\end{array}$ & Min & Max \\
\hline 64 & B41 & 3.79 & 0.93 & -1.69 & 0.38 & 1 & 5 \\
\hline
\end{tabular}

Relational: Interpersonal

Sample Item: The staff who worked with me took the time to establish a good relationship with

\begin{tabular}{llllllll} 
me & & & & & & & \\
\hline 31 & B5 & 3.95 & 1.12 & -3.96 & 2.12 & 1 & 5 \\
79 & B21 & 4.42 & 0.84 & -5.90 & 6.98 & 1 & 5 \\
82 & B42 & 4.31 & 0.77 & -5.04 & 7.97 & 1 & 5 \\
94 & B44 & 4.22 & 0.98 & -5.25 & 4.91 & 1 & 5 \\
96 & B45 & 4.05 & 1.04 & -3.50 & 1.61 & 1 & 5 \\
97 & B46 & 4.16 & 0.98 & -4.52 & 3.85 & 1 & 5 \\
101 & B47 & 4.27 & 0.99 & -5.51 & 5.15 & 1 & 5 \\
\hline
\end{tabular}

Relational: Consistency over time \& transitions

Sample Item: I could count on my primary provider to help me when I was in need

\begin{tabular}{cccccccc}
\hline 16 & B4 & 3.75 & 1.01 & -2.51 & 0.81 & 1 & 5 \\
33 & B6 & 4.05 & 0.92 & -3.50 & 2.26 & 1 & 5 \\
36 & B8 & 2.89 & 1.25 & 0.65 & -1.37 & 1 & 5 \\
83 & B43 & 4.11 & 1.10 & -4.46 & 2.68 & 1 & 5 \\
92 & B22 & 3.25 & 1.20 & -1.36 & -1.23 & 1 & 5 \\
\hline
\end{tabular}

NOTE: $N=57 ; 38$ items. ${ }^{\text {a }}$ Item ID can be used to link the parent items to the youth items. 
Appendix BB: C3MH-Y Social Desirability Correlations, Item Efficiency Index and Factor Loadings

\begin{tabular}{|c|c|c|c|c|c|c|}
\hline Item & Youth & BIDR & IEI & Management: & Informational: & Relational: \\
\hline \multirow[t]{2}{*}{$\mathrm{ID}^{\mathrm{a}}$} & Questionnaire & & & Collaboration & Provider & Interpersonal \\
\hline & Item Number & & & & Knowledge & \\
\hline
\end{tabular}

Management: Collaboration

Sample Item: I felt involved in decisions about my care

\begin{tabular}{|c|c|c|c|c|c|}
\hline 1 & B1 & .18 & .23 & .544 & \\
\hline 17 & $\mathrm{~B} 11$ & .003 & .35 & .607 & \\
\hline 47 & B16 & -.10 & .24 & .866 & \\
\hline 126 & B13 & -.086 & .37 & .490 & \\
\hline 9 & $\mathrm{~B} 10$ & $.33 * *$ & .33 & .314 & \\
\hline 127 & B26 & -.21 & .25 & .620 & \\
\hline \multicolumn{6}{|c|}{ Informational: Provider Knowledge } \\
\hline \multicolumn{6}{|c|}{ Sample Item: My primary provider knew my strengths } \\
\hline 52 & B34 & .078 & .45 & & .889 \\
\hline 53 & B35 & .20 & .43 & & .794 \\
\hline 55 & B36 & .016 & .53 & & .830 \\
\hline 57 & B38 & .12 & .31 & & .780 \\
\hline 59 & B40 & .15 & .46 & & .677 \\
\hline
\end{tabular}




\begin{tabular}{|c|c|c|c|c|c|c|}
\hline Item & Youth & BIDR & IEI & Management: & Informational: & Relational: \\
\hline \multirow[t]{2}{*}{$\mathrm{ID}^{\mathrm{a}}$} & Questionnaire & & & Collaboration & Provider & Interpersonal \\
\hline & Item Number & & & & Knowledge & \\
\hline
\end{tabular}

\section{Relational: Interpersonal}

Sample Item: The staff who worked with me took the time to establish a good relationship with me

\begin{tabular}{llllll}
\hline 31 & B5 & .18 & .43 & $\mathbf{. 7 4 7}$ \\
94 & B44 & .045 & .53 & $\mathbf{9 5 9}$ \\
97 & B46 & .014 & .46 & $\mathbf{9 1 1}$ \\
101 & B47 & .095 & .58 & $\mathbf{. 9 1 6}$ \\
16 & B4 & .075 & .36 & $\mathbf{. 5 8 0}$ \\
33 & B6 & .11 & .36 & $\mathbf{. 7 2 8}$ \\
36 & B8 & .000 & .19 & $\mathbf{. 5 7 9}$ \\
83 & B43 & .014 & .49 & $\mathbf{8 8 4}$ \\
\hline
\end{tabular}

NOTE: $N=57 ; 19$ items. Factor loadings were obtained from the confirmatory factor analysis.

${ }^{a}$ Item ID can be used to link the parent items to the youth items.

Blank cells $=$ item was not modeled to load on the factors 
Appendix CC: C3MH-P Confirmatory Factor Analysis Models

\begin{tabular}{|c|c|c|c|c|c|c|c|c|c|c|c|}
\hline \multirow[t]{2}{*}{ Iteration } & \multirow[t]{2}{*}{ Number of items } & \multirow[t]{2}{*}{ Models } & \multicolumn{3}{|c|}{ Chi-squared statistics $^{\mathrm{a}}$} & \multicolumn{6}{|c|}{ Goodness-of-fit indices } \\
\hline & & & $\chi^{2}$ & df & p-value & RMSEA & $90 \% \mathrm{CI}$ & CFI & NNFI & IFI & SRMR \\
\hline \multicolumn{12}{|c|}{ Iterations of Preliminary Item Elimination } \\
\hline 1 & 39 & 7-factor & 1858.23 & 681 & .000 & .069 & $(.065, .073)$ & .803 & .785 & .805 & .078 \\
\hline 2 & 32 & 6-factor & 1227.26 & 449 & .000 & .069 & $(.064, .074)$ & .841 & .825 & .843 & .075 \\
\hline 3 & 32 & 5-factor & 1222.41 & 454 & .000 & .068 & $(.064, .073)$ & .843 & .829 & .845 & .075 \\
\hline 4 & 31 & 5-factor & 1022.63 & 424 & .000 & .062 & $(.054, .064)$ & .874 & .862 & .875 & .067 \\
\hline 5 & 30 & 5-factor & 902.11 & 395 & .000 & .056 & $(.051, .061)$ & .892 & .881 & .893 & .055 \\
\hline 6 & 25 & 5-factor & 514.93 & 265 & .000 & .046 & $(.039, .053)$ & .935 & .926 & .936 & .051 \\
\hline \multicolumn{12}{|c|}{ Alternative Model Comparisons } \\
\hline & 25 & 3-factor & 963.58 & 272 & .000 & .081 & $(.075, .086)$ & .798 & .778 & .800 & .065 \\
\hline
\end{tabular}




\begin{tabular}{|c|c|c|c|c|c|c|c|c|c|c|c|}
\hline \multirow[t]{2}{*}{ Iteration } & \multirow[t]{2}{*}{ Number of items } & \multirow[t]{2}{*}{ Models } & \multicolumn{3}{|c|}{ Chi-squared statistics ${ }^{\mathrm{a}}$} & \multicolumn{6}{|c|}{ Goodness-of-fit indices } \\
\hline & & & $\chi^{2}$ & $\mathrm{df}$ & p-value & RMSEA & $90 \% \mathrm{CI}$ & CFI & NNFI & IFI & SRMR \\
\hline & 25 & 1-factor & 1197.32 & 275 & .000 & .093 & $(.087, .099)$ & .727 & .702 & .729 & .066 \\
\hline & 25 & $\begin{array}{l}2^{\text {nd }} \text { Order } 3- \\
\text { factor, } 5 \text { scales }\end{array}$ & 452.592 & 268 & .000 & .048 & $(.041, .054)$ & .967 & .963 & .967 & .058 \\
\hline & 25 & $\begin{array}{l}2^{\text {nd }} \text { Order } 1- \\
\text { factor, } 5 \text { scales }\end{array}$ & 547.81 & 271 & .000 & .049 & $(.042, .055)$ & .926 & .919 & .927 & .060 \\
\hline & 25 & $\begin{array}{l}3^{\text {rd }} \text { Order } 1- \\
\text { factor, } 3 \text { scales, } \\
5 \text { subscales }\end{array}$ & 718.31 & 268 & .000 & .064 & $(.058, .070)$ & .873 & .858 & .874 & .080 \\
\hline
\end{tabular}

Note. $N=364$. Iterations $1-6$ reflect preliminary analyses reducing measure from 39-item to 25 -items.

${ }^{a}$ Yuan-Bentler scaled chi-squared statistic used. This statistic is equivalent to the Satorra-Bentler (S-B $\left.\chi^{2}\right)$ when the data are incomplete and non-normally distributed. 


\section{Appendix DD: C3MH-P Nested Model Comparisons}

\begin{tabular}{|c|c|c|c|}
\hline \multirow[b]{2}{*}{ Model Comparisons } & \multicolumn{3}{|c|}{ Difference in ${ }^{\mathrm{a}}$} \\
\hline & $\chi^{2}$ & df & $\mathrm{CFI}$ \\
\hline \multicolumn{4}{|l|}{ First-Order } \\
\hline 5-factor vs. 3-factor & 6.33 & 7 & .14 \\
\hline 5-factor vs. 1-factor & 8.48 & 10 & .21 \\
\hline \multicolumn{4}{|l|}{ Second-Order } \\
\hline 5-first-order-factor vs. 3-second-order factor & .022 & 3 & -.32 \\
\hline 5-first-order-factor vs. 1-second-order factor & 0.54 & 6 & .090 \\
\hline \multicolumn{4}{|l|}{ Third-Order } \\
\hline 5-first-order-factor vs. 1-third-order factor & 3.14 & 3 & .062 \\
\hline
\end{tabular}

Note. $N=364$.

${ }^{a}$ The Satorra-Bentler Chi-squared difference test for comparing models with robust estimation was used. Satorra, S., \& Bentler, P.M. (1999). A scaled difference chisquared test statistic for moment structure analysis. Psychometrika, 66, 507-514. 
Appendix EE: C3MH-Y Confirmatory Factor Analysis Models

\begin{tabular}{|c|c|c|c|c|c|c|c|c|c|c|c|}
\hline \multirow[t]{2}{*}{ Iteration } & \multirow[t]{2}{*}{ Number of items } & \multirow[t]{2}{*}{ Models } & \multicolumn{3}{|c|}{ Chi-squared statistics $^{\mathrm{a}}$} & \multicolumn{6}{|c|}{ Goodness-of-fit indices } \\
\hline & & & $\chi^{2}$ & $\mathrm{df}$ & $\mathrm{p}$-value & RMSEA & $90 \% \mathrm{CI}$ & CFI & NNFI & IFI & SRMR \\
\hline \multicolumn{12}{|c|}{ Preliminary Item Elimination } \\
\hline 1 & 23 & 5-factor & 313.30 & 220 & .000 & .066 & $(.035, .089)$ & .831 & .806 & .847 & .087 \\
\hline 2 & 22 & 4-factor & 279.27 & 203 & .000 & .058 & $(.018, .084)$ & .872 & .854 & .883 & .079 \\
\hline 3 & 20 & 3-factor & 248.58 & 167 & .000 & .073 & $(.040, .098)$ & .829 & .805 & .841 & .080 \\
\hline 4 & 19 & 3-factor & 209.90 & 149 & .001 & .068 & $(.030, .095)$ & .859 & .838 & .869 & .079 \\
\hline \multicolumn{12}{|c|}{ Alternative Model Comparisons } \\
\hline & 19 & 1-factor & 154.81 & 152 & .421 & .042 & $(.000, .076)$ & .881 & .866 & .897 & .095 \\
\hline
\end{tabular}

Note. $N=57 .{ }^{\text {a }}$ Yuan-Bentler scaled chi-squared statistic used. This statistic is equivalent to the Satorra-Bentler (S-B $\left.\chi^{2}\right)$ when the data are incomplete and non-normally distributed. 
Appendix FF: Correlations Between C3MH-Y Scales

\begin{tabular}{lccc}
\hline & $\begin{array}{c}\text { Management: } \\
\text { Collaboration }\end{array}$ & $\begin{array}{c}\text { Informational: } \\
\text { Provider Knowledge }\end{array}$ & $\begin{array}{c}\text { Relational: } \\
\text { Interpersonal }\end{array}$ \\
\hline $\begin{array}{l}\text { Management: } \\
\text { Collaboration }\end{array}$ & 1 & & \\
Informational: Provider & .53 & 1 & \\
Knowledge & & & \\
Relational: & .72 & .80 & \\
Interpersonal & & & \\
\hline \# of items & 6 & 5 & 93 \\
Cronbach's alpha & .77 & .90 & 3.92 \\
Mean & 3.88 & 4.09 & .86 \\
Standard Deviation & .69 & .75 & 1.13 \\
Minimum & 2.17 & 5.00 & 5.00 \\
Maximum & 5.00 & & \\
\hline
\end{tabular}

Note. $N=57 ; 19$ items. All correlations are significant at $p<.001$. 


\section{Appendix GG: C3MH-Y Factor Correlations}

\begin{tabular}{llll}
\hline & $\begin{array}{c}\text { Management: } \\
\text { Collaboration }\end{array}$ & $\begin{array}{c}\text { Informational: } \\
\text { Provider Knowledge }\end{array}$ & $\begin{array}{c}\text { Relational: } \\
\text { Interpersonal }\end{array}$ \\
\hline $\begin{array}{l}\text { Informational: Provider } \\
\text { Knowledge }\end{array}$ & .73 & & \\
Relational: & & & .90 \\
Interpersonal & .85 & & \\
\hline
\end{tabular}

Note. $N=57 ; 19$ items. Factor correlations were obtained from the confirmatory factor analysis. 


\section{Appendix HH: C3MH-Y Convergent and Discriminant Validity Correlations}

\begin{tabular}{|c|c|c|c|c|}
\hline & $\begin{array}{c}\text { Total } \\
\text { Continuity }\end{array}$ & $\begin{array}{l}\text { Management: } \\
\text { Collaboration }\end{array}$ & $\begin{array}{c}\text { Informational: } \\
\text { Provider } \\
\text { Knowledge }\end{array}$ & $\begin{array}{l}\text { Relational: } \\
\text { Interpersonal }\end{array}$ \\
\hline \multicolumn{5}{|l|}{ Convergent Validity } \\
\hline Depression (BCFPI) & -.075 & -.087 & .009 & -.095 \\
\hline Satisfaction (CSQ) & $.82 * * *$ & $.71 * * *$ & $.58 * * *$ & $.84 * * *$ \\
\hline Therapeutic Alliance (WAI) & & & & $.70 * * *$ \\
\hline \multicolumn{5}{|l|}{ Child adjustment (BCFPI) } \\
\hline Internalizing & -.035 & -.059 & .057 & -.053 \\
\hline Externalizing & -.050 & .104 & -.051 & -.134 \\
\hline Total Problem & -.048 & .003 & .024 & -.101 \\
\hline Child Impairment & -.090 & -.039 & -.072 & -.104 \\
\hline Discriminant Validity & & & & \\
\hline
\end{tabular}

Social Desirability (BIDR)

$\begin{array}{lllllll}\text { Impression Management } & .087 & .039 & .13 & .080\end{array}$

Note. $N=54$. 


\section{Appendix II: C3MH-P Demographic Correlations}

\begin{tabular}{|c|c|c|c|c|c|}
\hline & $\begin{array}{l}\text { Management: } \\
\text { Collaboration }\end{array}$ & $\begin{array}{l}\text { Management: } \\
\text { Transitions }\end{array}$ & $\begin{array}{c}\text { Informational: } \\
\text { Provider } \\
\text { Knowledge }\end{array}$ & $\begin{array}{l}\text { Relational: } \\
\text { Interpersonal }\end{array}$ & $\begin{array}{l}\text { Relational: } \\
\text { Consistency }\end{array}$ \\
\hline Parent Sex & .069 & -.015 & .041 & .000 & .052 \\
\hline Parent Age & .041 & .028 & .082 & .033 & .022 \\
\hline Parent Race & -.001 & -.079 & -.030 & -.032 & .010 \\
\hline $\begin{array}{l}\text { Marital } \\
\text { Status }\end{array}$ & -.057 & -.046 & .008 & -.011 & -.10 \\
\hline $\begin{array}{l}\text { Relationship } \\
\text { to child }\end{array}$ & -.030 & .032 & .077 & .046 & .006 \\
\hline $\begin{array}{l}\text { Family } \\
\text { Income }\end{array}$ & -.057 & -.025 & -.007 & -.069 & -.11 \\
\hline $\begin{array}{l}\text { Education } \\
\text { Level }\end{array}$ & -.034 & -.023 & -.058 & -.10 & -.13 \\
\hline $\begin{array}{l}\text { Spouse } \\
\text { Education }\end{array}$ & .012 & -.031 & .033 & -.038 & -.069 \\
\hline $\begin{array}{l}\text { Parent } \\
\text { Employment }\end{array}$ & -.033 & -.041 & -.007 & -.040 & -.092 \\
\hline $\begin{array}{l}\text { Spouse } \\
\text { Employment }\end{array}$ & -.095 & -.11 & -.11 & -.069 & -.11 \\
\hline Child Sex & .026 & .009 & -.112 & -.111 & .039 \\
\hline Child Age & -.068 & -.025 & .035 & .008 & -.046 \\
\hline
\end{tabular}

Note. $N=364$. None of the correlations were significant after adjusting for multiple comparisons using the False Discovery Rate. 


\section{Appendix JJ: C3MH-Y Demographic Correlations}

\begin{tabular}{|c|c|c|c|c|}
\hline & $\begin{array}{c}\text { Total } \\
\text { Continuity }\end{array}$ & $\begin{array}{l}\text { Management: } \\
\text { Collaboration }\end{array}$ & $\begin{array}{c}\text { Informational: } \\
\text { Provider } \\
\text { Knowledge }\end{array}$ & $\begin{array}{c}\text { Relational: } \\
\text { Interpersonal }\end{array}$ \\
\hline Primary & -.071 & .181 & .012 & -.042 \\
\hline \multicolumn{5}{|l|}{ Language } \\
\hline Present & -.095 & -.148 & .056 & -.086 \\
\hline \multicolumn{5}{|l|}{ Living } \\
\hline \multicolumn{5}{|l|}{ Situation } \\
\hline Employment & .033 & .083 & -.079 & .042 \\
\hline Income & -.053 & .061 & -.225 & -.021 \\
\hline \multicolumn{5}{|l|}{ Source } \\
\hline Child Sex & .017 & -.005 & -.052 & .082 \\
\hline Child Age & .13 & .004 & .178 & .145 \\
\hline Number of & -.079 & .002 & .123 & -.090 \\
\hline \multicolumn{5}{|l|}{ Services } \\
\hline Received & & & & \\
\hline
\end{tabular}

Note. $N=54$. None of the correlations were significant after adjusting for multiple comparisons using the False Discovery Rate. 
Appendix KK: Maximum Number of Allowable Item Omissions

\begin{tabular}{|c|c|c|c|}
\hline Measure & Scale & Number of Items & $\begin{array}{l}\text { Maximum Number } \\
\text { of Omitted Items }\end{array}$ \\
\hline \multirow{7}{*}{$\begin{array}{l}\text { C3MH Parent } \\
\text { Measure }\end{array}$} & Management: Collaboration & 7 & 3 \\
\hline & Management: Transitions & 5 & 2 \\
\hline & Informational: Provider & 5 & 1 \\
\hline & Knowledge & & \\
\hline & Relational: Interpersonal & 4 & 1 \\
\hline & Relational: Consistency & 4 & 1 \\
\hline & Total & 25 & 5 \\
\hline \multirow{5}{*}{$\begin{array}{l}\text { C3MH Youth } \\
\text { Measure }\end{array}$} & Management: Collaboration & 6 & 3 \\
\hline & Informational: Provider & 5 & 1 \\
\hline & Knowledge & & \\
\hline & Relational: Interpersonal & 8 & 1 \\
\hline & Total & 19 & 3 \\
\hline
\end{tabular}




\section{Curriculum Vitae}

Name:

Post-secondary Education and Degrees:

\section{Honours and Awards:}

Juliana I Tobon

McMaster University

Hamilton, Ontario, Canada

2001-2005 B.Arts.Sc.

The University of Western Ontario

London, Ontario, Canada

2005-2007 M.Sc.

The University of Western Ontario

London, Ontario, Canada

2007-2013 Ph.D.

Social Sciences and Humanities Research Council (SSHRC)

Canada Graduate Scholarship Master's Award (CGS)

2005-2006

The Provincial Centre of Excellence for Child and Youth Mental

Health at CHEO

Graduate Award

2006-2009

Canadian Institutes of Health Research (CIHR)

Canada Graduate Scholarship Doctoral Award (CGS)

2009-2012

Mitacs-Accelerate Internship (SickKids and MHS)

2012

Teaching Assistant

The University of Western Ontario

2005-2012

\section{Publications:}

Reid, G.J., Tobon, J.I., \& Shanley, D.C. (2008). What is a mental health clinic? How to ask parents about help-seeking contacts within the mental health system. Administration and Policy in Mental Health and Mental Health Services Research, 35(4), 241-249. 
Tobon, J.I., Ouimet, A.J., Dozois, D.A. (2011). Attentional bias in anxiety disorders following cognitive behavioural treatment. Journal of Cognitive Psychotherapy, 25(2), 114-129.

Tobon, J.I., Eichstedt, J., Phoenix, E., Wolfe, V., Brisebois, S., Zayed, R. \& Harris, K. (2011). Group cognitive-behavioral therapy for anxiety in a clinical setting: Does child involvement predict outcome? Behavior Therapy, 42, 306-322.

Reid, G.J., Cunningham, C.E., Tobon, J.I., Evans, B., Stewart, M., Brown, J.B., Lent, B., Neufeld, R.W.J., Vingilis, E., Zaric, G.S., \& Shanley, D.C. (2011). Help-seeking for children with mental health problems: Parents' efforts and experiences. Administration and Policy in Mental Health and Mental Health Services Research, 38(5), 384-397.

Eichstedt, J., Tobon, J.I., Phoenix, E., \& Wolfe, V. (2011). Worried no more: The effects of medication status on treatment response to a CBT group for children with anxiety in a community setting. Clinical Child Psychology and Psychiatry, 16(2), 265-277.

\section{Related Grants:}

Reid, G.J. (co-PI), Tobon, J. (co-PI), Brown, J.B. (2009-2010). Continuity of Care in Children's Mental Health: Parent and Professional Perspectives. Children's Health Research Institute Internal Grants Competition. \$7,500

Reid, G.J., Tobon, J., Stewart, S., Evans, B., Brown, J.B., Goffin, R. (04/2010 03/2012). Continuity of Care in Children's Mental Health: Development of a Measure (2 years). Canadian Institutes of Health Research: Advancing Theoretical and Methodological Innovations in Health Research. \$195,482

\section{Related Conference Presentations:}

Tobon, J.I., Reid, G.J. \& Brown, J.B. (March, 2011). The Experience if (Dis)continuity in Children's Mental Health. Poster presented at: the 24th Annual Children's Mental Health Research and Policy Conference, Tampa, FL, March 20-23, 2011.

Tobon, J.I., Reid, G.J. \& Brown, J.B. (June, 2011). Families’ Experiences of Continuity of Care in the Children's Mental Health System. Poster presented at the Annual Meeting of the Canadian Psychological Association, Toronto ON, June 2-4, 2011.

Tobon, J.I., Reid, G.J. \& Goffin, R. (March, 2013). Continuity of Care in Children's Mental Health: Validation of a New Measure. Symposium presented at: the 26th Annual Children's Mental Health Research and Policy Conference, Tampa, FL, March 3-6, 2013.

Tobon, J.I., Reid, G.J. \& Goffin, R. (June, 2013). Continuity of Care in Children's Mental Health: Development of a Parent and Youth Measure. Poster presented at the Annual Meeting of the Canadian Psychological Association, Toronto ON, June 13-15, 2013. 


\section{Related Professional and Community Presentations:}

Tobon, J.I. \& Reid, G.J. (Feb, 2012). Continuity of care in children's mental health: A qualitative study. Presentation to the Child and Parent Resource Institute, Regional Advisory Committee London, ON, February 16, 2012.

Tobon, J.I. (Jan, 2013). Continuity of care in children's mental health: System Measurement from Parent and Youth Perspectives. Presentation at CAMH Interdisciplinary Research Rounds, Toronto, ON, January 14, 2013.

Tobon, J.I. \& Reid, G.J. (June, 2013). Understanding and Measuring Continuity of Care in Ontario's Children's Mental Health System. Presentation at $11^{\text {th }}$ Annual South West Region 0-6 Mental Health Symposium: Building Resilience in Young Children, Families and Communities, London, ON, June 7, 2013. 